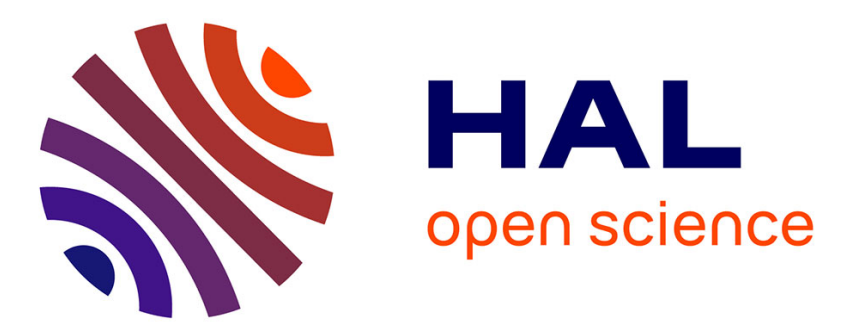

\title{
Le secteur GG2 de la grotte du Pape à Brassempouy (Landes) : un dépôt intentionnel d'armes gravettiennes?
}

Nejma Goutas, Aurélien Simonet

\section{To cite this version:}

Nejma Goutas, Aurélien Simonet. Le secteur GG2 de la grotte du Pape à Brassempouy (Landes) : un dépôt intentionnel d'armes gravettiennes?. Bulletin de la Société préhistorique française, 2009, 106 (2), pp.257-292. halshs-00408864

\section{HAL Id: halshs-00408864 https://shs.hal.science/halshs-00408864}

Submitted on 25 Feb 2019

HAL is a multi-disciplinary open access archive for the deposit and dissemination of scientific research documents, whether they are published or not. The documents may come from teaching and research institutions in France or abroad, or from public or private research centers.
L'archive ouverte pluridisciplinaire HAL, est destinée au dépôt et à la diffusion de documents scientifiques de niveau recherche, publiés ou non, émanant des établissements d'enseignement et de recherche français ou étrangers, des laboratoires publics ou privés.

$$
\text { Copyright }
$$


Nejma GOUTAS et Aurélien SIMONET
Le secteur GG2

de la grotte du Pape à Brassempouy (Landes) : un dépôt intentionnel d'armes gravettiennes?

\title{
Résumé
}

Le secteur GG2 correspond à l'extrémité nord de la grotte du Pape de Brassempouy, la plus éloignée de son entrée principale, célèbre par les fouilles qu'É. Piette y réalisa à la fin du XIX ${ }^{e}$ siècle. L'assemblage de la couche $2 D$, bien calé entre un niveau aurignacien et un niveau magdalénien grâce à l'existence de planchers stalagmitiques et phosphatiques, est caractérisé par une proportion importante d'armatures lithiques et en ivoire. À l'exception de quelques burins de Noailles, les outils domestiques contenus dans ce niveau sont ubiquistes et c'est donc sur ces armatures que repose l'attribution de ce niveau au Gravettien. L'approche que nous proposons de ce contexte, tenant compte des perturbations ayant affecté la couche 2D et s'appuyant sur l'analyse technologique et taphonomique des armatures qu'elle contient, a pour objectif d'évaluer l'homogénéité de cet assemblage et de discuter l'intentionnalité de ce dépôt singulier.

\begin{abstract}
Sector GG2 corresponds to the north extremity of the Grotte du Pape at Brassempouy, the furthest from the main entrance. The celebrity of the Grotte du Pape was assured thanks to the meticulous excavations that E. Piette carried out there at the end of the 19th century. It was the Gravettian levels of the cave's entrance which yielded one of the most important collections of ivory feminine statuettes, including the "Lady of Brassempouy» who was to give a face to Prehistory. Our article concerns the data of the recent excavations made in the low back section of the cave where the ceiling rises only about $1 m 20$. A remarkable assemblage was discovered in this zone a long way from the main activity sector in front of the cave (excavation I). It comes mainly from the layer 2D, well situated between an Aurignacian level and a Magdalenian level thanks to the existence of stalagmitic and phosphatic floors. It is characterized by an important proportion of lithic points mainly composed of the mesial part of backed bladelets, microgravettes and shouldered points together with ivory points, some of which are decorated with incisions. Besides the high proportion of points, this assemblage is also distinguished by the quality of objects gathered within a small space of a few square metres (choice of materials and care given to the production). With the exception of some Noailles burins, the domestic tools contained in this level are ubiquitous and it is thus on these points and on their link with those (also Gravettian) from the Brassempouy excavation I as well as those from the nearby important site of
\end{abstract}


Isturitz that the attribution of this level to the Gravettian rests. The approach we propose for this context, taking into account disturbances having affected layer 2D and founded on the technological and taphonomical analysis of the points which it contains, aims at estimating the homogeneity of this assemblage and discussing the intentionality of this singular deposit. Finally we will set this assemblage in the material and symbolic context of the Gravettian in Central and Western Europe in order to interpret this unusual concentration of points which henceforth adds to the cultural wealth of the Brassempouy Gravettian.

\section{PROBLÉMATIQUE}

L'industrie lithique et osseuse dont nous présentons l'étude fut découverte dans l'extrémité nord de la grotte du Pape à Brassempouy, secteur dénommé GG2. Elle provient principalement d'une unité stratigraphique, la couche $2 \mathrm{D}$. L'originalité de cette série tient à la fois à sa localisation (zone non habitable), à ses composantes (dominée par les armatures), à la spécificité des matériaux exploités (ivoire de Mammouth, silex de très bonne qualité) et à l'investissement poussé dont a bénéficié cet équipement hautement spécialisé. Découverte dans un contexte topographique et sédimentaire particulier et en partie remanié, l'origine de cette industrie ainsi que son homogénéité et son attribution chronoculturelle restaient à élucider. L'objectif de cette étude croisée (lithique/osseux) est donc triple : il s'agit de vérifier s'il existe une cohérence technique, spatiale et taphonomique interne à cette série de manière à rediscuter des différentes attributions chronoculturelles (gravettienne, solutréenne, épigravettienne) qui ont été proposées (Buisson, 1996). Enfin, ces données archéologiques seront confrontées aux conditions sédimentaires régnant dans cette partie du site, afin d'apporter de nouveaux éléments de réflexion sur la signification de cet assemblage original dans le contexte des grottes de Brassempouy.

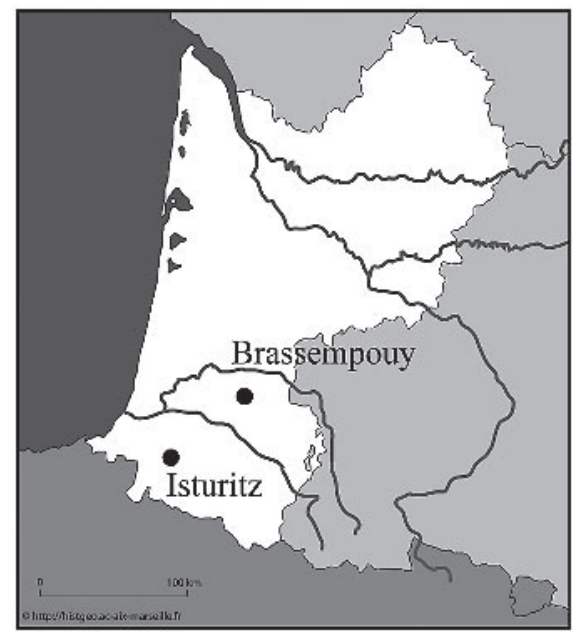

Fig. 1 - Localisation du site de Brassempouy (C) http://histgeo.ac-aix-marseille.fr, carte modifiée). Fig. 1 - Location of the Brassempouy site (ㄷ http:// histgeo.ac-aix-marseille.fr, modified map).

\section{PRÉSENTATION DU SITE}

Le gisement de Brassempouy est situé en Chalosse, au sud du département des Landes, à $2 \mathrm{~km}$ environ du village de Brassempouy (fig. 1). Les fouilles du XIX ${ }^{\mathrm{e}}$ siècle (P.-E. Dubalen, J. de Laporterie et É. Piette) ont mis en évidence une longue séquence d'occupations magdaléniennes, gravettiennes et solutréennes dans l'entrée de la grotte du Pape. Plus récemment, la reprise des fouilles par H. Delporte à partir de 1981 (Delporte, 1996; Buisson, 1996), puis leur poursuite par D. Buisson (1995-1996) et D. HenryGambier (1997-2004), ont permis la découverte d'autres secteurs et notamment d'une riche occupation gravettienne partiellement fouillée devant la grotte du Pape (chantier I). Réduit aux seuls éléments lithiques compte tenu de la mauvaise conservation des vestiges organiques à cet endroit, la majeure partie du mobilier archéologique associé à cette occupation a été récemment étudiée (Dartiguepeyrou, 1995; Klaric, 2003). Par la quantité de matériel récolté lors des fouilles et l'estimation de l'ampleur originelle de ce niveau ${ }^{1}$, ces observations relancèrent la question de l'importance des occupations gravettiennes à Brassempouy. Cette question fut également au cœur des recherches entreprises dans l'extrémité nord de la grotte du Pape, où fut découvert par H. Delporte le secteur GG2, troisième et dernier emplacement ayant livré des témoignages d'occupations gravettiennes à Brassempouy (fig. 2) et auquel nous nous consacrons dans le présent travail.

\section{PRÉSENTATION DU SECTEUR GG2}

La Grande Galerie constitue, avec la galerie du Puits, la principale ramification de la grotte du Pape. Le secteur concerné ici (GG2) représente son extrémité nord, sous la forme d'une étroite galerie, dont la voûte s'élève à 1,60 m en moyenne (Delporte, 1991, p. 78) au-dessus d'un socle rocheux traversé de profondes diaclases (cf. fig. 2).

Les fouilles récentes du fond de la Grande Galerie (GG2) se sont déroulées de 1982 à $1995^{2}$ et concernent une surface de $25 \mathrm{~m}^{2}$. Elles ont permis l'individualisation de quatre grands ensembles chronoculturels (fig. 3). Bien qu'une partie des couches archéologiques de ce secteur de la grotte du Pape ait été perturbée par des terriers, leur conservation a été localement favorisée 

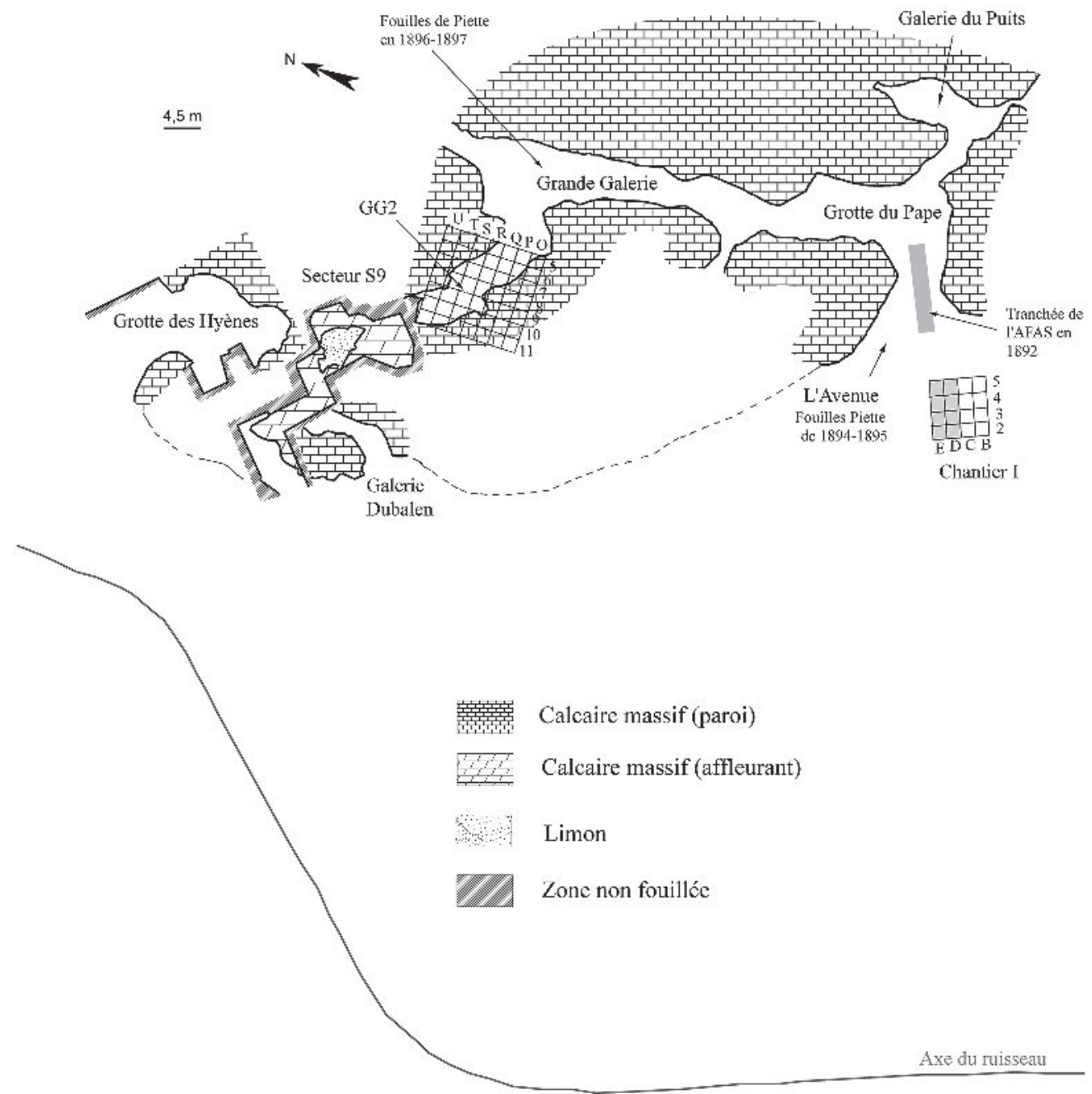

Fig. 2 - Plan du site (modifié, d'après Delporte, 1986, fig. 10).

Fig. 2 - Plan of the site (modified, after Delporte 1986, fig. 10).

\section{plancher 1}

\section{plancher 2}

\section{plancher 3}

\begin{tabular}{lc}
\hline & plancher 3 \\
1A & Magdalénien $13900 \pm 600 \mathrm{BP}$ \\
\hline 1B & microfaunc calcitéc \\
\hline $2 \mathrm{~A}$ & \\
$2 \mathrm{~B}$ & \\
$2 \mathrm{C}$ & Gravettien $19700 \pm 160 \mathrm{BP}$ \\
$2 \mathrm{D}$ & Aurignacien $28620 \pm 410 \mathrm{BP}$ \\
\hline 2E & plancher 4 \\
\hline 2F & Châtelperronien $31690 \pm 810 \mathrm{BP}$ \\
\hline & plancher 5 \\
\hline $2 \mathrm{G}$ &
\end{tabular}

Fig. 3 - Stratigraphie synthétique du secteur GG2 (Buisson, 1996, fig. 3).

Fig. 3 - Synthetic stratigraphy of GG2 sector (Buisson 1996, fig. 3). par l'existence de planchers stalagmitiques et phosphatiques. L'ensemble formé des niveaux $2 \mathrm{~A}$ à $2 \mathrm{E}$ qui nous intéresse ici est épais de $35 \mathrm{~cm}$ environ. Il s'agit d'un ensemble brun argileux contenant des passées sableuses. Il est intercalé entre le niveau 1 sus-jacent qui contient des horizons magdaléniens et le niveau $2 \mathrm{~F}$ sous-jacent qui a livré un assemblage aurignacien. Ce dernier surmonte le niveau $2 \mathrm{G}$, qui contient un maigre assemblage châtelperronien. La séquence stratigraphique du Paléolithique supérieur est donc à peu près complète et respectée, ce qui constitue, d'ores et déjà, l'un des caractères exceptionnels de ce remplissage.

Néanmoins, l'interprétation concernant l'origine et l'attribution des niveaux $2 \mathrm{~A}$ à $2 \mathrm{D}$ reste délicate. Tout d'abord, d'un point de vue sédimentaire, les niveaux retrouvés dans ce secteur ne sont peut-être pas des sols d'occupation en position primaire (HenryGambier et al., 2004) et ce malgré le respect de la chronologie du Paléolithique supérieur dans la succession des dépôts archéologiques. En effet, après avoir considéré que cette partie du site renfermait des 


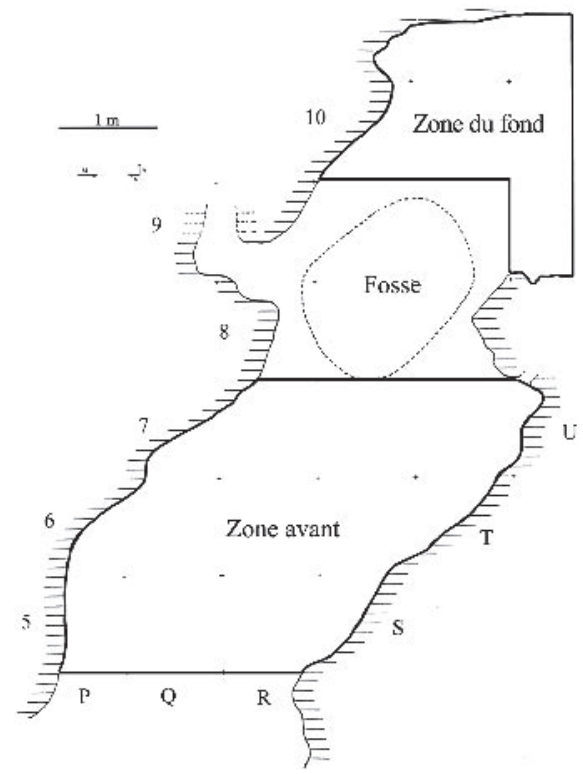

Fig. 4 - Plan général du secteur GG2 avec délimitation des trois zones individualisées (modifié, d'après Delporte, 1993, fig. 4).

Fig. 4 - General plan of the GG2 sector with delimitation of the three individualized zones (modified, after Delporte 1993, fig. 4).

\begin{tabular}{|c|c|}
\hline & $\mathbf{N}$ \\
\hline Grattoir sur bout de lame & 8 \\
\hline Grattoir sur bout de lame retouchée & 1 \\
\hline Grattoir à museau & 1 \\
\hline Grattoir Caminade & 1 \\
\hline Burin d'angle sur cassure & 3 \\
\hline Burin sur troncature & 1 \\
\hline Burin de Noailles & 4 \\
\hline Burin dièdre & 1 \\
\hline Burin multiple dièdre & 1 \\
\hline Encoche/denticulé & 5 \\
\hline Pièce esquillée & 6 \\
\hline Lame à dos & 2 \\
\hline Biface & 1 \\
\hline Produit laminaire retouché & 17 \\
\hline Produit lamellaire retouché & 4 \\
\hline Éclat retouché & 26 \\
\hline Total outils domestique & 82 \\
\hline Pointe à cran & 10 \\
\hline Pointe de la Gravette & 1 \\
\hline Micro-Gravette & 4 \\
\hline Lamelle à dos & 47 \\
\hline Lamelle à dos tronquée & 14 \\
\hline Lamelle à retouche marginale & 9 \\
\hline Lamelle à retouche inverse & 2 \\
\hline Lamelle Dufour & 6 \\
\hline Triangle scalène & 4 \\
\hline Divers & 5 \\
\hline Total armatures & 102 \\
\hline Total & 184 \\
\hline
\end{tabular}

Tabl. 1 - Décompte synthétique de l'industrie lithique de la couche $2 \mathrm{~A}$ à la couche $2 \mathrm{E}$.

Tabl. 1 - Synthetic count of the lithic industry of layer $2 A$ to layer $2 E$. dépôts endokarstiques et que le mobilier qui leur est associé avait été apporté par des groupes humains ayant effectivement séjourné dans cet espace (Buisson, 1996), il a ensuite été proposé que «la mise en place des dépôts stratifiés de GG2 pourrait être consécutive au remaniement d'occupations situées en dehors de la galerie» (Bon et al., 1998, p. 217; HenryGambier et al., 2004). En 1999, cette hypothèse a été confortée par la démonstration que la grotte du Pape possède en effet un second débouché sur le plateau sous la forme d'un étroit couloir oblique communiquant avec un aven (S9, cf. fig. 4) (Bon, 2002a; Henry-Gambier et al., 2004). Cependant, la fouille conduite ultérieurement dans cet aven n'a pas permis de retrouver une séquence stratigraphique permettant, outre les sédiments, d'illustrer l'origine possible de l'ensemble des différents mobiliers archéologiques présents en GG2. En particulier, aucun vestige clairement attribuable à une phase postérieure à l'Aurignacien n'y a été rencontré (Bon, 2004). Par ailleurs, toujours d'un point de vue sédimentologique, les remplissages de GG2 possèdent une importante variabilité latérale en termes de cohérence stratigraphique. En particulier, une zone de forte perturbation a été observée à l'aplomb d'une cheminée karstique, dans les carrés T7 et S8 notamment (Potin et Mensan, 1998). Cette partie centrale du secteur fouillé correspond à la présence d'une «fosse» décrite par D. Buisson et dont le remplissage est en effet reconnu par lui comme bouleversé (Buisson, 1996). En revanche, de part et d'autre de cette «fosse», deux zones présentent une succession beaucoup plus cohérente de dépôts sédimentaires, respectant la stratigraphie décrite précédemment.

Par ailleurs, et cette fois-ci en ce qui concerne l'attribution chronoculturelle du mobilier archéologique contenu dans le niveau 2D, la seule datation effectuée $(19700$ +/- 160 BP $)$ et la présence de pointes à cran ont donné lieu à un élargissement des premières interprétations culturelles en faveur du Gravettien (Buisson, 1996) vers une attribution solutréenne (Foucher, 2004), voire épigravettienne (Buisson, 1996). Toutefois, dans un tel contexte archéologique, donner une valeur diagnostique à la seule datation effectuée ne possède à nos yeux aucune valeur méthodologique et il convient de revenir avant tout à une analyse approfondie du mobilier contenu dans cet ensemble stratigraphique.

Plusieurs précautions méthodologiques sont donc nécessaires pour appréhender un tel contexte et toute approche se doit d'aborder en premier lieu la question de l'homogénéité des assemblages qu'il renferme. Or, comme nous l'avons évoqué, le mode et la nature du remplissage paraissent cumuler des dépôts et/ou des perturbations chronologiquement et spatialement différenciés. Afin de tenter d'en rendre compte, nous avons donc choisi d'étudier dans un premier temps le matériel archéologique en individualisant les deux zones identifiées à la fouille (avant et fond de la galerie) afin de tester leur homogénéité respective et, dans un deuxième temps, de vérifier leur correspondance. Cette étude spatiale a été effectuée avec une résolution de l'ordre du $\mathrm{m}^{2}$. Ainsi, la zone avant regroupe les 


\begin{tabular}{|c|c|c|c|c|c|c|c|c|c|c|c|}
\hline Site & Secteur & $\mathbf{N}^{\circ}$ & Année & Couche & Carré & L & I. min & I. max & ép. min & ép. max & Matière \\
\hline Brassempouy & GG 2 & 164 & 1982 & 2B & bC2 & 77 & 12,5 & 15 & 4,8 & 10,1 & ivoire \\
\hline Brassempouy & GG 2 & 361 & 1988 & 2D & T 7 & 112 & 6 & 11 & & 9 & ivoire \\
\hline Brassempouy & GG 2 & $\mathbf{9 6}^{*}$ & 1992 & 2D sup. & U9 & 110 & 8,4 & 13 & 4,5 & 9 & ivoire \\
\hline Brassempouy & GG 2 & $\mathbf{2 4 6}^{*}$ & 1988 & 2 D sup. & S8 & 19 & & 6 & & 10 & ivoire \\
\hline Brassempouy & GG 2 & $\mathbf{2 3 6}+^{1}$ & 1992 & 2D base & T10 & 117 & 3 & 8 & 1 & 7 & ivoire \\
\hline Brassempouy & GG 2 & $\mathbf{1 8 2 +}$ & 1988 & 2B & S8 & 71 & 9 & 10 & 8 & 10 & ivoire \\
\hline Brassempouy & GG 2 & $\mathbf{3 5 +}$ & 1989 & 2D & S9 & 90 & 10 & 10 & 10 & 10 & ivoire \\
\hline Brassempouy & GG 2 & 666 & 1987 & 2D & R7 & 108 & 3 & 12 & 4 & 11 & ivoire \\
\hline Brassempouy & GG 2 & $\mathbf{3 6 9}^{\wedge}$ & 1989 & 2E & S8 & 80 & 12 & 14 & 8,6 & 10 & ivoire \\
\hline Brassempouy & GG 2 & $\mathbf{5 2 3}^{\wedge}$ & 1992 & 2F fosse & T9 & 23 & 11 & 14 & 4 & 7 & ivoire \\
\hline Brassempouy & GG 2 & 43 & 1989 & 1 & T9 & 25 & 7,5 & 9 & & 3,8 & ivoire \\
\hline Brassempouy & GG 2 & 50 & 1990 & 2A & R9 & 17 & & 10,5 & & 3 & ivoire \\
\hline Brassempouy & GG 2 & 93 & 1992 & 2D sup. & U9 & 33 & 0,5 & 6,5 & 0,8 & 2 & ivoire \\
\hline
\end{tabular}

Tabl. 2 - Données métriques et provenance stratigraphique de l'industrie sur ivoire découverte dans le secteur GG2 de Brassempouy. Les symboles $\left(*,+,^{\wedge}\right)$ présents à côté des numéros d'inventaire indiquent les raccords inter-pièces.

Tabl. 2 - Metric data and stratigraphic origin of the ivory industry discovered in sector GG2, Brassempouy. The symbols (*, ,$\left.+{ }^{\wedge}\right)$ next to the inventory numbers indicate conjoining between pieces.

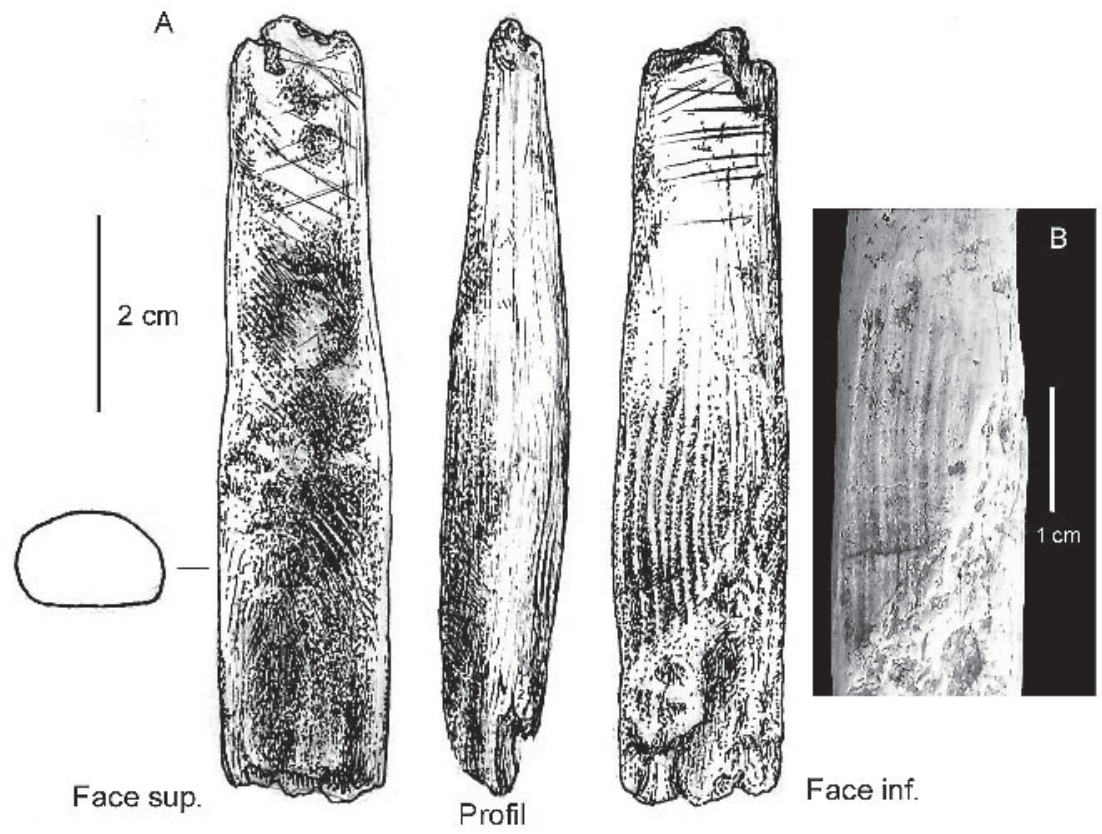

Fig. 5 - Brassempouy, GG2. Outil biseauté en ivoire portant un décor géométrique. $\mathrm{N}^{\circ} 1$ : vue générale (dessin F. Bongni); $n^{\circ} 2$ : détail de la surface attestant d'une reprise de façonnage par raclage (cliché N. Goutas).

Fig. 5 - Brassempouy, GG2. Ivory bevelled tool with geometric decoration. No. 1: general view (drawing F. Bongni); no. 2: detail of the surface attesting reshaping by scraping (photograph N. Goutas).

bandes 5, 6 et 7; la zone médiane (fosse) correspond aux bandes 8 et 9 excepté le carré U9 que nous avons associé aux deux bandes 10 et 11 de la zone du fond, étant donné qu'il n'est pas affecté par la fosse.

\section{PRÉSENTATION DU CORPUS D'ÉTUDE}

L'industrie lithique sur laquelle porte notre étude est composée de 93 outils domestiques et de 102 armatures (tabl. 1). La présence de pointes à cran (NR : 12/N0 : 9) ${ }^{3}$ et la forte proportion d'armatures constituent les principales caractéristiques de cet ensemble. Les armatures sont dominées par des portions mésiales de lamelles à dos $(\mathrm{N}=39$; lamelles à dos mésiales). Les outils sont quant à eux dominés par les éclats retouchés $(\mathrm{N}=26)$ et les produits laminaires retouchés $(\mathrm{N}=21)$. Quatre burins de Noailles sont également présents.

L'industrie osseuse retrouvée dans le secteur GG2 est composée d'objets fragmentaires en ivoire (NR : 13/NO : 9) (tabl. 2) ${ }^{4}$. À l'exception d'une pièce pouvant se rapporter à la catégorie typofonctionnelle des outils biseautés (fig. $5, \mathrm{n}^{\circ} 1$ ), le reste de l'équipement est exclusivement composé de fragments de pointes de 
Fig. 7 - Brassempouy, GG2. Mésioproximal de pointe en ivoire, pièce $\mathrm{n}^{\circ} 666$ (dessin F. Bongni).

Fig. 7 - Brassempouy, GG2. Mesioproximal fragment of ivory point, piece no. 666 (drawing F. Bongni).
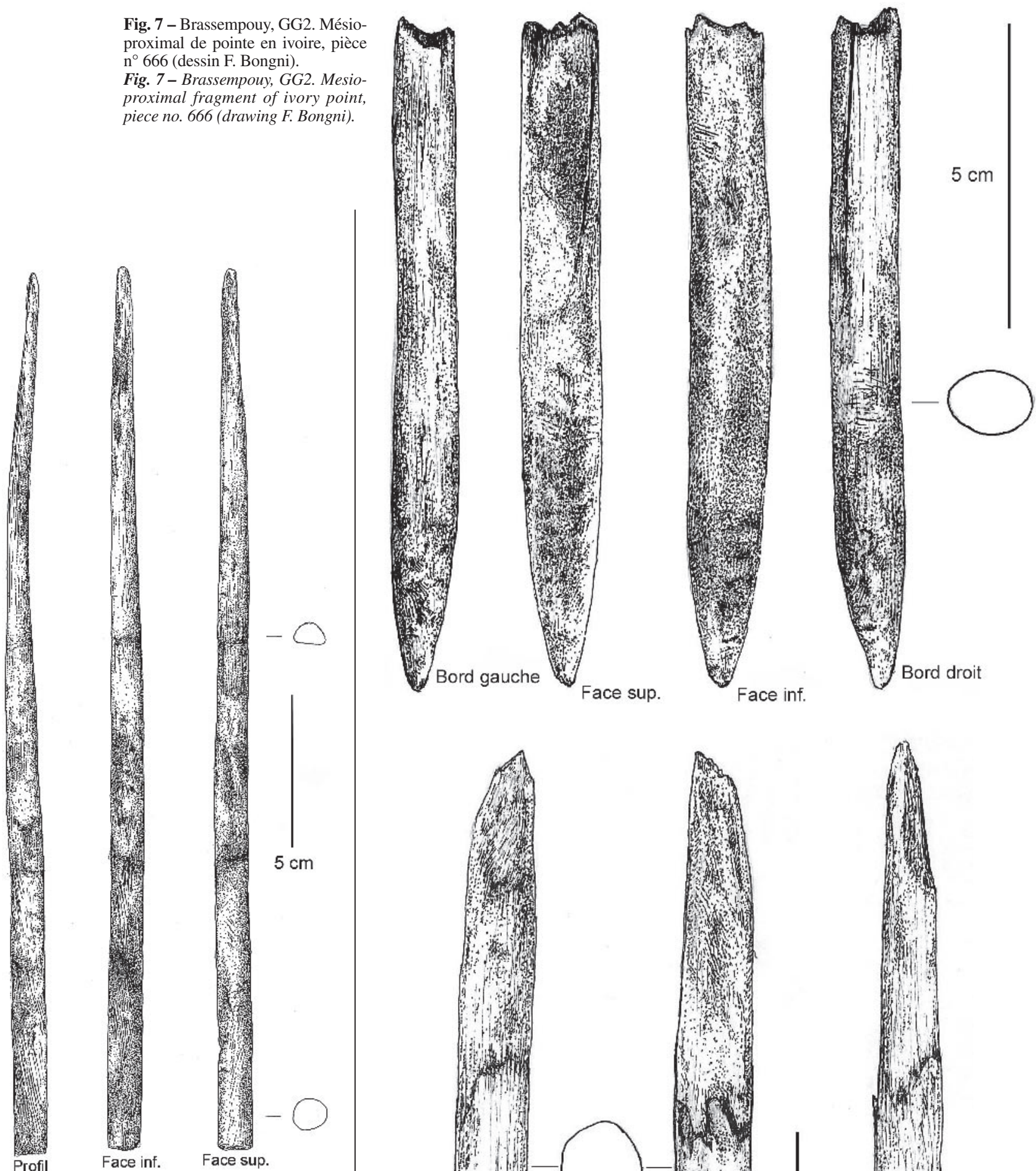

Fig. 6 - Brassempouy, GG2. Long fragment de pointe en ivoire (dessins F. Bongni).

Fig. 6- Brassempouy, GG2. Long fragment of ivory point (drawings F. Bongni).

Fig. 8 - Brassempouy, GG2. Mésial de pointe en ivoire, pièce $\mathrm{n}^{\circ} 361$ (dessin F. Bongni).

Fig. 8 - Brassempouy, GG2. Mesial fragment of ivory point, piece no. 361 (drawing F. Bongni).
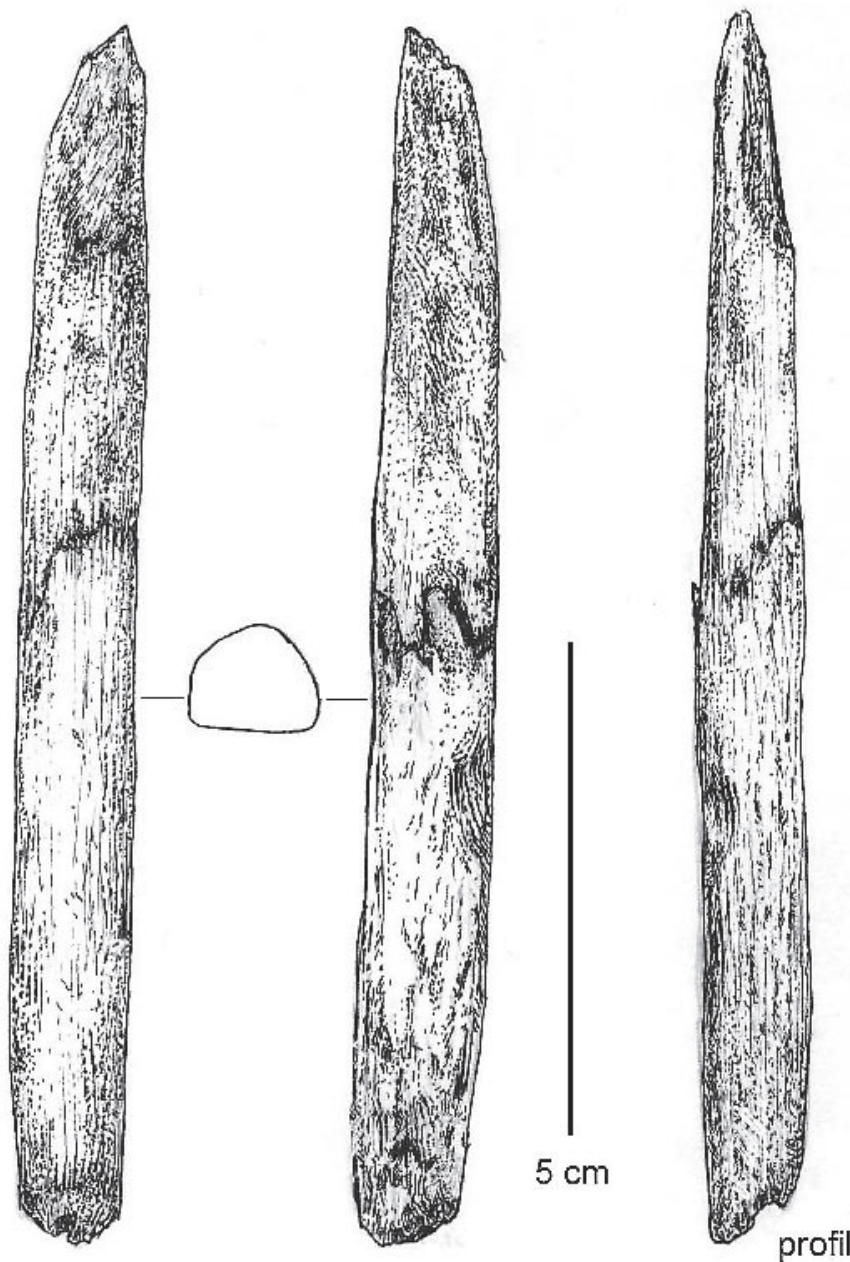


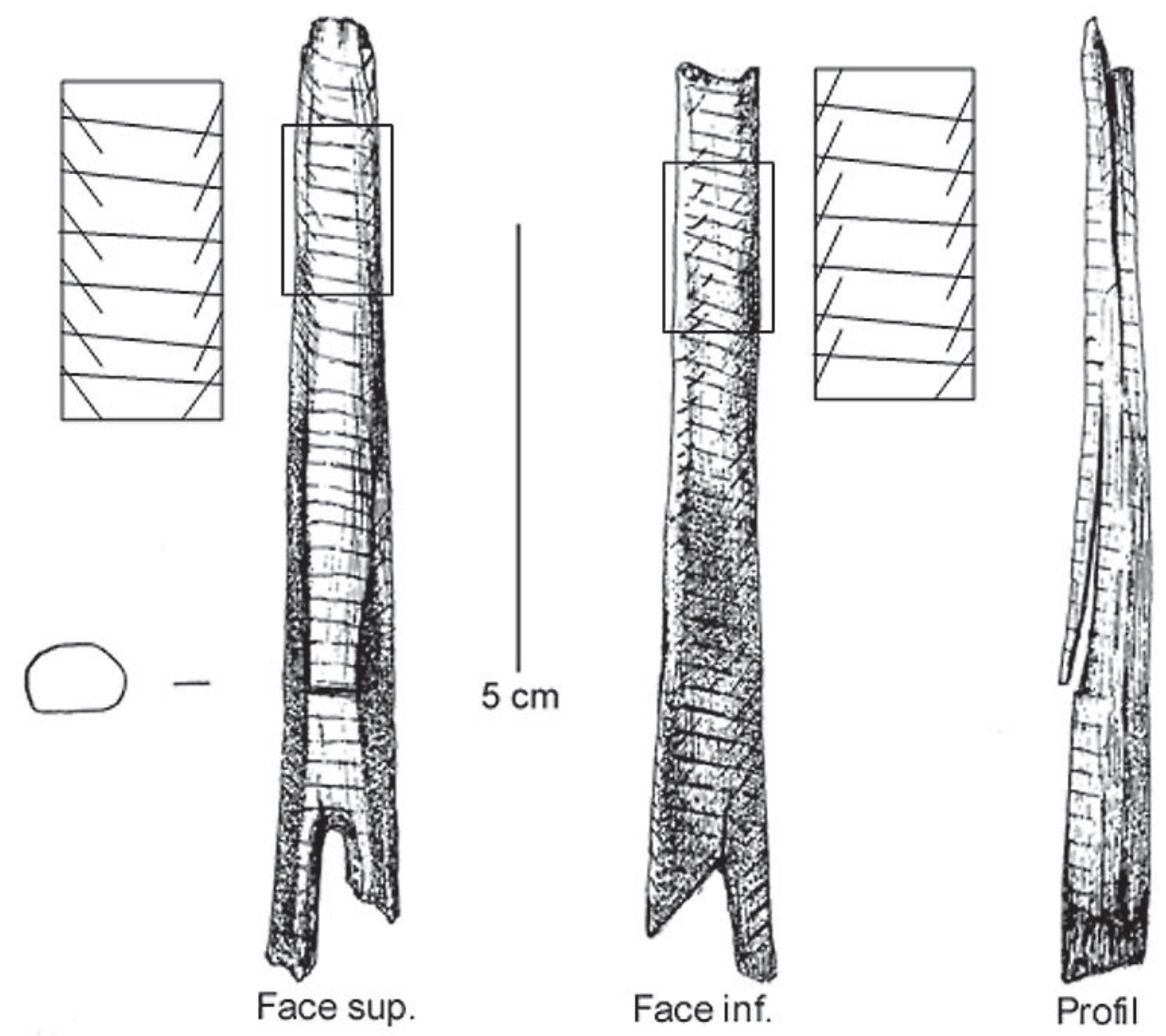

Fig. 9 - Schématisation du décor géométrique de l'une des pointes en ivoire (pièce n 96/246). Fig. 9 - Schematization of the geometric decoration on one of the ivory points (piece no. 96/246).

projectile $(\mathrm{N}=12)$, dont certaines sont investies d'un décor géométrique simple (fig. 6, 7, 8 et 9). Les pièces en ivoire provenant de la couche $2 \mathrm{~A}$ à $2 \mathrm{E}$ de GG2 se distribuent dans les différentes parties de la galerie (fig. 10), à savoir dans la zone avant $(\mathrm{N}=2$; bande 7$)$, dans la fosse $(\mathrm{N}=8$; bandes $8-9)$ et dans la partie profonde ( $\mathrm{N}=3$; bande 10 et carré U9). Comme nous le verrons plus tard, la localisation des pièces au sein de ces différentes zones semble avoir eu des conséquences directes sur leur état de conservation.

\section{RÉFLEXION SUR LE DEGRÉ D’HOMOGÉNÉITÉ DES SÉRIES ÉTUDIÉES}

\section{Description morphométrique, typologique et technologique}

\section{Industrie lithique}

Comme nous l'avons évoqué précédemment, la panoplie d'armatures recueillie dans les niveaux $2 \mathrm{~A}$ à 2E est largement dominée par des lamelles à dos mésiales : 39 pièces sur 102 armatures toutes zones confondues. Dans chacune des trois zones, ces objets représentent le type dominant (tabl. 3 et fig. 11 à 13). Leur gabarit est très homogène avec une largeur comprise en moyenne entre 3 et $5 \mathrm{~mm}$, pour une épaisseur comprise en moyenne entre 1,5 et 2,5 mm (fig. 14). La présence de nombreuses fractures complexes (Fisher et al., 1984; O'Farrell, 1996) et le raccord de deux lamelles (cf. fig. $13, \mathrm{n}^{\circ} 9$ ) laissent envisager des pièces de longueur beaucoup plus importante avant qu'elles soient fracturées lors de l'utilisation.

Les lamelles à dos mésiales contiennent une composante de pièces possédant une extrémité tronquée (l'autre extrémité étant alors fracturée), plus nombreuses que celles dont les deux extrémités le sont (tabl. 3). Quantitativement, les lamelles à dos présentant une seule troncature se retrouvent aussi bien dans la zone avant (5 exemplaires) que dans la zone du fond (6 exemplaires). Elles sont donc proportionnellement plus nombreuses dans cette dernière. Si la majorité des lamelles à dos avec une extrémité tronquée possède des troncatures rectilignes perpendiculaires à l'axe du dos (cf. fig. $13, n^{\text {os }} 1$ et 2 ), deux exemplaires provenant de la zone du fond (carré T10) possèdent des troncatures rectilignes légèrement obliques (cf. fig. $13, \mathrm{n}^{\circ} 6$ ). Les lamelles à dos bitronquées sont beaucoup moins nombreuses puisqu'elles ne se retrouvent que sous la forme de deux exemplaires dans la fosse (cf. fig. 12, ${ }^{\text {os }} 1$ et 4) et d'un exemplaire dans la zone du fond (cf. fig. 13, $\mathrm{n}^{\circ} 3$ ). Il est possible que la rareté des lamelles à dos bitronquées s'explique partiellement par le fait que certaines soient fracturées notamment lors de 


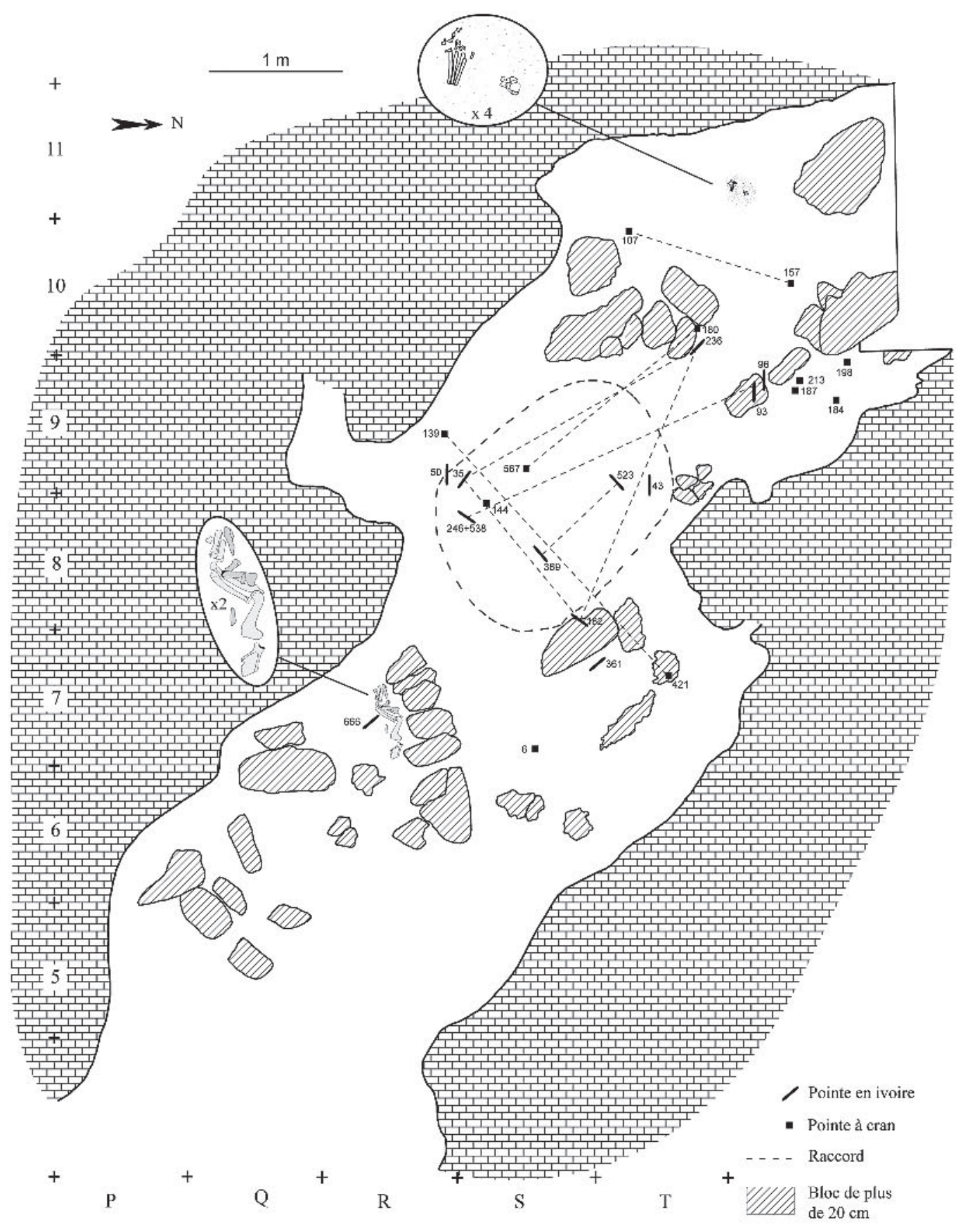

Fig. 10 - Plan de répartition spatiale des raccords des pièces en ivoire (en trait pointillé) et en silex (en trait continu) (modifié, d'après Delporte, 1993, fig. 4)

Fig. 10 - Spatial distribution plan of conjoining pieces of ivory (dotted line) and flint (continuous line) (modified, after Delporte 1993, fig. 4)

l'utilisation. Deux lamelles à dos bitronquées possèdent des troncatures rectilignes obliques opposées. Les troncatures ne sont pas parallèles mais divergentes : la morphologie générale de l'objet tend vers le trapèze (cf. fig. 12, $\mathrm{n}^{\circ} 4$; fig. 13, $\mathrm{n}^{\circ}$ 3). Le dernier exemplaire possède deux troncatures rectilignes perpendiculaires à l'axe du dos (cf. fig. 12, n 1 ).

Les (micro)pointes à dos sont très rares $(5$ exemplaires). Une seule pièce est presque entière (fig. 15, $\mathrm{n}^{\circ} 1$ ). Celle-ci possède une morphologie symétrique, un dos épais aménagé par retouche croisée alors que le bord opposé est aménagé par retouche directe totale ainsi que par une retouche inverse rasante de l'extrémité distale. Sa morphologie, alliant recherche d'épaisseur avec aménagement du dos par percussion et symétrie longitudinale selon un axe joignant les deux extrémités, la rattache au groupe des micro-Vachons selon la définition effectuée à partir de l'étude du mobilier d'Isturitz (Simonet, 2005). Les autres exemplaires sont des parties proximales (4 exemplaires), dont une seule, de gabarit plus important, pourrait constituer l'unique indice de Gravette. L'ensemble de 
ces pièces est localisé dans la zone antérieure à la fosse, ce qui renforce la très faible probabilité que les lamelles à dos mésiales évoquées précédemment soient des fragments de micro-Gravette.

Parmi les 9 pointes à cran (fig. 16 et 17), 6 exemplaires sont entiers (dont 3 exemplaires après raccord), deux exemplaires possèdent une fracture au niveau du cran et un exemplaire possède deux fractures, l'une au niveau du cran, l'autre distale. Une seule pointe possède une fracture complexe (fig. 17, $n^{\circ} 5$ ). Les gabarits des pointes sont assez variés. La longueur des pièces est le paramètre métrique qui varie le plus. Les longueurs des pièces entières oscillent ainsi entre $55 \mathrm{~mm}$ (fig. 17, $\mathrm{n}^{\circ}$ 4) et $107 \mathrm{~mm}$ (fig. 16, $\mathrm{n}^{\circ} 1$ ). En revanche, le rapport largeur maximale/épaisseur maximale et surtout le rapport largeur/épaisseur pris au milieu du cran sont assez homogènes. Ce dernier gravite en effet autour d'une largeur de $10 \mathrm{~mm}$ pour une épaisseur de $5 \mathrm{~mm}$ (fig. 18). Les supports laminaires sont majoritairement très épais : sur 6 exemplaires, l'épaisseur maximale dépasse $6 \mathrm{~mm}$ (cf. fig. 16, n ${ }^{\text {os }} 1$ à 3 ; fig. $17, \mathrm{n}^{\text {os }} 1,4$ et 5). Six pointes possèdent un cran latéralisé à droite, les trois autres à gauche. Concernant la position du dos, 8 exemplaires sur 9 possèdent un cran aménagé sur le même bord que le dos et seul un exemplaire se distingue par l'aménagement d'un cran sur le bord opposé (cf. fig. 17, n²). La majorité des pièces possèdent un dos abattu par retouche totale (cf. fig. 16, $\mathrm{n}^{\text {os }} 3$ et 4 ; fig. 17). Cependant, deux pointes possèdent un dos partiel, la morphologie générale de la pièce étant définie par l'aménagement d'un cran dans la partie inférieure et par l'appointement de l'extrémité opposée par l'aménagement d'un dos dans la moitié supérieure (cf. fig. 16, $\mathrm{n}^{\text {os }} 1$ et 2 ).

La quasi-totalité des pointes possède un cran dont la longueur équivaut au tiers de la longueur totale. Seul un exemplaire se distingue par un cran plus dégagé et dont la longueur atteint la moitié de la longueur totale (cf. fig. 17, $\mathrm{n}^{\circ} 4$ ). Le dos et le cran sont aménagés par retouche directe (4 exemplaires) ou par retouche croisée (5 exemplaires) notamment au niveau de la partie distale. L'utilisation de la percussion dans l'aménagement du dos et du cran semble exclusive. Il n'existe en tout cas aucun indice de l'utilisation de la pression. Enfin, 8 pointes possèdent une retouche inverse rasante, le plus souvent d'une extrémité (7 exemplaires dont 5 entiers) ou des deux (1 exemplaire). À l'instar du dos, aucun indice technique ne semble diagnostique de l'utilisation de la pression en ce qui concerne l'aménagement des extrémités. En revanche, certaines retouches inverses (cf. fig. 17, $\mathrm{n}^{\circ}$ 1) dévoilent clairement l'utilisation de la percussion (contre-bulbe prononcé). En conclusion, ces 9 pointes à cran possèdent un style homogène par l'utilisation de supports laminaires épais et réguliers, par l'aménagement d'un cran et d'un dos quasi exclusivement adjacents par percussion dure et par une morphologie générale élancée et symétrique où le dos, le cran et les retouches inverses participent à l'élaboration d'un type dont les caractéristiques morphotechniques sont très proches, selon nous, de celles des pointes des Vachons d'Isturitz (Simonet, 2005).

Pour terminer la présentation des types d'armatures, signalons également la présence de 9 lamelles à retouche marginale : 7 sont localisées dans la zone avant dont 5 de gabarit très mince et 2 dans la zone du fond. Parmi ces deux lamelles, l'une est un fragment distal de lamelle à pan revers avec retouche marginale de type lamelle de la Picardie. Notons enfin la présence d'une lame à dos (zone avant), de quatre triangles scalènes ( 3 dans la zone avant et 1 dans la fosse), de 2 lamelles à retouche inverse (zone avant) et de 6 lamelles Dufour ( 5 dans la zone avant et 1 dans la zone du fond).

L'étude des matières premières (tabl. 4 à 6) montre une proportion importante du silex d'Audignon parmi les armatures à dos (lamelle à dos, tronquées ou non...).

\begin{tabular}{|l|r|r|r|r|}
\cline { 2 - 4 } \multicolumn{1}{c|}{} & $\begin{array}{c}\text { Zone } \\
\text { avant }\end{array}$ & Fosse & $\begin{array}{c}\text { Zone } \\
\text { du fond }\end{array}$ & Total \\
\hline Pointe à cran & 2 & 2 & 6 & 10 \\
\hline Lamelle à dos & 4 & & & 4 \\
\hline Lamelle à dos mésiale & 27 & 3 & 9 & 39 \\
\hline Fine lamelle à dos & 3 & & 1 & 4 \\
\hline Lamelle à dos et 1 extrémité tronquée & 5 & & 6 & 11 \\
\hline Lamelle à dos et 2 extrémités tronquées & & 2 & 1 & 3 \\
\hline Micro-Gravette & 4 & & & 4 \\
\hline Lamelle à retouche marginale & 2 & & 2 & 4 \\
\hline Fine lamelle à retouche marginale & 5 & & & 5 \\
\hline Pointe de la Gravette & 1 & & & 1 \\
\hline Lamelle à retouche inverse & 2 & & & 2 \\
\hline Lamelle Dufour & 5 & & 1 & 6 \\
\hline Triangle scalène & 3 & 1 & & 4 \\
\hline Divers & 3 & 2 & & 5 \\
\hline Total armatures & $\mathbf{6 6}$ & $\mathbf{1 0}$ & $\mathbf{2 6}$ & $\mathbf{1 0 2}$ \\
\hline Outils domestiques & $\mathbf{7 1}$ & $\mathbf{8}$ & $\mathbf{3}$ & $\mathbf{8 2}$ \\
\hline Total & $\mathbf{1 3 7}$ & $\mathbf{1 8}$ & $\mathbf{2 9}$ & $\mathbf{1 8 4}$ \\
\hline
\end{tabular}

Tabl. 3 - Décompte détaillé par zones des armatures lithiques de GG2.

Tabl. 3 - Detailed count by areas of the GG2 sector flint points. 


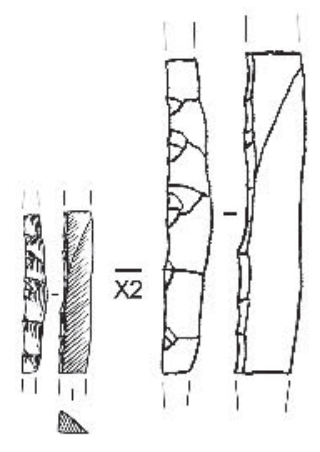

1

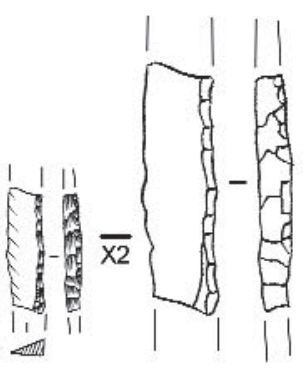

2

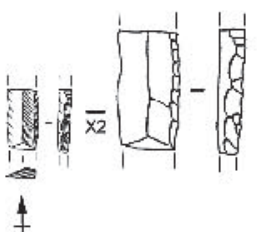

3
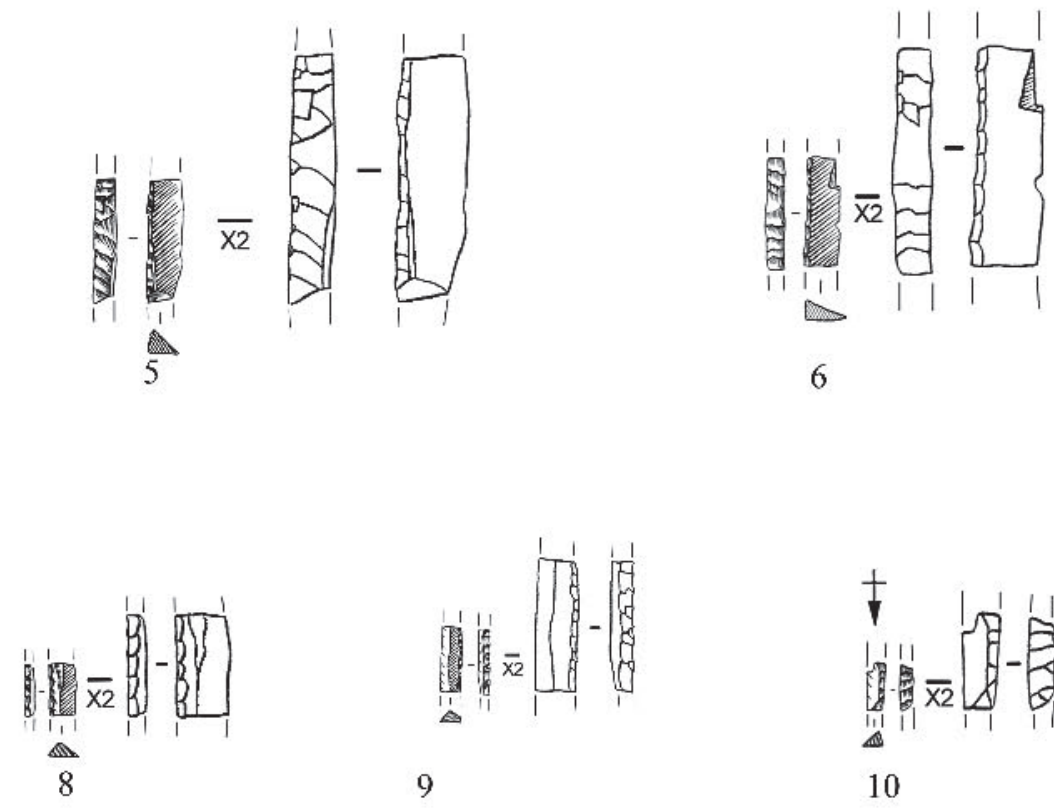

9

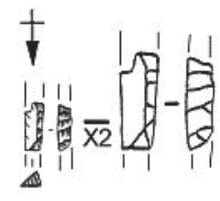

10

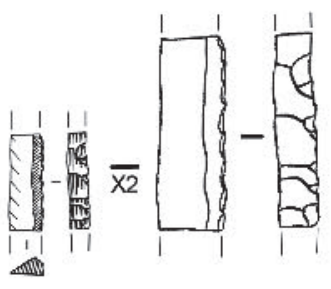

13

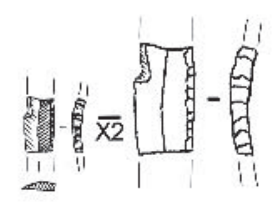

14

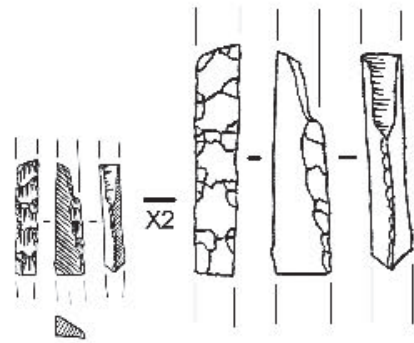

12

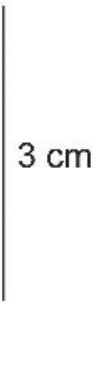

Fig. 11 - Brassempouy, GG2. Lamelles à dos. Zone avant, carrés P5, P6, Q5, Q6, Q7, R5, R6, R7, S5, S6, S7, T6, T7, U7 (dessins A. Simonet). Fig. 11 - Brassempouy, GG2. Backed bladelets. Foremost area, squares P5, P6, Q5, Q6, Q7, R5, R6, R7, S5, S6, S7, T6, T7, U7 (drawings A. Simonet). 

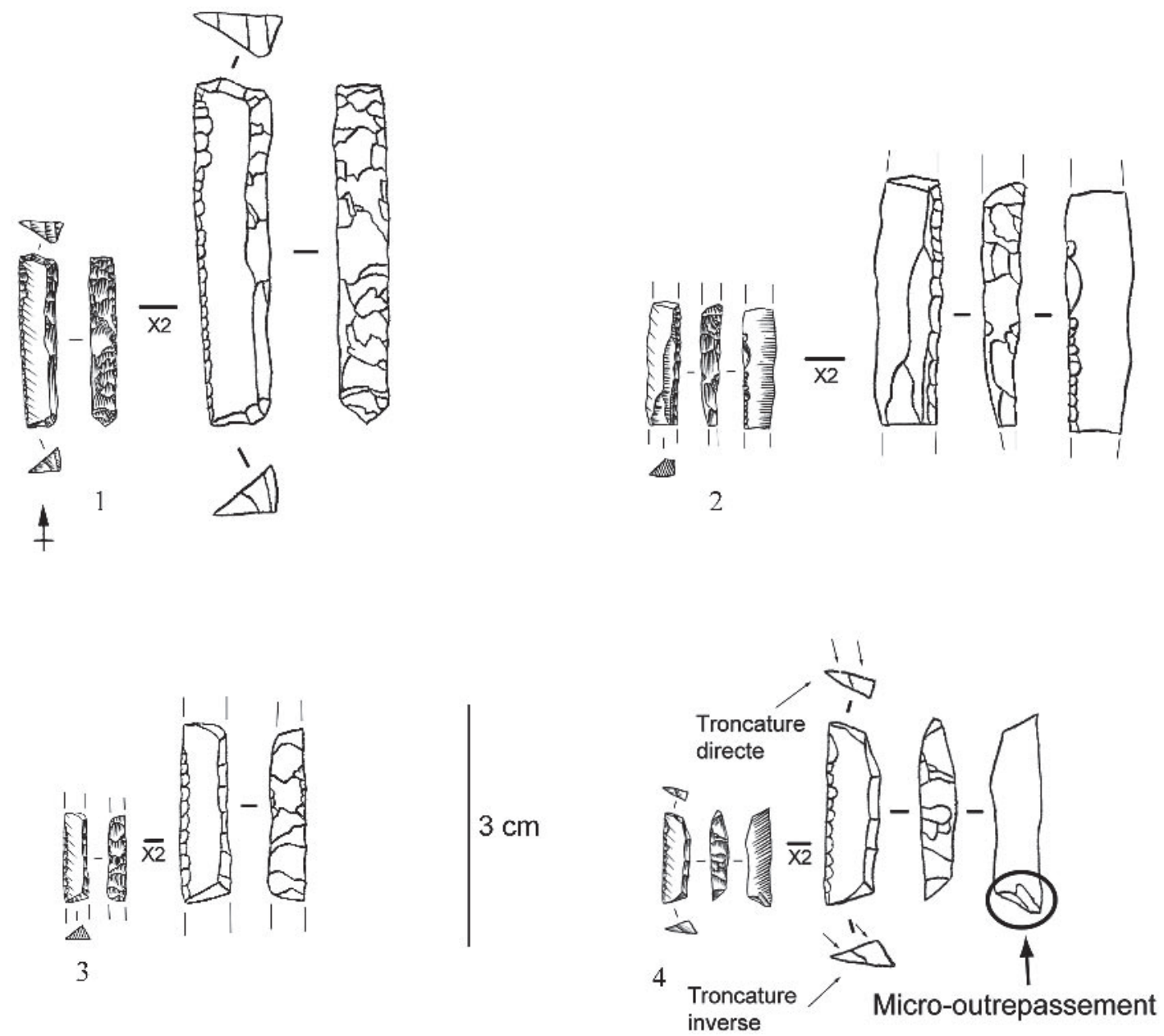

Fig. 12 - Brassempouy, GG2. Lamelles à dos. Fosse, carrés Q9, R8, R9, S8, S9, T8, T9 (dessins A. Simonet).

Fig. 12 - Brassempouy, GG2. Backed bladelets. Pit, squares Q9, R8, R9, S8, S9, T8, T9 (drawings A. Simonet).

Inversement, le silex local de Bastennes-Gaujacq apparaît uniquement dans les lamelles à retouche marginale, les triangles scalènes ainsi que deux lamelles à dos de la zone avant. Il est intéressant de remarquer l'utilisation exclusive d'une variété de silex très homogène pour la confection des pointes à cran. Ce silex de très bonne qualité se retrouve également en grande quantité au sein des lamelles à dos. Sa texture très homogène, sa couleur grise et l'absence de Lepidorbitoides sp. le rapprochent du silex de Tercis identifié par Christian Normand (1986 et 2002), bien qu'il puisse également provenir du secteur plus proche d'Audignon. L'absence du fossile caractéristique du silex maastrichtien de Chalosse, tel qu' on le connaît notamment sur les gîtes de l'anticlinal d'Audignon (Bon, 2002b), explique la grande quantité d'armatures dont la matière première est, pour l'instant, d'identification incertaine (Audignon/Tercis?).

On note une proportion particulièrement importante d'armatures possédant des fractures complexes dans la zone du fond. Près de la moitié des lamelles à dos provenant de cette partie de la galerie comporte une fracture complexe alors que moins de $7 \%$ des lamelles provenant de la zone avant sont concernées (tabl. 7). Étant donné le gabarit restreint des lamelles à dos, le manque d'expérimentation pour ce type d'armature et les premières conclusions concernant une corrélation directement proportionnelle entre la dimension de l'armature et celle de la fracture d'impact (Fisher et al., 1984; Odell et Cowan, 1986; O'Farrell, 1996), nous avons identifié comme fracture complexe, de manière provisoire et dans l'attente de nouvelles expérimentations, les fractures en plume, en marche et en charnière de plus de $2 \mathrm{~mm}$.

D'une manière générale, si l'on prend en compte l'ensemble des trois zones, les armatures sont caractérisées par la quasi-absence de déchets de fabrication (pièce à dos partiel, pièce à encoche, etc.) ou de pièces ratées. Ce sont des pièces particulièrement soignées, terminées et qui, au moins pour une grande partie d'entre elles, ont été utilisées, comme l'illustre la forte proportion de fractures complexes (tabl. 7).

L'étude du matériel lithique retouché en différenciant trois zones (fig. 4) met en avant la singularité de la zone du fond. D'une part, l'industrie lithique est ici constituée quasi exclusivement d'armatures (25 armatures contre 3 outils), dont près de la moitié porte des fractures complexes. D'autre part, la majorité des pointes à cran a été retrouvée dans cette zone ( 6 pièces sur 10 dont 4 dans le carré U9). Notons enfin que, dans 

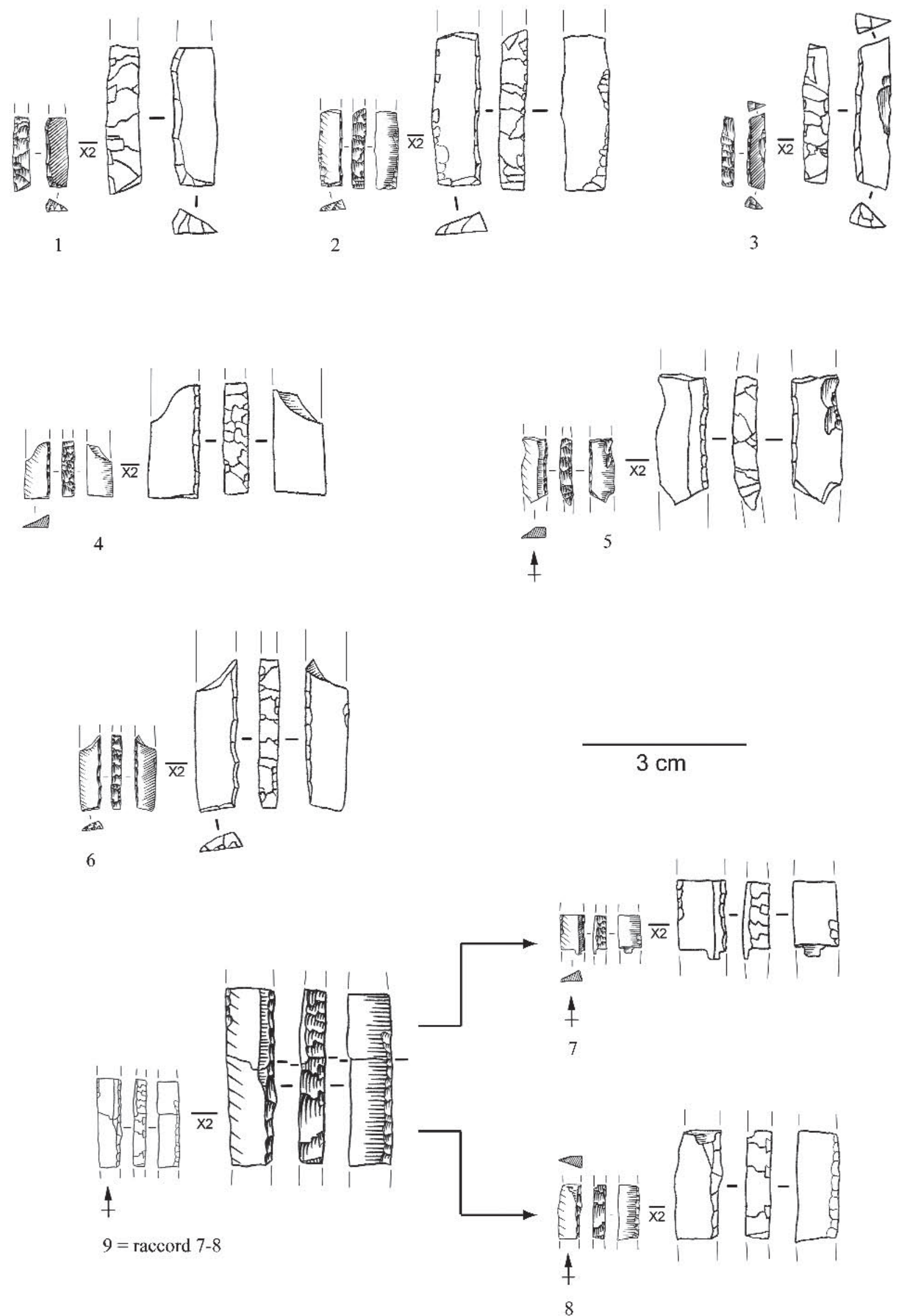

Fig. 13 - Brassempouy, GG2. Lamelles à dos. Zone du fond, carrés S10, S11, T10, T11, U9, U10, U11 (dessins A. Simonet).

Fig. 13 - Brassempouy, GG2. Backed bladelets. Furthermost area, squares S10, S11, T10, T11, U9, U10, U11 (drawings A. Simonet). 


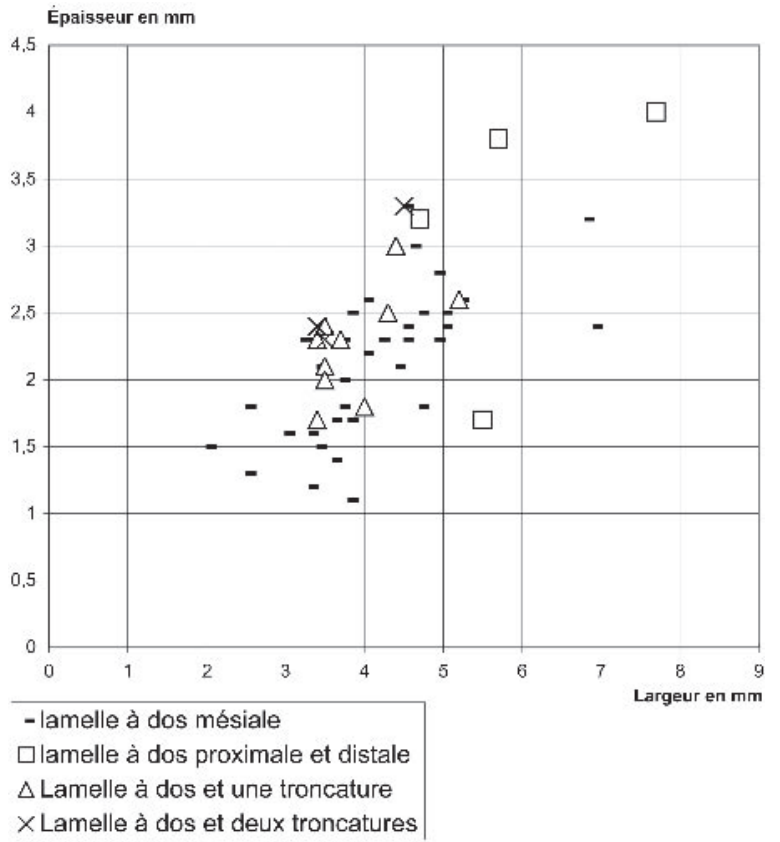

Fig. 14 - Rapport largeur/épaisseur des lamelles à dos. GG2, couches 2A à $2 \mathrm{E}$, toutes zones confondues.

Fig. 14 - Width/thickness ratio of backed bladelets. GG2, layers $2 A$ to $2 E$, all areas.

cette zone, tous les types d'armatures sont en accord avec une attribution gravettienne, en l'occurrence sous la forme d'un faciès dominé par la présence de lamelles à dos mésiales (cf. infra). On peut d'ailleurs noter une véritable concentration de ces objets dans l'angle sudest du carré U10 (Buisson et al., 1995, p. 5). Cet ensemble de faits concourt à appuyer l'homogénéité du matériel issu du fond de GG2. Un test effectué sur le matériel restant issu de la fouille et non pris en compte lors de l'étude, à partir des deux carrés T10 et U9, confirme l'homogénéité aperçue sur les armatures (tabl. 8). Le matériel restant est en grande partie constitué de produits de débitage bruts et de quelques outils oubliés lors du tri effectué au moment de la fouille. Il importe de souligner qu'aucune pièce lithique ne permet d'argumenter la confection d'armatures dans la galerie ou dans ses abords immédiats. Ce test confirme la présence exclusive d'armatures dont la fabrication était achevée avant qu'elles soient introduites par l'Homme dans ce secteur du site ou dans ses parages extérieurs.

À l'inverse, le matériel provenant de la zone avant et de la fosse pose davantage de problèmes. Ces deux zones sont caractérisées par une proportion d'outils domestiques légèrement plus importante par rapport aux armatures (cf. tabl. 3). D'autre part, les triangles scalènes (et, dans une moindre mesure, certaines lamelles à dos fines et étroites et certaines lamelles à retouche marginale) sous-tendent la possibilité d'une contamination inter-couches, notamment avec la couche magdalénienne, tandis que les lamelles Dufour soulignent une pollution en provenance de la couche aurignacienne sous-jacente. Rappelons au passage que les rares pointes à dos proviennent de cette zone.

\section{Industrie osseuse}

Comme nous l'avons déjà évoqué, l'industrie osseuse de GG2 se rapporte presque exclusivement à une catégorie typofonctionnelle, celle des armatures de projectile, et engage une seule matière première : l'ivoire. Par ailleurs, l'ensemble des pièces indique une exploitation exclusive des couches internes de la défense (dentine). L'absence de vestige de la cavité pulpaire, très importante dans la première moitié de la défense, et le diamètre important de plusieurs pièces, même après un façonnage intense, suggèrent qu'elles ont été fabriquées à partir de blocs originaires de la deuxième moitié de la défense; cette dernière offre en effet, sur une grande longueur, une épaisseur importante de dentine (fig. 19). Enfin, l'orientation des lamelles de desquamation sur les pièces indique qu'elles ont toutes été fabriquées à partir de supports débités suivant l'axe longitudinal de la défense. Ce débitage, que nous ne pouvons directement renseigner, a pu toutefois faire intervenir la technique de l'éclatement en percussion indirecte dont on connaît l'efficacité sur ivoire sec ou subfossile (Poplin, 1995; Christensen, 1999). En effet, plusieurs éléments suggèrent l'exploitation d'un ivoire vieilli. Les données paléontologiques traduisent ainsi un climat assez humide et tempéré (Patou-Mathis et Boukhima, 1996), qui n'est pas compatible avec le biotope du Mammouth puisque ce dernier vit sous un climat froid et aride. Cet état de fait, loin de constituer un argument irréfutable compte tenu de la représentativité et de la cohérence de l'assemblage faunique associé à ce mobilier, pourrait néanmoins parler en faveur d'une exploitation d'ivoire vieilli; hypothèse pour laquelle nous disposons en outre de rares indices technologiques ${ }^{5}$. Selon cette hypothèse, l'acquisition de la matière relèverait de la collecte. Il est d'ailleurs intéressant de souligner que les études récentes conduites sur les figurines féminines et les «bandeaux» en ivoire découverts dans la grotte du Pape à Brassempouy indiquent elles aussi l'exploitation d'un ivoire en cours de délitage (Thiault, 1999; White, 2006).

En définitive, tant par la matière que la partie anatomique choisie et l'orientation des supports exploités au sein de la défense, la série étudiée est fortement homogène. Comme nous allons le voir, d'autres éléments confirment la cohérence de cette série.

Les pointes en ivoire présentent en outre de fortes similitudes morphologiques. Il s'agit de pièces assez massives, tout du moins dans leur partie mésiale, de section ovalaire à cylindrique dans leur état originel. Bien que nous ne disposions d'aucun exemplaire complet, au moins deux fragments semblent provenir de doubles-pointes ( ${ }^{\text {os }} 361$ et 666, cf. fig. 7 et 8). Au regard de la pièce $n^{\circ} 666$ - que nous rapprochons plus volontiers d'un fragment mésio-proximal que d'une partie mésio-distale - la base de ces doubles-pointes devait être assez trapue. Au contraire, la partie distale, comme l'indiquent les pièces $n^{\text {os }} 93$ et 236 , est très fine, pourvue d'une extrémité appointée mousse et d'un court méplat sur la face inférieure, lui conférant une 


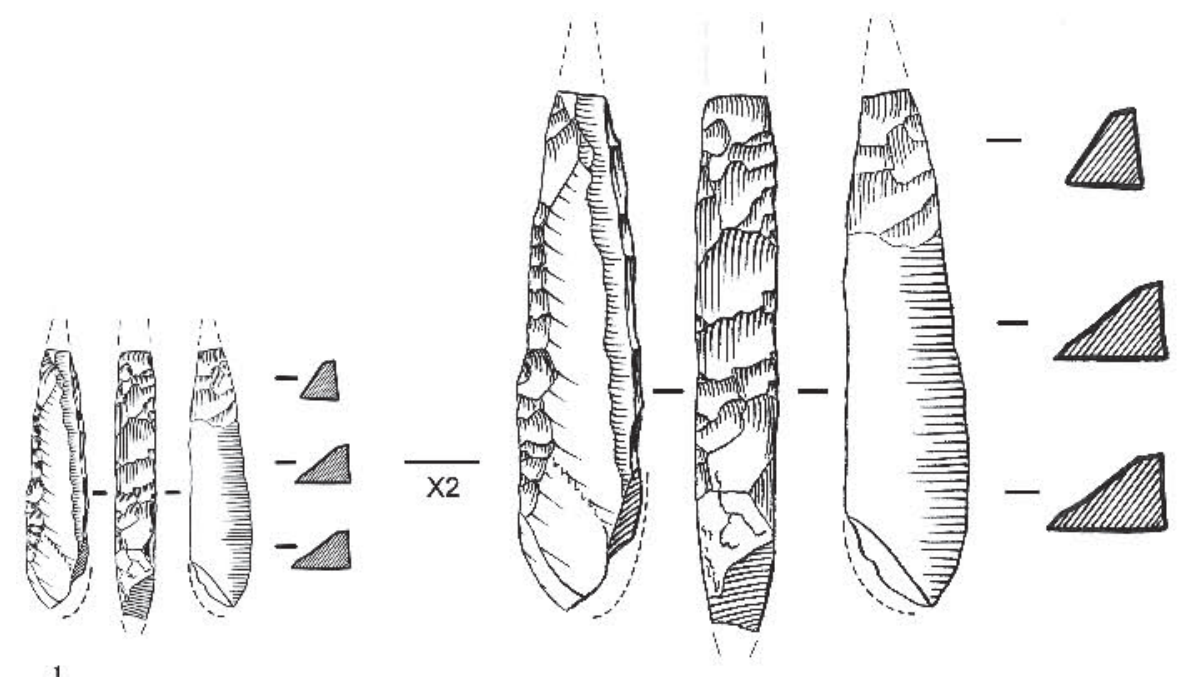

Fig. 15 - Brassempouy, GG2. Zone avant. Micro-Vachon, triangles scalènes, lamelles à bord abattu, lamelle à retouche marginale, lame à dos (dessins A. Simonet).

Fig. 15-Brassempouy, GG2. Front area. Micro-Vachon points, scalene triangles, backed bladelets, bladelet with marginal retouches, backed blade (drawings A. Simonet).

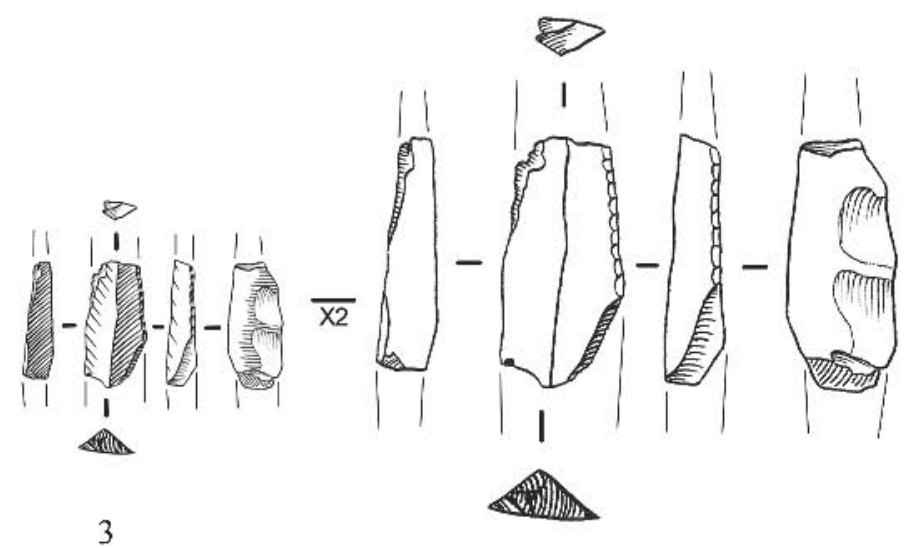

3
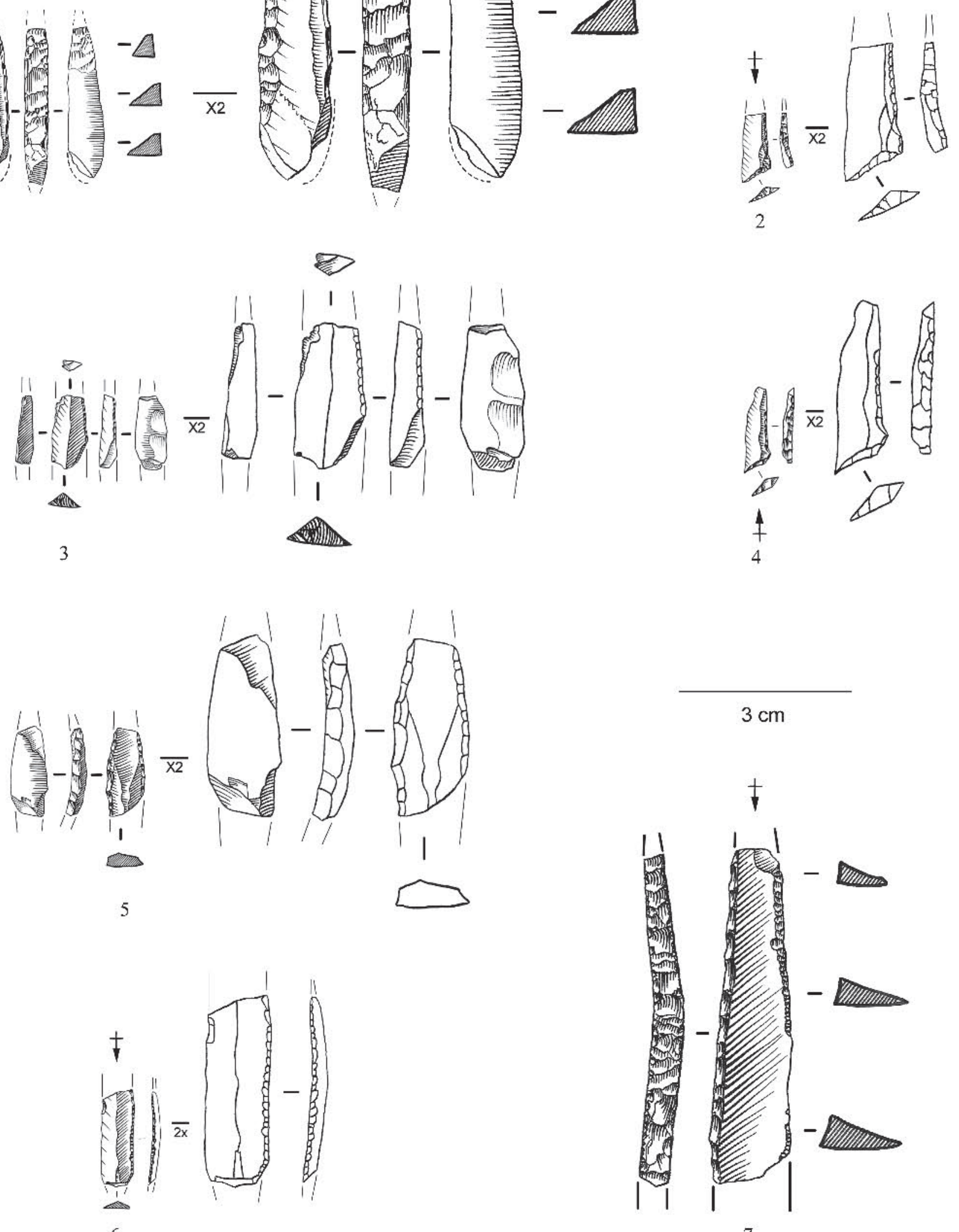

6 

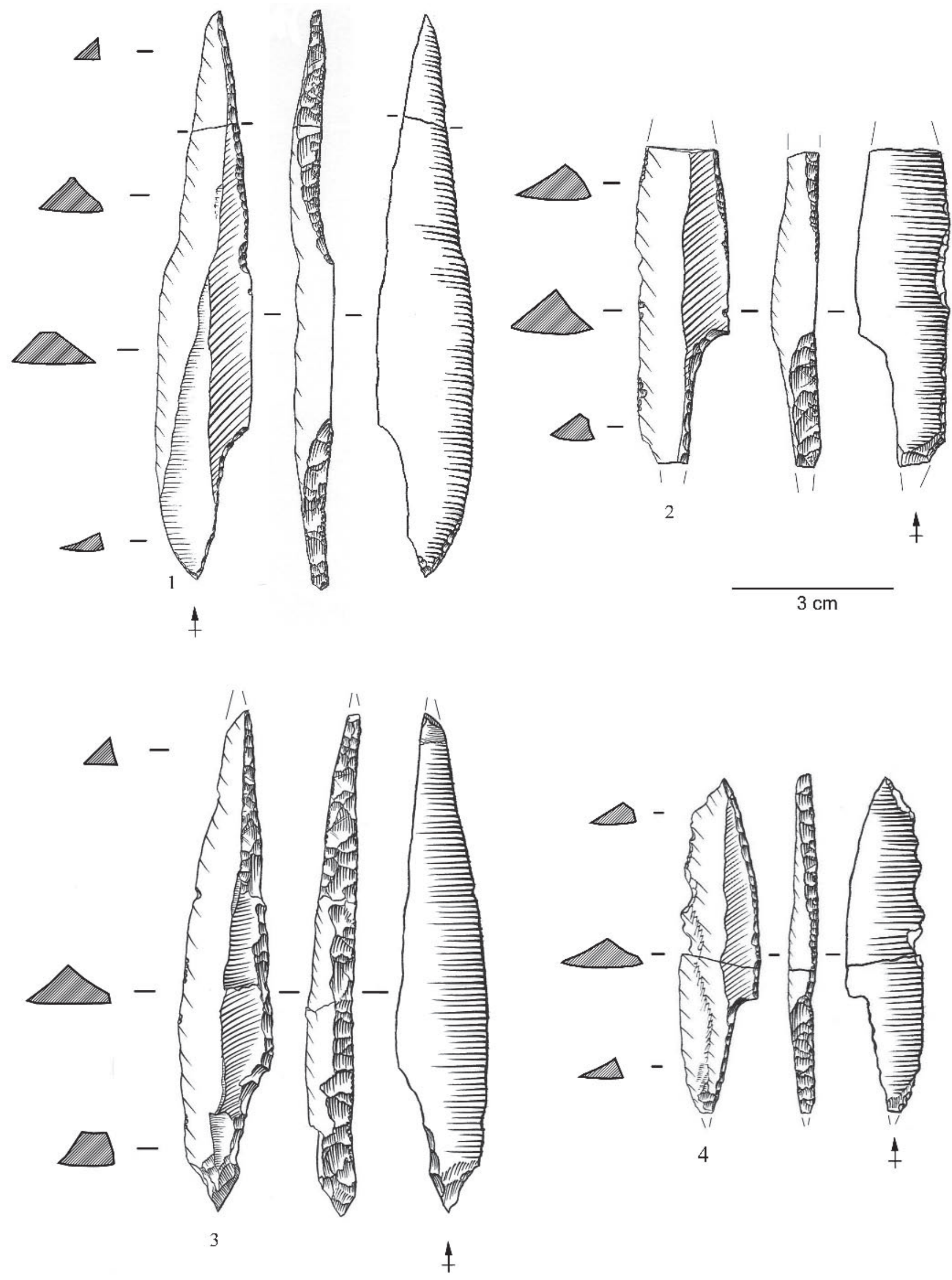

Fig. 16 - Brassempouy, GG2. Pointes à cran (dessins A. Simonet).

Fig. 16 - Brassempouy, GG2. Shouldered points (drawings A. Simonet). 

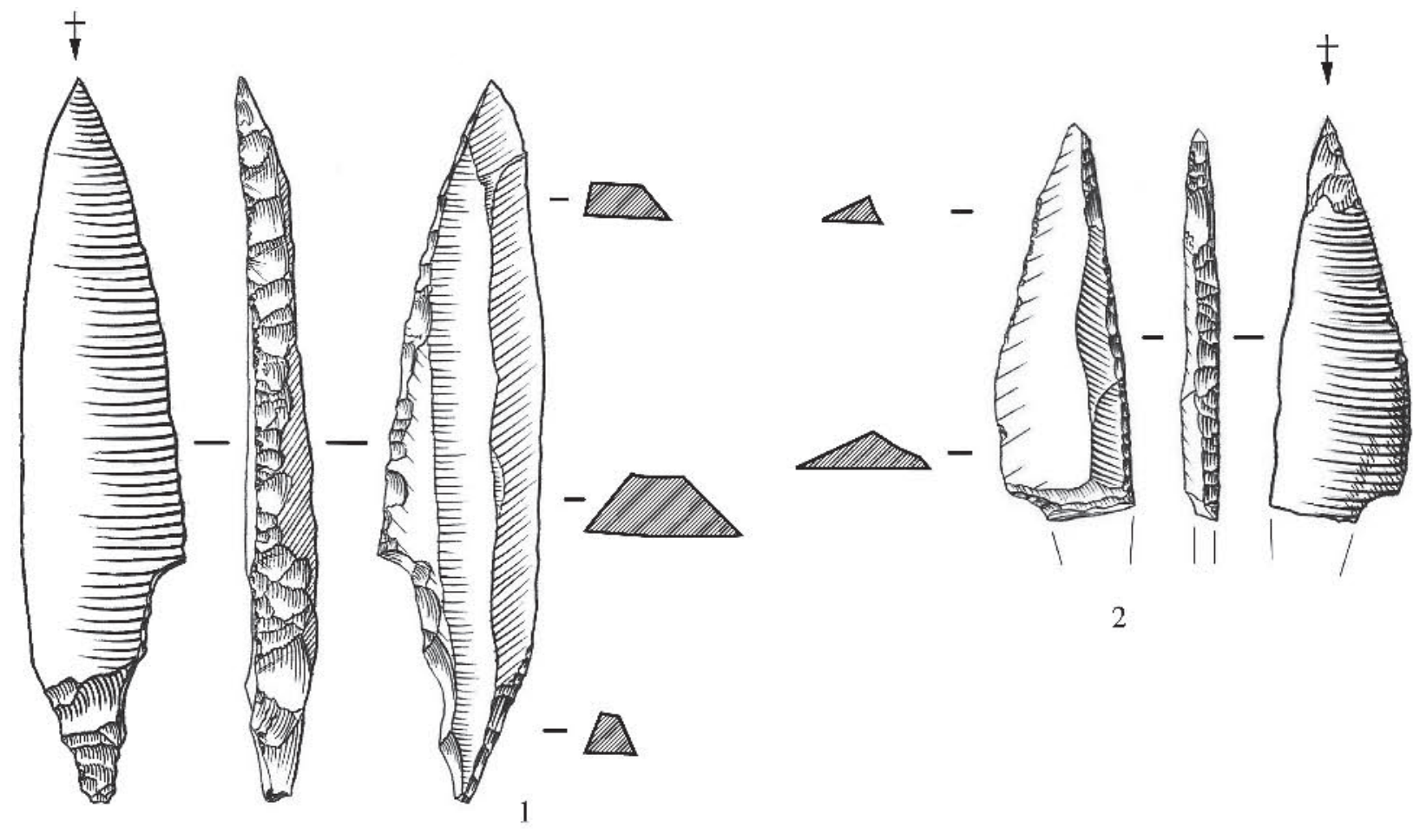

2
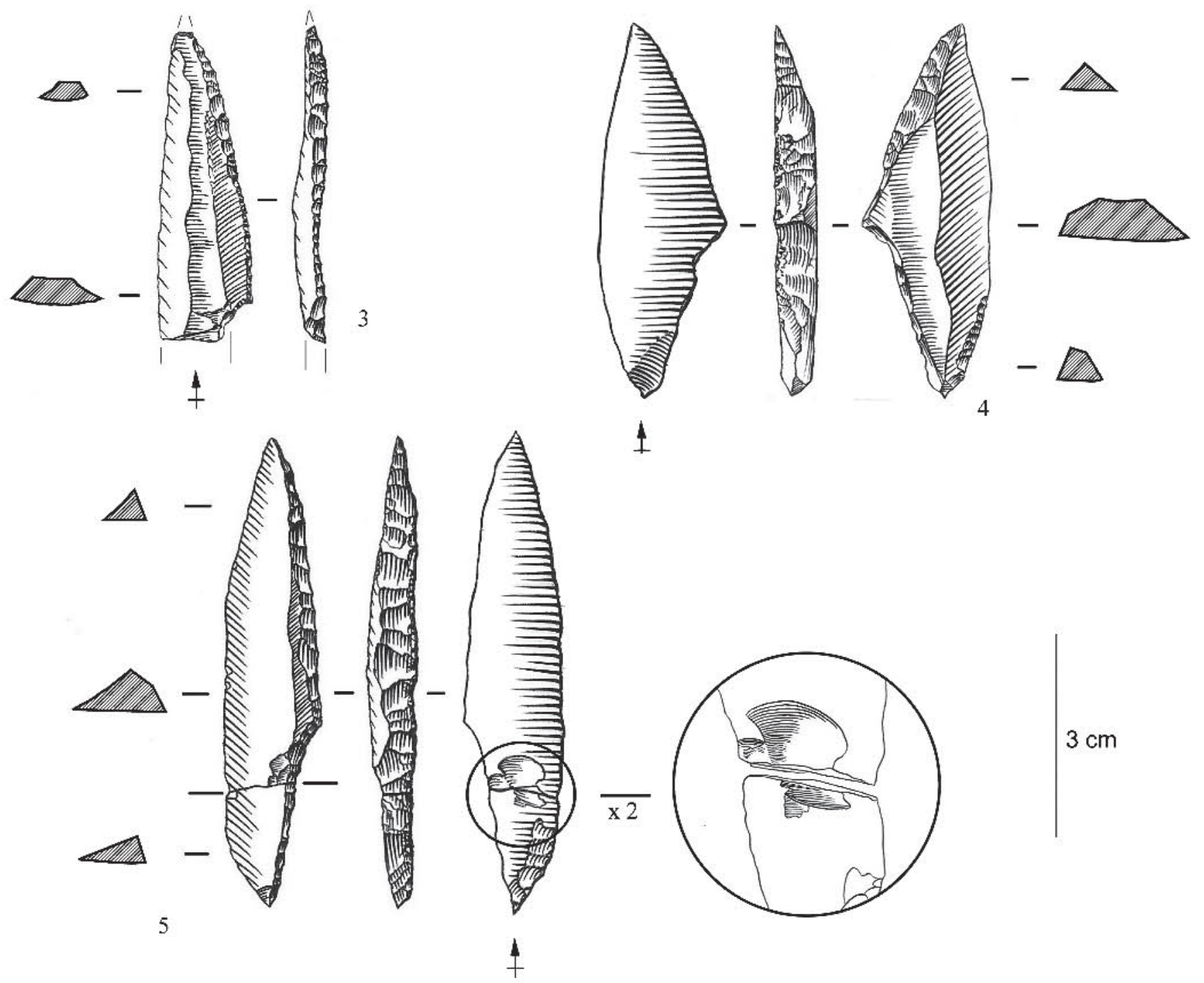

1
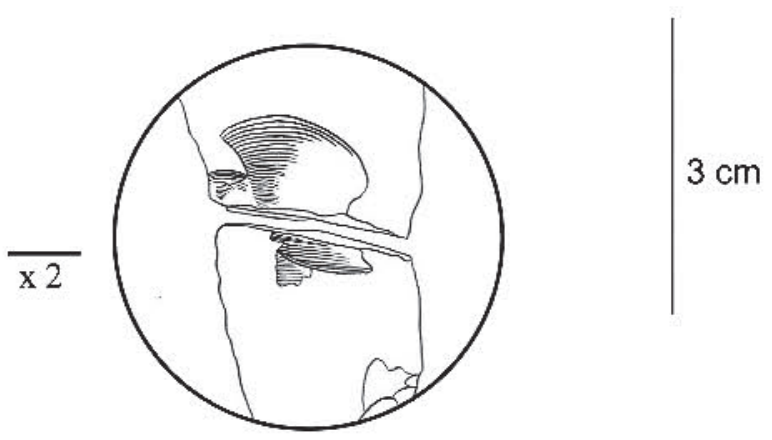

Fig. 17 - Brassempouy, GG2. Pointes à cran (dessins A. Simonet).

Fig. 17 - Brassempouy, GG2. Shouldered points (drawings A. Simonet). 
section aplatie. L'absence de pièce entière et les nombreux délitages post-dépositionnels ne nous ont pas permis de calculer les indices d'allongement et d'épaississement. Néanmoins, nous pouvons constater une certaine homogénéité dans la largeur du fût qui varie entre $10 \mathrm{~mm}$ et $14 \mathrm{~mm}^{6}$ (cf. tabl. 2). Une pointe,

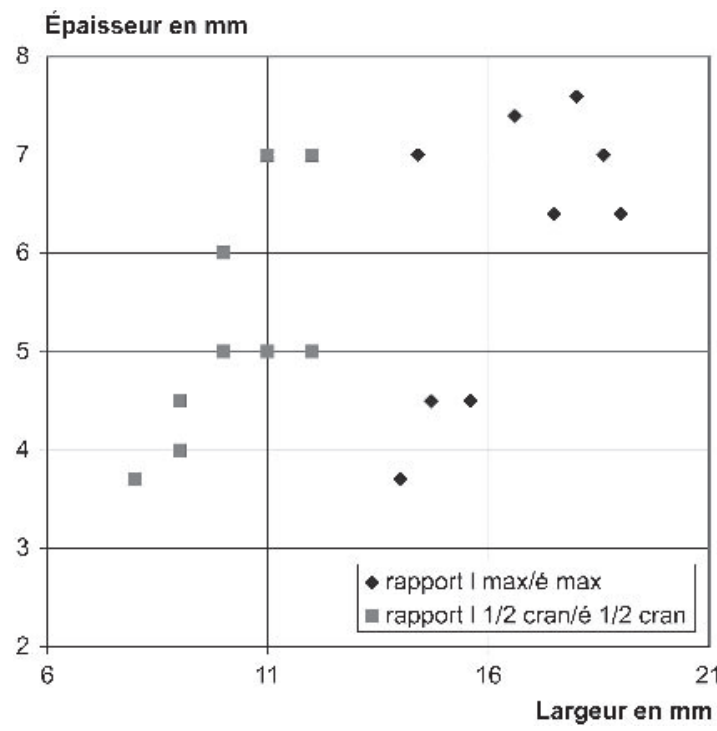

Fig. 18 - Rapport largeur maximale/épaisseur maximale et rapport largeur/ épaisseur pris au milieu de la hauteur du cran des 9 pointes à cran de GG2 (dans deux cas, la largeur à la moitié du cran est une estimation).

Fig. 18 - Maximal width/maximal thickness ratio and width/thickness ratio measured in the middle of the height of the shoulder of the 9 shouldered points from the GG2 sector (in two cases, the width measured on the middle of the shouldered part is an estimation). pourtant fragmentaire, se distingue par sa longueur assez exceptionnelle ( $\mathrm{L}: 300 \mathrm{~mm}$ ).

La seule pièce ne se rapportant pas à la catégorie des pointes de projectile est un outil biseauté ${ }^{7}$. Il présente, en sa partie mésiale, des stigmates de façonnage assez grossiers se superposant à une ancienne surface de fracture (probablement lié au débitage du support, cf. note 7) et recoupant d'autres stries de raclage plus fines et plus régulières (cf. fig. $5, \mathrm{n}^{\circ} 2$ ), ainsi qu'un profil dissymétrique et une section non régulière (subovalaire à subquadrangulaire) qui sont cohérents avec une étape de réfection. Toutefois, nous ne sommes pas en mesure de dire si cette étape de reconfiguration partielle de la pièce s'inscrit dans un objectif de réparation de l'outil ou de recyclage d'une ancienne pointe de projectile cassée. Cet outil présente certes un taux de transformation important et un décor géométrique à l'image de plusieurs des pointes; cependant, le décor est ici légèrement différent et il se situe sur la partie biseautée de la pièce, c'est-à-dire à un endroit où il n'y pas eu de reprise de façonnage. Or, aucune des pointes ne semble devoir être rattachée à la catégorie des pointes à base biseautée; par ailleurs, sur les pointes, les incisions ont été réalisées au niveau de la partie mésiale. Enfin, malgré la suppression de matière occasionnée par l'étape de réfection, cet outil offre une largeur légèrement supérieure et une épaisseur équivalente à celles des pointes de première facture (cf. tabl. 2).

D'un point de vue technique, nous ne pouvons éclairer directement que les dernières étapes de la chaîne opératoire de fabrication des pièces. En effet, suite au façonnage, les stigmates liés au débitage ont

\begin{tabular}{|c|c|c|c|c|c|c|c|c|}
\hline & $\begin{array}{l}\text { Gaujacq/ } \\
\text { Senssacq }\end{array}$ & $\begin{array}{l}\text { Audignon ou } \\
\text { Senssacq/ } \\
\text { Gaujacq }\end{array}$ & Audignon & $\begin{array}{l}\text { Audignon gris } \\
\text { sans le fossile } \\
\text { caractéristique }\end{array}$ & $\begin{array}{c}\text { Audignon/ } \\
\text { Tercis? }\end{array}$ & Flysch & Indéterminé & Total \\
\hline Pointe à cran & & & & 2 & & & & 2 \\
\hline lamelle à retouche marginale & 2 & & 1 & 2 & 1 & & 1 & 7 \\
\hline Lamelle à dos & 2 & 2 & 1 & 11 & 11 & 2 & 5 & 34 \\
\hline Lamelle à dos tronquée & & 2 & & 2 & 1 & & & 5 \\
\hline Pointe de la Gravette & & & & 1 & & & & 1 \\
\hline Micro-Gravette & & 1 & & & 2 & & 1 & 4 \\
\hline Triangle & 1 & & & & 2 & & & 3 \\
\hline Divers & 3 & & & & & & & 3 \\
\hline Total & 8 & 5 & 3 & 18 & 17 & 2 & 7 & 59 \\
\hline
\end{tabular}

Tabl. 4 - Distribution des matières premières au sein des armatures lithiques de la zone avant. GG2, couches $2 \mathrm{~A}$ à $2 \mathrm{E}$. Tabl. 4-Distribution of raw materials within the lithic points from the front area. GG2, layers $2 A$ to $2 E$.

\begin{tabular}{|c|c|c|c|c|c|c|c|c|}
\hline & $\begin{array}{l}\text { Gaujacq/ } \\
\text { Senssacq }\end{array}$ & $\begin{array}{l}\text { Audignon ou } \\
\text { Senssacq/ } \\
\text { Gaujacq }\end{array}$ & Audignon & $\begin{array}{l}\text { Audignon gris } \\
\text { sans le fossile } \\
\text { caractéristique }\end{array}$ & $\begin{array}{c}\text { Audignon/ } \\
\text { Tercis? }\end{array}$ & Flysch & Indéterminé & Total \\
\hline Pointe à cran & & & & 2 & & & & 2 \\
\hline Lamelle à dos mésiale & & & & 1 & 1 & & 1 & 3 \\
\hline Lamelle à dos bitronquée & & & 2 & & & & & 2 \\
\hline Triangle & & & & & 1 & & & 1 \\
\hline Divers & & 1 & & & 1 & & & 2 \\
\hline Total & & 1 & 2 & 3 & 3 & & 1 & 10 \\
\hline
\end{tabular}

Tabl. 5 - Distribution des matières premières au sein des armatures de la fosse. GG2, couches $2 \mathrm{~A}$ à $2 \mathrm{E}$.

Tabl. 5 - Distribution of raw materials within the lithic points from the pit. GG2, layers $2 A$ to $2 E$. 


\begin{tabular}{|l|c|c|c|c|c|c|c|c|}
\cline { 2 - 8 } \multicolumn{1}{c|}{} & $\begin{array}{c}\text { Gaujacq/ } \\
\text { Senssacq }\end{array}$ & $\begin{array}{c}\text { Audignon ou } \\
\text { Senssacq/ } \\
\text { Gaujacq }\end{array}$ & Audignon & $\begin{array}{c}\text { Audignon gris } \\
\text { sans le fossile } \\
\text { caractéristique }\end{array}$ & $\begin{array}{c}\text { Audignon/ } \\
\text { Tercis ? }\end{array}$ & Flysch & Indéterminé & Total \\
\hline Pointe à cran & & & & 6 & & & & 6 \\
\hline lamelle à retouche marginale & 1 & & & & & 1 & & 2 \\
\hline Lamelle à dos & & & 2 & 7 & & & 1 & 10 \\
\hline Lamelle à dos tronquée & & & 2 & 4 & & & & 6 \\
\hline Lamelle à dos bitronquée & & & & & 1 & & & 1 \\
\hline Total & $\mathbf{1}$ & $\mathbf{0}$ & $\mathbf{4}$ & $\mathbf{1 7}$ & $\mathbf{1}$ & $\mathbf{1}$ & $\mathbf{1}$ & $\mathbf{2 5}$ \\
\hline
\end{tabular}

Tabl. 6 - Distribution des matières premières au sein des armatures de la zone du fond. GG2, couches $2 \mathrm{~A}$ à $2 \mathrm{E}$. Tabl. 6 - Distribution of raw materials within the lithic points from the furthermost area. GG2, layers $2 A$ to $2 E$.

\begin{tabular}{|c|c|c|c|c|c|c|c|c|}
\hline & \multicolumn{2}{|c|}{ Zone avant } & \multicolumn{2}{|r|}{ Fosse } & \multicolumn{2}{|c|}{ Zone du fond } & \multicolumn{2}{|r|}{ Total } \\
\hline & Total & $\begin{array}{c}\text { avec fracture } \\
\text { complexe }\end{array}$ & Total & $\begin{array}{c}\text { avec fracture } \\
\text { complexe }\end{array}$ & Total & $\begin{array}{c}\text { avec fracture } \\
\text { complexe }\end{array}$ & total & $\begin{array}{c}\text { avec fracture } \\
\text { complexe }\end{array}$ \\
\hline Lamelle à dos (tronquée et mésiale) & 39 & 6 & 5 & 0 & 17 & 8 & 61 & 14 \\
\hline Lamelle à retouche marginale & 7 & 1 & 0 & 0 & 2 & 1 & 9 & 2 \\
\hline Pointe à cran & 2 & 0 & 2 & 0 & 6 & 1 & 10 & 1 \\
\hline Total & 48 & 7 & 7 & $\mathbf{0}$ & 25 & 10 & 80 & 17 \\
\hline
\end{tabular}

Tabl. 7 - Nombre total d'armatures et nombre d'armatures avec fracture complexe selon les 3 grandes zones. Tabl. 7 - Total number of points and number of points with complex fractures, according to the 3 main areas.

\begin{tabular}{|l|r|r|}
\hline \multicolumn{1}{|c|}{ Matériel des couches 2A à 2E } & T10 & U9 \\
\hline Éclat brut & 29 & 8 \\
\hline Produit laminaire brut & 6 & 1 \\
\hline Produit lamellaire brut & 8 & 1 \\
\hline Éclat retouché & 2 & \\
\hline Nucléus à éclat & 1 & \\
\hline Chute de burin & 1 & \\
\hline Pièce esquillée à retouche marginale & & 1 \\
\hline Pièce tronquée & 1 & \\
\hline Fragment de quartz (galet) & 7 & \\
\hline Casson & 1 & \\
\hline Total & $\mathbf{5 6}$ & $\mathbf{1 1}$ \\
\hline
\end{tabular}

Tabl. 8 - Test d'homogénéité des carrés T10 et U9 visant à contrôler les produits restants dans les sacs de fouille et non pris en compte lors de l'étude.

Tabl. 8 - Homogeneity test of squares T10 and U9 in order to check the remaining products in the excavation bags and not taken into account during the study.

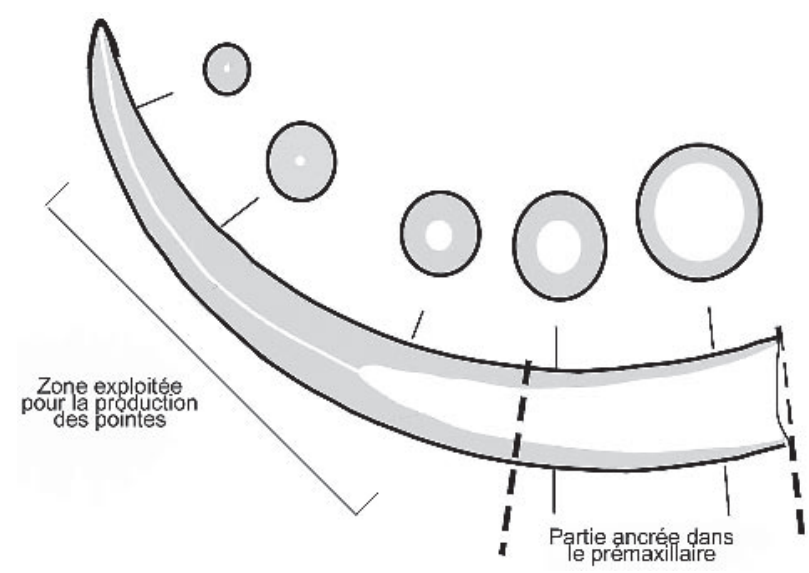

Fig. 19 - Repositionnement anatomique des pointes en ivoire au sein de la défense de mammouth (d'après Christensen, 1999, fig. 38, modifié). Fig. 19 - Anatomical repositioning of ivory points within the mammoth tusk (after Christensen 1999, fig. 38, modified). été supprimés; par ailleurs, la série ne comportait aucun déchet de débitage, ni même de support brut. Nous pouvons ainsi noter que le façonnage des pièces repose sur une utilisation mixte de trois techniques : le raclage (majoritaire), le polissage et, ponctuellement, l'abrasion. L'investissement porté à cette étape de la fabrication est très important puisque la morphologie du support d'origine est intégralement modifiée (fig. 20). Certaines pièces témoignent enfin d'un investissement supplémentaire, et ce par l'aménagement de décors géométriques très soigneusement incisés à l'aide d'un fin tranchant en silex. Le décor de la pièce $\mathrm{n}^{\circ} 96$ est le plus abouti et révèle une recherche de symétrie (cf. fig. 9). Le jeu d'opposition dans l'organisation des incisions courtes et longues entre les deux faces est très particulier et nous ne connaissons pas d'équivalent direct dans le Paléolithique supérieur ancien de France.

Enfin, trois pièces portent des traces d'impact probablement d'origine fonctionnelle. La première pièce $\left(n^{\circ} 93\right)$ est une portion distale présentant un début d'arrachement en languette de très petites dimensions associé à de micro-esquillements en son extrémité apicale (fig. 21). La seconde pièce (raccord 369/523), que nous avons déjà évoquée, porte une fracture en languette probablement à mettre en relation avec l'utilisation de l'armature. Enfin, la troisième pointe $\left(\mathrm{n}^{\circ} 361\right.$, fig. 22 et cf. fig. 8 ) porte une fissure qui la traverse de part en part, amorçant le début d'une fracture en dent de scie sur le fût; elle s'accompagne sur une face d'un léger arrachement de matière. Il est délicat de se prononcer sur l'origine de ces stigmates car nous manquons de référentiels expérimentaux sur les impacts fonctionnels générés par l'utilisation d'une armature en ivoire. Toutefois, la nature de ces stigmates ne semble pas incohérente avec des stigmates fonctionnels d'armatures de projectile. 


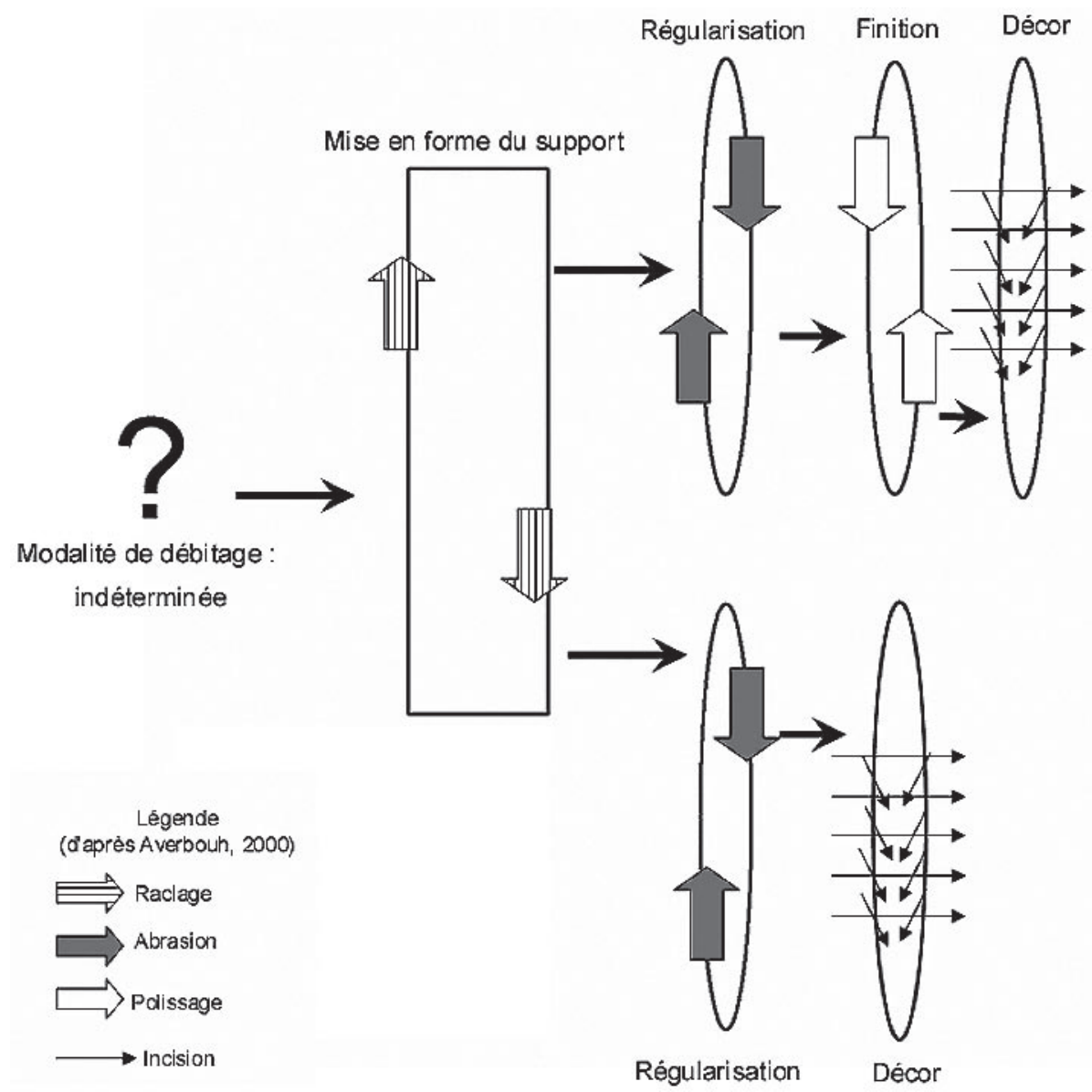

Fig. 20 - Schéma opératoire de façonnage des pointes en ivoire issues du secteur GG2.

Fig. 20 - Shaping of ivory points from the GG2 sector: «schéma opératoire».

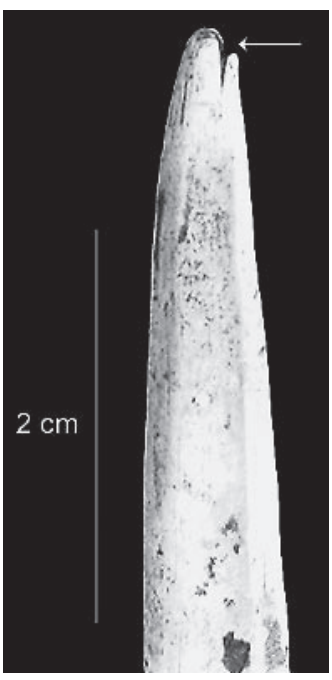

Fig. 21 - Brassempouy, GG2. Pointe $n^{\circ} 93$, détail de l'arrachement présent en son extrémité apicale (cliché N. Goutas).

Fig. 21 - Brassempouy, GG2. Point no. 93, detail of the removal situated on its apical extremity (photograph N. Goutas)

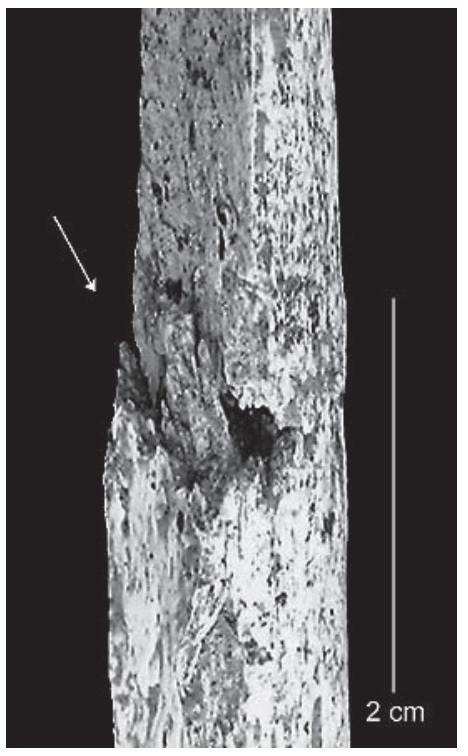

Fig. 22 - Brassempouy, GG2. Pointe n 361 , détail de la fissure traversant la partie mésiale (cliché N. Goutas).

Fig. 22 - Brassempouy, GG2. Point no. 361, detail of the crack crossing the mesial part (photograph N. Goutas) 


\section{D'un point de vue spatial et taphonomique}

\section{Industrie lithique}

En ce qui concerne la répartition de l'ensemble des armatures lithiques, celle-ci montre clairement une concentration dans la couche 2D (tabl. 9). Plus précisément, la prise en compte globale (tabl. 10) des différents niveaux distingués lors de la fouille montre que, d'une part, les armatures à dos présentes dans la couche aurignacienne $2 \mathrm{~F}$ et donc susceptibles de provenir d'une contamination avec le niveau sus-jacent 2D sont localisées exclusivement dans la zone avant et dans la fosse; d'autre part, les lamelles Dufour et les lamelles à retouche inverse présentes dans la couche $2 \mathrm{D}$ sont localisées quasi exclusivement dans la zone avant. Les triangles scalènes rencontrés dans les niveaux $2 \mathrm{~F}$ et $2 \mathrm{D}$ se retrouvent également dans la zone avant et dans la fosse. Précisons que le niveau magdalénien ne semble pas s'étendre jusqu'au fond de la grotte, comme

\begin{tabular}{|l|c|c|c|c|}
\cline { 2 - 5 } \multicolumn{1}{c|}{} & $\begin{array}{c}\text { Zone } \\
\text { avant }\end{array}$ & Fosse & $\begin{array}{c}\text { Zone } \\
\text { du fond }\end{array}$ & Total \\
\cline { 2 - 5 } \multicolumn{1}{c|}{} & $\mathrm{N}$ & $\mathrm{N}$ & $\mathrm{N}$ & $\mathrm{N}$ \\
\hline Couche 1A & 1 & 0 & 0 & 1 \\
\hline Couche 2A & 3 & 1 & 2 & 6 \\
\hline Couche 2A-2C & 1 & 0 & 0 & 1 \\
\hline Couche 2B & 9 & 1 & 0 & 10 \\
\hline Couche 2B-2C & 1 & 0 & 0 & 1 \\
\hline Couche 2C & 8 & 1 & 1 & 10 \\
\hline Couche 2C-2D & 1 & 0 & 4 & 5 \\
\hline Couche 2D & $\mathbf{2 7}$ & $\mathbf{5}$ & $\mathbf{1 7}$ & $\mathbf{4 9}$ \\
\hline 2D-2E & 1 & 0 & 0 & 1 \\
\hline Couche 2E & 9 & 2 & 1 & 12 \\
\hline Couche 2E-2F & 1 & 0 & 0 & 1 \\
\hline Couche 2? & 4 & 0 & 1 & 5 \\
\hline Total & $\mathbf{6 6}$ & $\mathbf{1 0}$ & $\mathbf{2 6}$ & $\mathbf{1 0 2}$ \\
\hline
\end{tabular}

Tabl. 9 - Répartition globale par couche et par zone des armatures lithiques de GG2.

Tabl.9 - Global distribution by layer and by area of GG2 sector lithic points. l'indique la concentration des armatures provenant de la couche 1 dans la zone avant (fig. 23). Il s'ensuit que, premièrement, la répartition spatiale des triangles scalènes au sein des niveaux autres que la couche 1 et celle des armatures à dos au sein de la couche aurignacienne sont cohérentes avec une perturbation verticale du secteur GG2 qui affecte principalement la zone centrale du secteur (fosse), mais aussi une partie au moins de la zone avant. En revanche, l'assemblage lithique provenant de la zone du fond de la couche 2D ne semble pas avoir subi de contaminations. Ce dernier présente un assemblage typologiquement très homogène (cf. supra), bien calé au dessus d'un assemblage aurignacien riche en lamelles Dufour.

Quatre raccords ont pu être effectués parmi ce mobilier : trois entre deux fragments de pointes à cran, le dernier entre deux lamelles à dos mésiales. Parmi les pointes à cran, une seule d'entre elles porte une fracture complexe.

Le raccord de la pointe à cran 157-107 concerne un fragment issu de la couche 2 ? ( $\left.{ }^{\circ} 107\right)$ et un autre issu de la couche $2 \mathrm{D}\left(\mathrm{n}^{\circ}\right.$ 157). Ces deux fragments proviennent des carrés U10 et T10. Ils sont séparés horizontalement par une distance d'environ 1,20 m selon une orientation et un pendage nord-est/sud-ouest et verticalement par une hauteur de $13 \mathrm{~cm}$. Le raccord de la pointe à cran 180-567 concerne un fragment issu de la couche $2 \mathrm{D}\left(\mathrm{n}^{\circ} 180\right)$ et un autre issu de la couche $2 \mathrm{~F}$ $\left(\mathrm{n}^{\circ}\right.$ 567). Ces deux fragments proviennent des carrés T10 et S9. Ils sont séparés horizontalement par une distance d'environ $1,50 \mathrm{~m}$ selon une orientation et un pendage nord-ouest/sud-est et verticalement par une hauteur de $50 \mathrm{~cm}$. Ce raccord met en jeu une fracture complexe au niveau du cran, diagnostique d'une utilisation en pointe de projectile.

Le raccord de la pointe à cran 421-139 concerne un fragment issu de la couche $2 \mathrm{D}\left(\mathrm{n}^{\circ} 421\right)$ et un autre issu de la couche $2 \mathrm{E}\left(\mathrm{n}^{\circ} 139\right)$. Ces deux fragments proviennent des carrés T7 et R9. Ils sont séparés horizontalement par une distance de plus de deux mètres selon une orientation et un pendage nord-est/sud-ouest et verticalement par une hauteur de $12 \mathrm{~cm}$ (cf. fig. 10). Le raccord des deux lamelles à dos mésiales concerne des pièces provenant du carré U10 et de la couche 2D.

\begin{tabular}{|l|r|r|r|r|}
\cline { 2 - 5 } \multicolumn{1}{c|}{} & Zone avant & Fosse & Zone du fond & Total \\
\hline Couche 1 magdalénienne & $\mathbf{3 1}$ & $\mathbf{2}$ & $\mathbf{1}$ & $\mathbf{3 4}$ \\
\hline Total armature & 7 & 0 & 1 & 8 \\
\hline Couche 2D (2A à 2E) gravettienne? & 53 & 7 & 25 & 85 \\
\hline Lamelle Dufour et à retouche inverse & 3 & 1 & 0 & 4 \\
\hline Armature à dos & $\mathbf{6 3}$ & $\mathbf{8}$ & $\mathbf{2 6}$ & $\mathbf{9 7}$ \\
\hline Triangle scalène & \multicolumn{5}{|l|}{} \\
\hline Total armature & 9 & 1 & 7 & 17 \\
\hline Couche 2F aurignacienne & 10 & 14 & 0 & 24 \\
\hline Lamelle Dufour et à retouche inverse & 0 & 1 & 0 & 1 \\
\hline Armatures à dos & $\mathbf{1 9}$ & $\mathbf{1 6}$ & $\mathbf{7}$ & $\mathbf{4 2}$ \\
\hline Triangle scalène & 113 & 26 & 34 & 173 \\
\hline Total armature &
\end{tabular}

Tabl. 10 - Répartition spatiale des grands types d'armatures des couches 1, 2D et 2F.

Tabl. 10 - Spatial distribution of the main types of points from layers $1,2 D$ and $2 F$. 


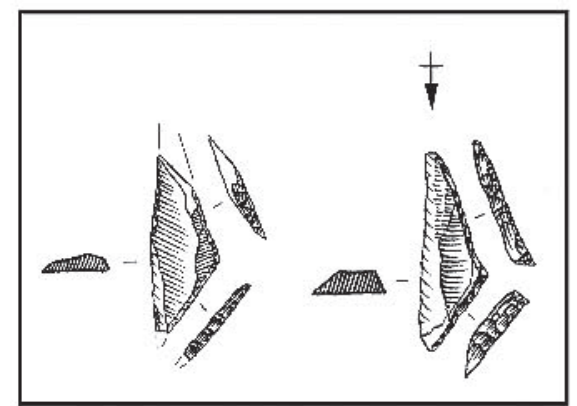

Triangle scalène

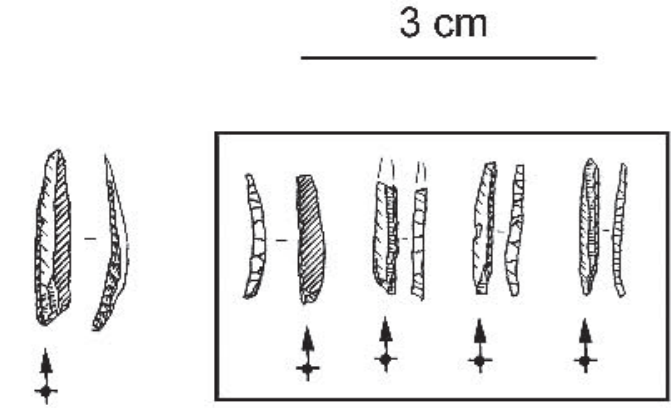

très fines lamelles à retouche marginale

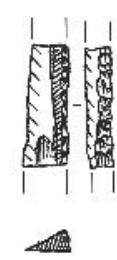

Lamelle à dos

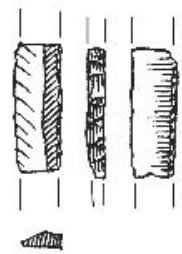

Lamelle à dos et retouche alterne marginale

Fig. 23 - Brassempouy, GG2. Armatures magdaléniennes de la couche 1 (dessins A. Simonet).

Fig. 23 - Brassempouy, GG2. Magdalenian points from layer 1 (drawings A. Simonet)

Ces deux lamelles ont été retrouvées à proximité l'une de l'autre. D'autre part, leur raccord met en jeu une fracture complexe (en marche plane de 1,4 mm), probablement diagnostique d'une utilisation en pointe de projectile.

L'état de conservation du mobilier lithique contenu dans les remplissages des différentes zones de la galerie livre une autre information : si l'ensemble des armatures lithiques présente un aspect très frais, les outils possèdent en revanche une altération beaucoup plus hétérogène. Ainsi, 29 outils sur 82 provenant des couches $2 \mathrm{~A}$ à $2 \mathrm{E}$ présentent des traces d'altération : 11 sous la forme de traces fortement développées avec notamment des stries de charriage, 18 sous la forme de traces légères, c'est-à-dire avec des arêtes et des nervures un peu émoussées. Le mode de perturbation des couches du secteur GG2, dont nous avons souligné le caractère plus ou moins localisé, n'exclut pas la possibilité de plusieurs apports. Si l'on combine l'ensemble de ces observations, une hypothèse peut être proposée : celle d'un dépôt in situ du mobilier le plus frais, auquel se mêlent des éléments apportés par fluage depuis l'aven. Certains indices taphonomiques corroborent cette hypothèse d'une double perturbation des dépôts, à la fois sous une forme de vidange ou de ruissellements localisés (fosse) et sous la forme de phénomènes successifs ayant associé à un dépôt primaire contenant, lui, principalement des armatures, un matériel beaucoup plus hétérogène provenant de l'extérieur de la cavité. Et la zone où ce dépôt primaire serait le mieux conservé correspond à la partie profonde de la galerie.

\section{Industrie osseuse}

Si la majorité des pièces en ivoire retrouvées dans le secteur GG2 provient de la couche $2 \mathrm{D}$, plusieurs autres ont été retrouvées au sein des couches sus et sous-jacentes : couches 1, 2A, 2B, 2E, 2F et 3 . Les couches $2 \mathrm{~A}$ à $2 \mathrm{D}$, bien qu'individualisées à la fouille, semblent appartenir à un même ensemble chronoculturel, le Gravettien (Bon et al., 1998; Bon, 2002a).

Les pièces en ivoire se répartissent obliquement suivant un axe majoritairement nord-ouest/sud-est, et ceci sur une épaisseur de plus de $500 \mathrm{~mm}$. On observe par ailleurs une assez large dispersion horizontale des pièces, puisque celles-ci se concentrent principalement au sein d'un losange formé des carrés R9, S8, S9, T7, T9, T10 et U9 et d'une superficie moyenne de $8 \mathrm{~m}^{2}$ (cf. fig. 10).

Au total quatre raccords, mettant en jeu trois armatures, ont été effectués. Les deux premiers (réalisés par D. Buisson) concernent un mésio-distal de pointe de $300 \mathrm{~mm}$ de long (cf. fig. 6) et font intervenir trois fragments issus des couches $2 \mathrm{D}$ (pièces 236 et 35 ) et 2B (pièce 182). Ces fragments se répartissent horizontalement sur environ $3 \mathrm{~m}^{2}$ au sein des carrés T10, S9, S8 suivant une orientation nord-ouest/sud-est et verticalement sur une hauteur de $80 \mathrm{~mm}$. Bien qu'originaire d'une même couche, la distance verticale séparant les deux pièces retrouvées dans la couche 2D est plus importante que celle séparant la pièce $n^{\circ} 35$ (couche 2D) de celle retrouvée dans la couche $2 \mathrm{~B}$. Ces trois fragments présentent en outre des fractures nettes; ces dernières sont diagnostiques de fractures post-dépositionnelles car elles ne se produisent que sur des matières à l'état sec. Qui plus est, chacun de ces fragments témoigne d'une histoire taphonomique qui lui est propre. Ceci se traduit par des colorations et des états de surface différents. Ainsi, les altérations sont de plus en plus importantes vers la base de l'armature (fig. 24). Le fragment distal, le mieux conservé des trois, présente une coloration majoritairement blanche, teintée de gris-bleu et de beige (pigments de manganèse ?) et quelques concrétions. Le deuxième fragment, situé au niveau du fût, a une teinte à dominante gris-bleu et en certains endroits beige. Contrairement au précédent fragment, les pigments colorés sont plus nombreux et la pièce est en moins bon état. Enfin, le troisième fragment - le plus 


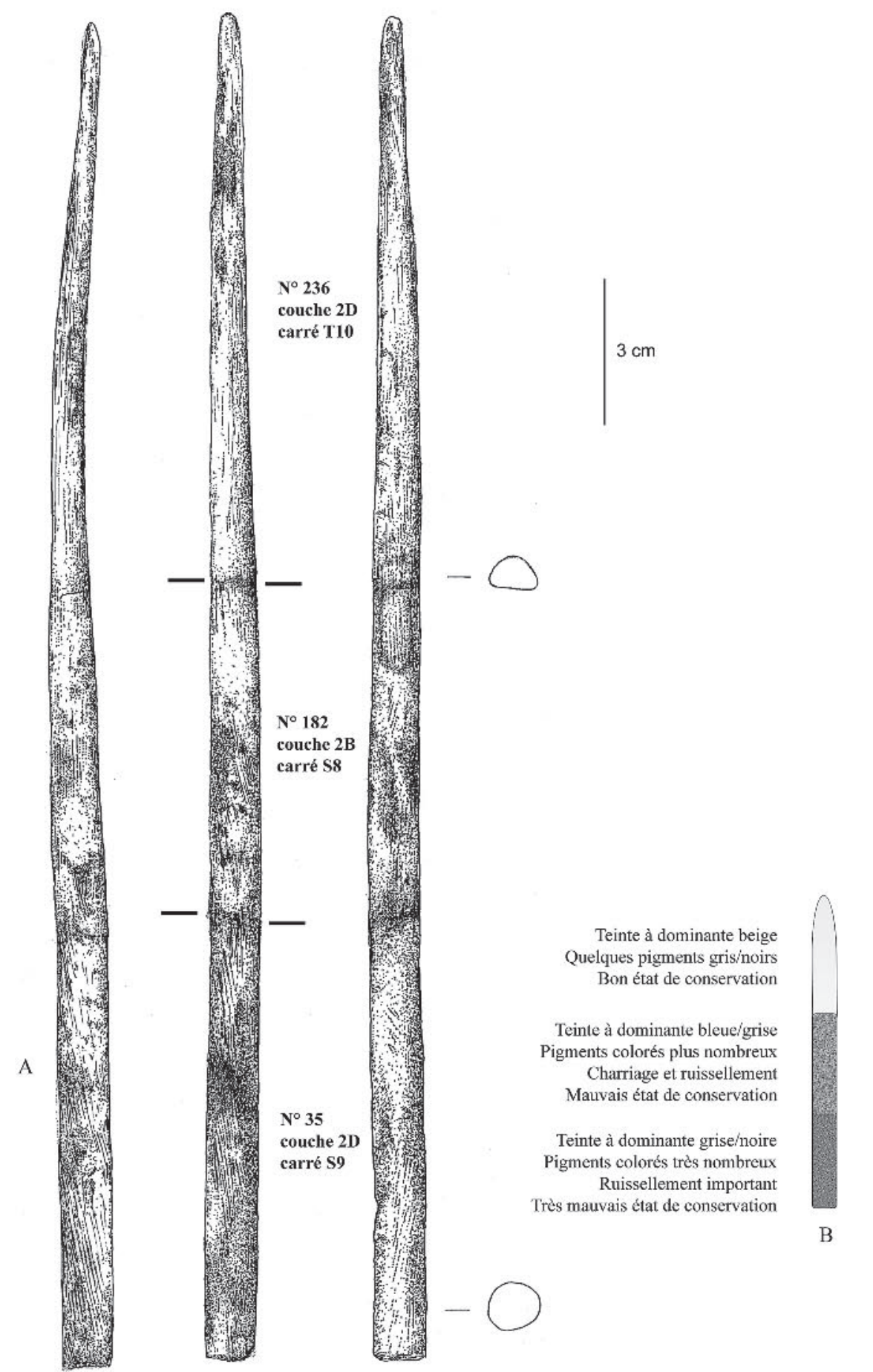

Fig. 24 - Brassempouy, GG2. Conservation différentielle des trois fragments constituant la grande pointe en ivoire. Fig. 24 - Brassempouy, GG2. Differential conservation of three fragments constituting the long ivory point.

proche de la base - est très mal conservé. Les pigments recouvrent presque complètement la pièce et les traces de dissolution ou d'altération par l'eau sont nombreuses.

Le troisième raccord concerne les pièces $n^{\text {os }} 246$ et 96 (fig. 25) situées respectivement dans les carrés S8 et U9 de la couche 2D et distantes d'environ 2,5 m. Le plus grand des deux fragments est celui qui est resté le plus proche de l'aven, le plus petit étant localisé plus en contrebas. La dispersion de ces pièces suit la même orientation que précédemment et leur état de surface est assez bon.

Le dernier raccord fait intervenir les pièces $n^{\text {os }} 369$ et 523 (fig. 26). Découvertes dans deux couches différentes (2E et $2 \mathrm{~F}$ ), au sein des carrés T9 et S8, elles sont séparées par une hauteur de $230 \mathrm{~mm}$ et distantes de moins d'un mètre sur le plan horizontal. Le plus grand des deux fragments est le plus éloigné de l'aven. Ces deux fragments forment un mésial de pointe. À une extrémité, on peut observer une fracture nette et 
de l'autre une fracture légèrement en spirale. De teinte majoritairement bleu-gris, la pièce est en mauvais état et présente de nombreux pigments noirs (manganèse?), ainsi que diverses altérations dues au ruissellement et au charriage. Si l'on reconstitue l'histoire de cette pièce, il apparaît que la pointe s'est fracturée une première fois (au-dessus de la partie proximale), entraînant un bord de fracture en dent de scie ou en languette (fig. 27, $\mathrm{n}^{\circ}$ 1). Cette fracturation semble d'origine fonctionnelle. Elle se serait donc produite avant l'arrivée de la pièce dans le secteur GG2. Puis serait intervenu un délitage (fig. 27, $\mathrm{n}^{\circ} 2$ ), cette fois postdépositionnel, ayant entraîné le détachement du fragment $n^{\circ} 523$ (fig. 27, $n^{\circ} 3$ ). Celui-ci a de nouveau subi une fracture nette ayant entraîné le détachement

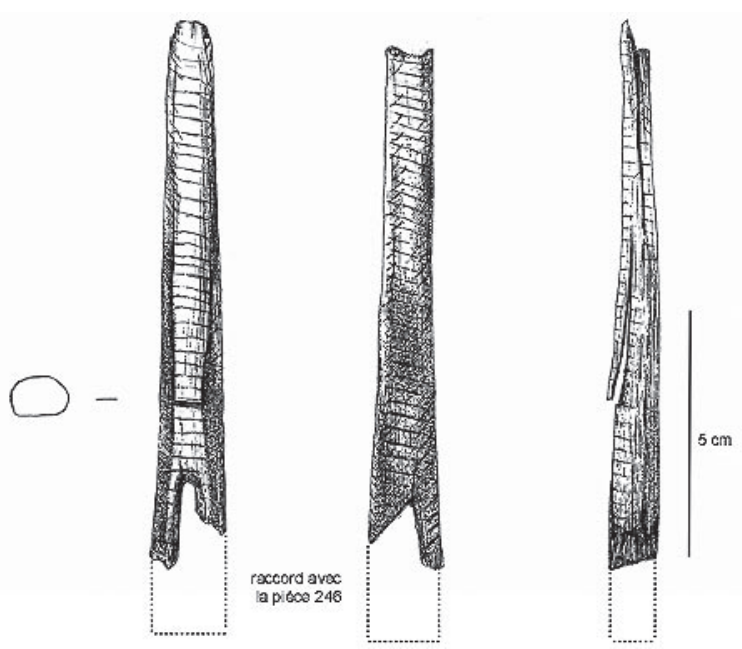

Fig. 25 - Brassempouy, GG2. Pièce $n^{\circ} 96$ raccordant avec la pièce $n^{\circ} 246$ (dessin F. Bongni).

Fig. 25 - Brassempouy, GG2. Piece no. 96 conjoining with piece no. 246 (drawing F. Bongni). d'un nouveau fragment qui a emporté avec lui le vestige du premier bord de fracture $\left(n^{\circ} 1\right)$, ce dernier n'ayant pas été retrouvé à la fouille. C'est pourquoi, lorsque l'on raccorde les pièces $n^{\text {os }} 369$ et 523 , leurs pans de fracture ne se correspondent pas (fig. 27).

En définitive, il est intéressant de noter que la conservation différentielle des pièces en ivoire est directement corrélée à leur localisation dans la grotte. Il apparaît ainsi que les pièces retrouvées dans la zone du fond présente un état de surface assez bon $\left(\mathrm{n}^{\text {os }} 93\right.$ et 96 ; carrés U9) à très bon ( ${ }^{\circ} 236$; carré T10). À l'inverse, le reste du matériel, localisé au sein des bandes 7,8 et 9 (en bordure de la bande 8 ), présente des états de surface moins bons à très mauvais. Seule une pièce située dans ce secteur $\left(\mathrm{n}^{\circ} 246\right)$ présente un état de conservation similaire à celui des pièces du fond de la grotte. Il existe donc une certaine dichotomie spatiale et taphonomique entre les pièces originaires de la zone du fond et celles découvertes au sein de la zone médiane, qui rejoint parfaitement certaines constatations établies à partir du mobilier lithique. Il apparaît ainsi que les zones avant et médiane de la grotte ont certainement souffert de contaminations intercouches et de perturbations horizontales, tandis que la zone profonde est beaucoup plus homogène.

\section{DISCUSSION SUR L'ATTRIBUTION CHRONOCULTURELLE DES ARMATURES LITHIQUES ET EN IVOIRE MISES AU JOUR DANS LE SECTEUR GG2}

\section{Industrie lithique}

Les produits bruts de débitage et les outils (tabl. 11) ne sont pas discriminants car, d'une part, la plupart des outils contenus dans cet assemblage s'avèrent ubiquistes
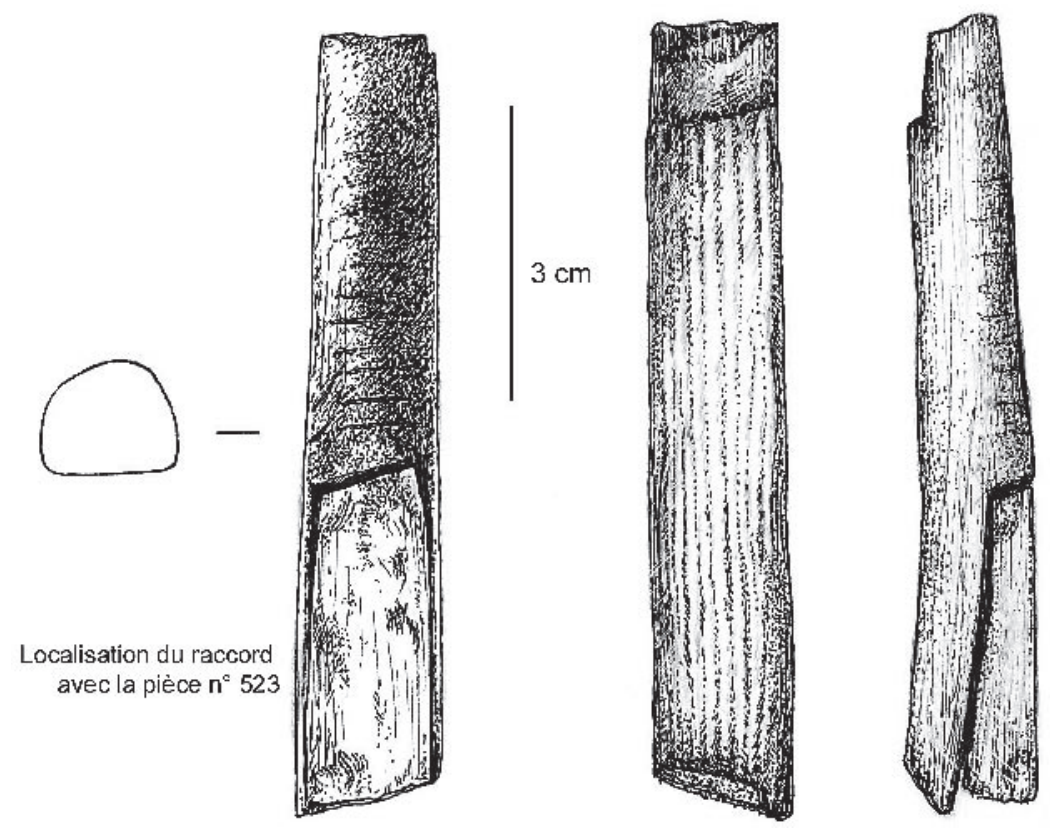

Fig. 26 - Brassempouy, GG2. Pièce ${ }^{\circ} 369$ raccordant avec la pièce $n^{\circ} 523$ (dessin F. Bongni).

Fig. 26-Brassempouy, GG2. Piece no. 369 conjoining with piece no. 523 (drawing F. Bongni). 
ÉTAPE I : choc violent et fracturation de la pièce

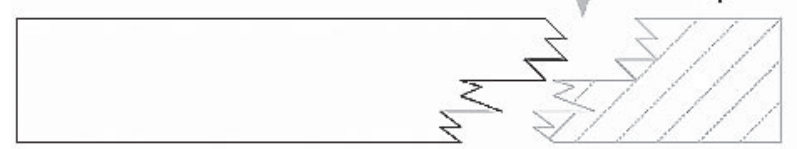

ÉTAPE II : délitage

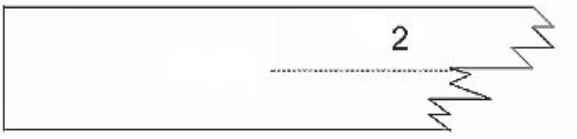

ÉTAPE III : détachement d'un second fragiment

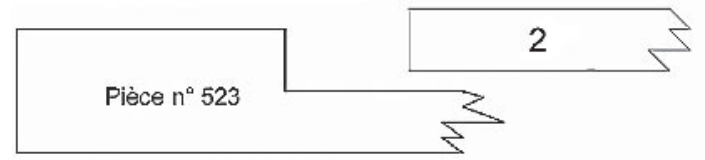

ÉTAPE IV : fracture post-dépositionnelle du second fragment

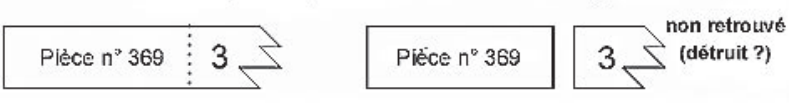

\section{RACCORD DES DEUX PIÈCES LORS DE L'ÉTUDE}

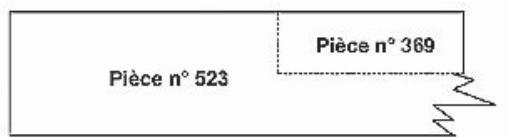

Fig. 27 - Brassempouy, GG2. Reconstitution de l'histoire postdépositionnelle de la pointe en ivoire $n^{\circ} 369 / 523$.

Fig. 27 - Brassempouy, GG2. Reconstruction of the post-depositional process which has affected ivory point no. 369/523.

à l'échelle du Paléolithique supérieur et, d'autre part, il n'est pas certain que l'ensemble du matériel issu des horizons $2 \mathrm{~A}$ à $2 \mathrm{E}$ ait la même origine dépositionnelle. Nous venons d'évoquer l'hypothèse selon laquelle une association postérieure à un premier dépôt, sous l'effet d'un ou d'une suite de transports successifs par l'eau, semble expliquer le mélange d'armatures d'aspect très frais et d'outils patinés et/ou qui accusent des stigmates de transport marqués (stries de charriage) ainsi que la localisation différentielle des armatures (proportionnellement dominante dans la zone du fond) et des outils domestiques (davantage présents dans la zone avant). Compte tenu de ces observations taphonomiques et spatiales, il n'est donc guère surprenant que les quelques outils discriminants d'un point de vue chronoculturel se rapportent aussi bien à l'Aurignacien (grattoir Caminade ${ }^{8}$ et grattoir à museau) qu'au Gravettien (lame à dos et burin de Noailles).

Inversement, la panoplie d'armatures est non seulement porteuse d'une forte charge diagnostique mais elle semble pouvoir être attribuée à un seul épisode culturel. En effet, la présence de pointes à cran en association avec de nombreuses lamelles à dos mésiales et de quelques lamelles à dos tronquées à l'une ou aux deux extrémités et d'un rapport largeur/ épaisseur identique aux lamelles à dos mésiales, rapproche GG2 de l'assemblage du chantier I de
Brassempouy (tabl. 12). Dans les deux cas, si l'on observe les microlithes à dos, les lamelles à dos mésiales sont largement majoritaires, suivies par ordre décroissant par les lamelles à dos tronquées à une extrémité puis par les lamelles à dos tronquées aux deux extrémités, selon un rapport numérique proche de 1-4-16 (c'est-à-dire que pour une quantité de lamelles à dos bitronquées, on trouve quatre fois plus de lamelles à dos tronquées et quatre fois plus de lamelles à dos mésiales que de lamelles à dos tronquées, soit 16 fois plus de lamelles à dos mésiales que de lamelles à dos bitronquées). Le reste du mobilier du chantier I est principalement constitué de nucléus, de produits de débitage, de burins de Noailles et de lamelles à retouche marginale qui ne se retrouvent pas dans le secteur GG2 (Dartiguepeyrou, 1995; Klaric, 2003). Le mobilier du chantier I diffère donc par sa composition mais également par sa densité qui s'avère bien plus importante (plusieurs centaines de nucléus et de burins de Noailles sur les quelques $\mathrm{m}^{2}$ fouillés) et témoigne d'une zone d'activité totalement différente de celle de GG2.

À Isturitz, principal autre gisement gravettien de la partie atlantique des Pyrénées, ce rapport numérique parmi les armatures est légèrement différent dans la couche IV (couche principale à Noailles),

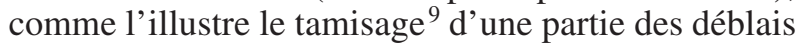
des fouilles anciennes des époux Saint-Périer, dont les collections sont amputées de cette catégorie de vestiges. Les lamelles à dos tronquées à deux extrémités sont aussi nombreuses que celles tronquées à une extrémité (cf. tabl. 12). Ce léger décalage dans les proportions pourrait être la conséquence de l'échantillonnage effectué à Isturitz (les campagnes 2004-2005 concernent moins d' $1 \mathrm{~m}^{3}$ de déblais tamisés).

\begin{tabular}{|l|c|c|c|c|}
\cline { 2 - 5 } \multicolumn{1}{c|}{} & $\begin{array}{c}\text { Zone } \\
\text { avant }\end{array}$ & Fosse & $\begin{array}{c}\text { Zone } \\
\text { du fond }\end{array}$ & Total \\
\hline Grattoir sur bout de lame & 4 & 3 & 1 & 8 \\
\hline $\begin{array}{l}\text { Grattoir sur bout de lame } \\
\text { retouchée }\end{array}$ & 0 & 1 & 0 & 1 \\
\hline Grattoir à museau & 1 & 0 & 0 & 1 \\
\hline Grattoir Caminade & 1 & 0 & 0 & 1 \\
\hline Burin d'angle sur cassure & 1 & 1 & 1 & 3 \\
\hline Burin sur troncature & 1 & 0 & 0 & 1 \\
\hline Burin de Noailles & 3 & 1 & 0 & 4 \\
\hline Burin dièdre & 1 & 0 & 0 & 1 \\
\hline Burin multiple dièdre & 1 & 0 & 0 & 1 \\
\hline Encoche/denticulé & 5 & 0 & 0 & 5 \\
\hline Pièce esquillée & 5 & 1 & 0 & 6 \\
\hline Lame à dos & 2 & 0 & 0 & 2 \\
\hline Biface & 1 & 0 & 0 & 1 \\
\hline Produit laminaire retouché & 15 & 1 & 1 & 17 \\
\hline Produit lamellaire retouché & 4 & 0 & 0 & 4 \\
\hline Éclat retouché & 26 & 0 & 0 & 26 \\
\hline Total & $\mathbf{7 1}$ & $\mathbf{8}$ & $\mathbf{3}$ & $\mathbf{8 2}$ \\
\hline
\end{tabular}

Tabl. 11 - Décompte des outils des horizons 2A à 2E par zone, Brassempouy, GG2.

Tabl. 11 - Count of tools from levels $2 A$ to $2 E$ by area, Brassempouy, $G G 2$. 


\begin{tabular}{|l|r|r|c|}
\cline { 2 - 4 } \multicolumn{1}{c|}{} & \multicolumn{2}{c|}{ Isturitz } & Brassempouy \\
\cline { 2 - 4 } \multicolumn{1}{c|}{} & \multicolumn{1}{c|}{2004} & 2005 & Chantier I \\
\hline Pointe de la Gravette & 6 & 8 & 10 \\
\hline Micro-Gravette & 13 & 6 & 17 \\
\hline Pointe à cran & $\mathbf{0}$ & $\mathbf{0}$ & $\mathbf{5}$ \\
\hline Lamelle à dos mésiale & $\mathbf{8}$ & $\mathbf{1 0}$ & $\mathbf{8 0}$ \\
\hline Lamelle à dos simple & $\mathbf{2}$ & $\mathbf{3}$ & $\mathbf{1 6}$ \\
\hline Lamelle à retouche marginale & $\mathbf{1 7}$ & $\mathbf{5 4}$ & $\mathbf{5 1}$ \\
\hline Lamelle à dos et une extrémité tronquée & $\mathbf{3}$ & $\mathbf{2}$ & $\mathbf{1 2}$ \\
\hline Lamelle à dos et deux extrémités tronquées & $\mathbf{2}$ & $\mathbf{3}$ & $\mathbf{3}$ \\
\hline Pièce à dos semi-abrupte & 0 & 5 & 0 \\
\hline Triangle à dos & 0 & 0 & 1 \\
\hline Lamelle Dufour & 0 & 0 & 2 \\
\hline Fine lamelle courbe et torse à retouche marginale & 0 & 0 & 7 \\
\hline Pièce à dos partiel ou gibbeux & 3 & 1 & 43 \\
\hline Divers & 2 & 3 & 0 \\
\hline Total armatures & $\mathbf{5 6}$ & $\mathbf{9 5}$ & $\mathbf{2 4 7}$ \\
\hline
\end{tabular}

Tabl. 12 - Décompte comparatif des armatures découvertes lors des tamisages-tests d' $1 / 2 \mathrm{~m}^{3}$ effectués sur les déblais des fouilles Saint-Périer (tamisages 2004 et 2005 réalisés par C. Normand) et du chantier I de Brassempouy (fouilles Delporte).

Tabl. 12 - Comparative count of the points discovered during the sieving tests carried out on $1 / 2 \mathrm{~m}^{3}$ of Saint-Perier excavation spoil (sieving 2004 and 2005 by C. Normand) and of the Brassempouy excavation I (Delporte excavations).

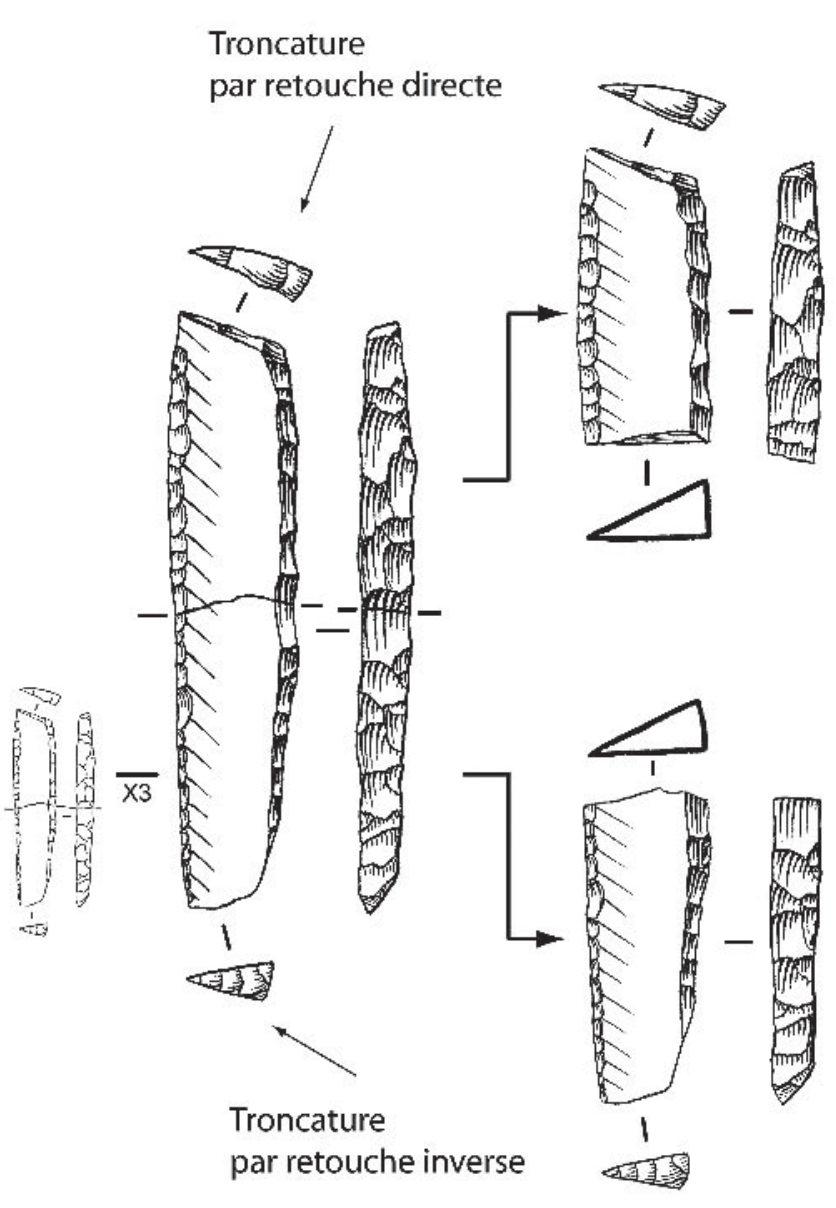

Fig. 28 - Isturitz, tamisage 2005 des déblais Saint-Périer, couche IV (dir. C. Normand). Lamelles à dos bitronquée (dessins A. Simonet).

Fig. 28 - Isturitz, 2005 sieving of the Saint-Périer excavation spoil, level IV (dir. C. Normand). Bitruncated backed bladelets (drawings A. Simonet).
À un degré de résolution beaucoup plus précis, un autre point commun existe entre ces microlithes à dos du secteur GG2 et ceux du Gravettien à Noailles d'Isturitz (couche IV). Celui-ci concerne les modalités d'aménagement des troncatures de certaines lamelles à dos bitronquées par retouche alterne, lequel se retrouve pareillement à Isturitz (fig. 28).

Conjointement à ces microlithes à dos, le style des pointes à cran (bien que ces dernières soient absentes à Isturitz), et surtout celui de la micro-Vachon, est le deuxième argument typologique qui permet d'associer l'assemblage du secteur GG2 à l'ensemble du Gravettien à Noailles pyrénéen.

Au niveau lithologique, l'utilisation d'une même variété de silex très homogène pour la confection des armatures du secteur GG2 se retrouve parmi les armatures à dos du chantier I. Qu'il provienne ou non des gîtes d'Audignon, ce silex d'excellente qualité n'a peu ou pas été utilisé par les Aurignaciens de ce même site (François Bon, comm. pers.). En revanche, nos premières observations montrent qu'il se retrouve également au sein du Gravettien à Noailles d'Isturitz (couche IV). Conjointement aux arguments typologiques, cette sélection lithologique appuie la cohérence entre les différents assemblages qui proviennent du secteur GG2, du chantier I et de la grotte d'Isturitz et converge vers une attribution commune au Gravettien à Noailles tel que l'on l'identifie dans cette région.

Finalement, seules les lamelles à retouche marginale qui représentent le type d'armature le plus fréquent du chantier I et d'Isturitz sont largement sous-représentées dans les armatures du secteur GG2. Cette rareté est particulièrement intéressante car elle converge avec l'utilisation quasi exclusive d'un silex différent pour la 
confection de ces lamelles dans chacun des trois exemples, en l'occurrence le silex de Bastennes-Gaujacq à Brassempouy et le silex du Flysch à Isturitz (Simonet, 2005). À l'instar du chantier I, celui-ci n'apparaît en proportion importante que dans ce type d'armature au sein du secteur GG2, ce qui renforce la différence entre ces dernières et l'ensemble des armatures à dos.

\section{Industrie osseuse}

L'industrie sur ivoire, bien que répartie de manière assez disparate au sein de la stratigraphie du secteur GG2, reste néanmoins concentrée au sein d'une même unité chronostratigraphique constituée des couches $2 \mathrm{~A}$ à 2D. Cette dernière couche concentre à elle seule la

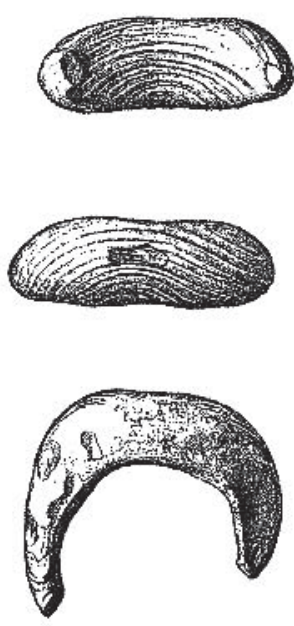

1

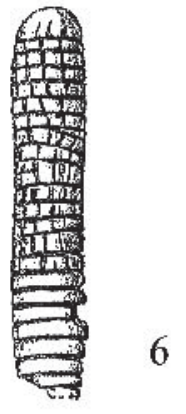

6

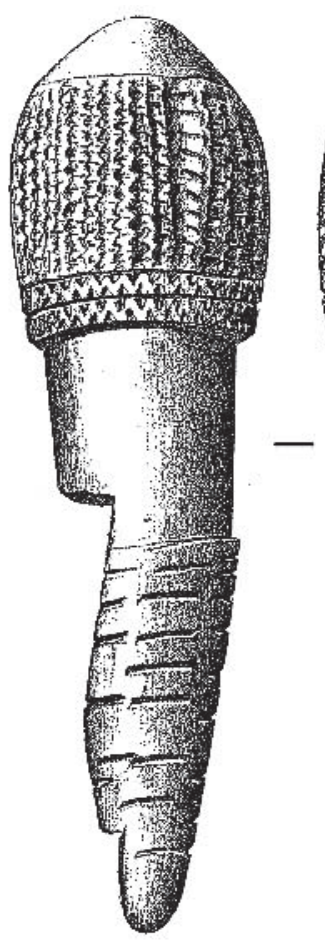

2

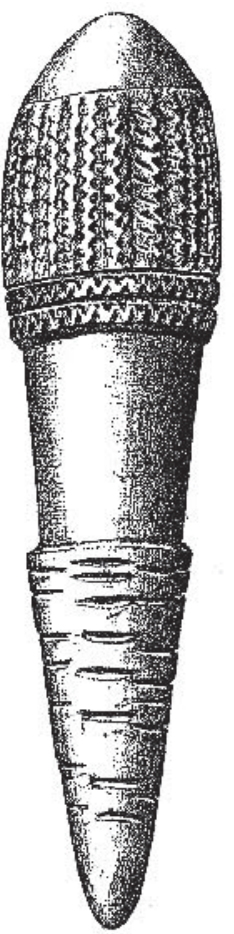

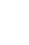
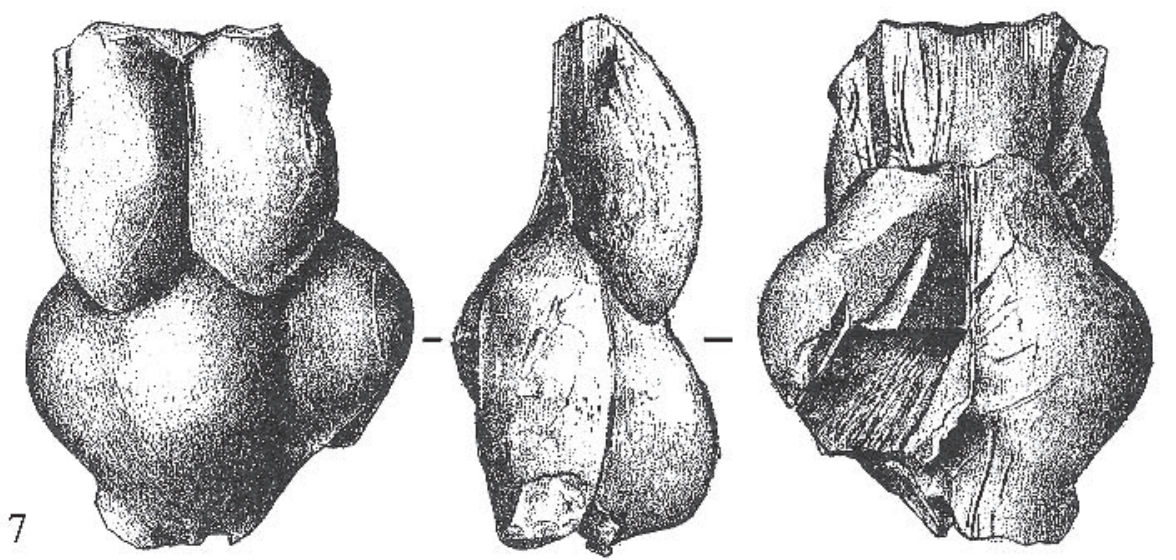

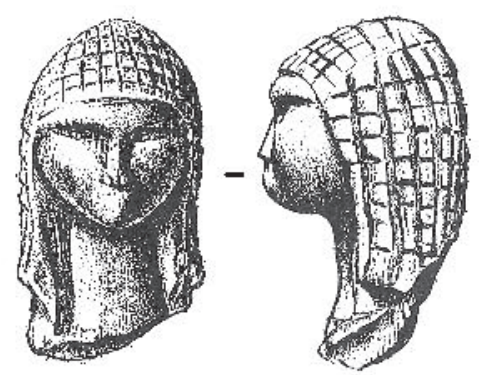

3

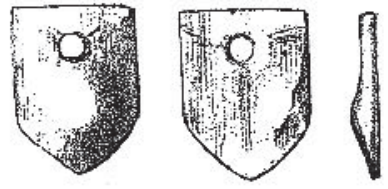

4

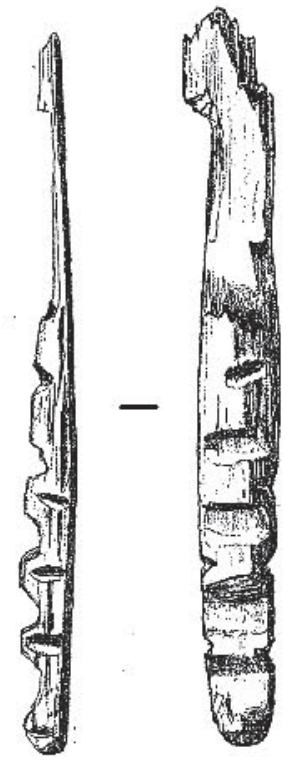

5

Fig. 29 - Objets en ivoire découverts à l'entrée de la grotte du Pape à Brassempouy lors des fouilles d'É. Piette (nºs 1, 2, 4, 5 et $6:$ d'après Piette, 1895, fig. 1, 3, 5, 6 et $7 ; n^{\text {os }} 3$ et $7:$ d'après Piette et Laporterie, 1894, fig. 1, 5).

Fig. 29-Ivory objects discovered in the entrance of the Grotte du Pape, Brassempouy, during E. Piette's excavations (nos. 1, 2, 4, 5, 6: after Piette 1895, fig. 1, 3, 5, 6, 7; nos. 3, 7: after Piette \& Laporterie 1894, fig. 1, 5). 
majorité des artefacts en ivoire (cf. tabl. 2). Or, les données relatives à l'industrie lithique confirment l'appartenance de ces couches au Gravettien (cf. supra).

L'hypothèse d'une origine culturelle commune à l'ensemble des pièces en ivoire étudiées est accréditée par deux autres faits :

- l'identification de plusieurs raccords intercouches concernant plus de la moitié du corpus $(\mathrm{N}=7)$;

- l'homogénéité qui caractérise cette industrie sur ivoire, que ce soit dans le choix de la matière travaillée, dans la morphologie, le gabarit des pointes et dans les procédures techniques en jeu dans la mise en forme des objets ainsi que dans la nature du décor affectant certaines d'entre elles.

Si l'homogénéité de cette série ne fait aucun doute, ce sont principalement des arguments indirects (industrie lithique et données spatiales, cf. supra) qui nous permettent de proposer une attribution gravettienne de ces artefacts en ivoire. En effet, le caractère transculturel des pointes étudiées (longues doubles-pointes) et l'ubiquité des techniques de façonnage mises en œuvre dans leur fabrication ne permettent pas de mettre en évidence des marqueurs qui soient spécifiques d'un technocomplexe. Nous pouvons néanmoins constater que ces armatures sont cohérentes (forme et technique) avec ce que nous connaissons des rares pointes en ivoire du Gravettien français. L'identification d'un «caractère gravettien» sur ces pointes pourrait en revanche venir des incisions à vocation non fonctionnelle qu'elles portent en leurs fûts. Si la réalisation de décors sur les productions osseuses est un fait connu durant tout le Paléolithique supérieur, ces décors tiennent toutefois une place essentielle sur les productions gravettiennes de France et même d'Europe. À l'image des pointes en ivoire de Brassempouy, il s'agit, pour la France, presque exclusivement de décors géométriques formés d'incisions (transversales et parallèles ou entrecroisées). Elles sont particulièrement abondantes dans le Gravettien moyen à burins de Noailles. Elles affectent tout l'équipement (tronçons de côtes, outils de transformation, parure), y compris les armes de chasse, pour lesquelles, toutefois, elles relèvent dans certains cas de stries d'adhérence intervenant dans leur emmanchement. La fréquence très élevée de ces fines incisions semble en outre particulièrement diagnostique du Gravettien à Noailles.

À la monotonie et à la simplicité des décors du Gravettien de France s'oppose la riche ornementation (géométrique ou figurative) des productions osseuses du Gravettien des grandes plaines moraves et russes. La portée exacte de ces incisions nous échappe, mais il est possible qu'elle devait revêtir une charge culturelle et symbolique très forte qui semble tracer les limites de territoires régionaux et vraisemblablement culturels (Goutas, 2004a).

Enfin, il est intéressant de noter que ces pointes ne sont pas les seuls objets en ivoire découverts dans le Gravettien de Brassempouy. Le niveau fouillé par É. Piette dans l'entrée de la grotte du Pape, que l'on peut aujourd'hui attribuer au Gravettien, est celui qui a offert le plus d'éléments en ivoire (fig. 29). La couche «éburnéenne» d'É. Piette a livré des productions exceptionnelles (Piette, 1894). À Brassempouy, l'utilisation de l'ivoire pour la confection des statuettes féminines (fig. 29, $\mathrm{n}^{\text {os }} 3$ et 7 ), du «bouchon d'outre» (fig. 29, $\mathrm{n}^{\circ} 2$ ) et des «bandeaux» caractérise le Gravettien (Thiault, 1999) et c'est d'ailleurs la Dame à la capuche qui a fait la célébrité du site. Notons que l'utilisation ponctuelle de l'ivoire pour la fabrication d'objets particuliers se retrouve dans d'autres sites du Gravettien à Noailles. La deuxième icône de l'art mobilier préhistorique, la célèbre statuette de Lespugue par exemple (Saint-Périer, 1922) ainsi que les «bouchons d'outre» de la Roque Saint-Christophe, de Roque de CombeCapelle, de Laugerie Haute (Sonneville-Bordes, 1960) sont associés à des niveaux à Noailles. En ce qui concerne les armes, les fouilles d'É. Piette dans la grotte du Pape n'ont livré que deux pointes en ivoire (fig. 30, $\mathrm{n}^{\circ} 8$ ). Au-delà des similitudes en termes de matière exploitée et de morphologie, la pointe illustrée par H. Delporte (1967) se caractérise par un décor géométrique anguleux (stries organisées en chevrons) proche de celui observé sur l'une des pièces du secteur GG2 (cf. fig. 9 et 25). En raison des frappantes analogies que revêt cette pièce avec la série de pointes du secteur GG2, nous pouvons légitimement supposer qu'elle est aussi d'origine gravettienne.

Les statuettes ont quant à elles été découvertes vers l'entrée de la grotte, dans la couche gravettienne E (Delporte, 1967; White, 2006). Un problème de conservation pourrait expliquer la quasi-absence de ces sagaies dans le prolongement de l'Avenue, entre l'entrée et le secteur GG2, ainsi que celle des statuettes. Lors de ses fouilles de 1896-1897 qui concernent la Grande Galerie, É. Piette note d'ailleurs que les sédiments avaient été bouleversés par l'eau et par les animaux fouisseurs. L'ivoire y était très mal conservé, prenant l'aspect de masses de «fromage blanc ». La galerie du Puits contenait également une grande quantité d'ivoire complètement désagrégé mais aucune figurine dans un niveau reposant sur le socle calcaire de la grotte qui correspondrait au niveau à statuette E de l'Avenue. Si les armes en ivoire sont quasi absentes de la grotte du Pape, il est intéressant de remarquer la présence de pointes des Vachons (fig. 30, $\mathrm{n}^{\text {os }} 7$ et 9 à 13), très caractéristiques du Gravettien à Noailles, qui se concentrent dans le fond de la grotte du Pape et de pointes à cran semblables à celles de GG2 dont la localisation stratigraphique précise, à l'instar de la sagaie en ivoire décorée, pose problème. Dans ses fouilles de 1896-1897, dans la grotte et dans la Grande Galerie, É. Piette a en effet associé les couches gravettienne(s) et solutréenne(s) de manière à respecter son système de classification basé sur les œuvres d'art (Delporte, 1967). D'autre part, les subdivisions stratigraphiques d'É. Piette sont locales et leur généralisation a probablement entraîné des mélanges. Seul indice qui nous permette de préciser l'attribution chronoculturelle de ces pointes à cran, É. Piette signale les avoir découvertes en association avec des pointes à dos (Piette et Laporterie, 1898, p. 543). 

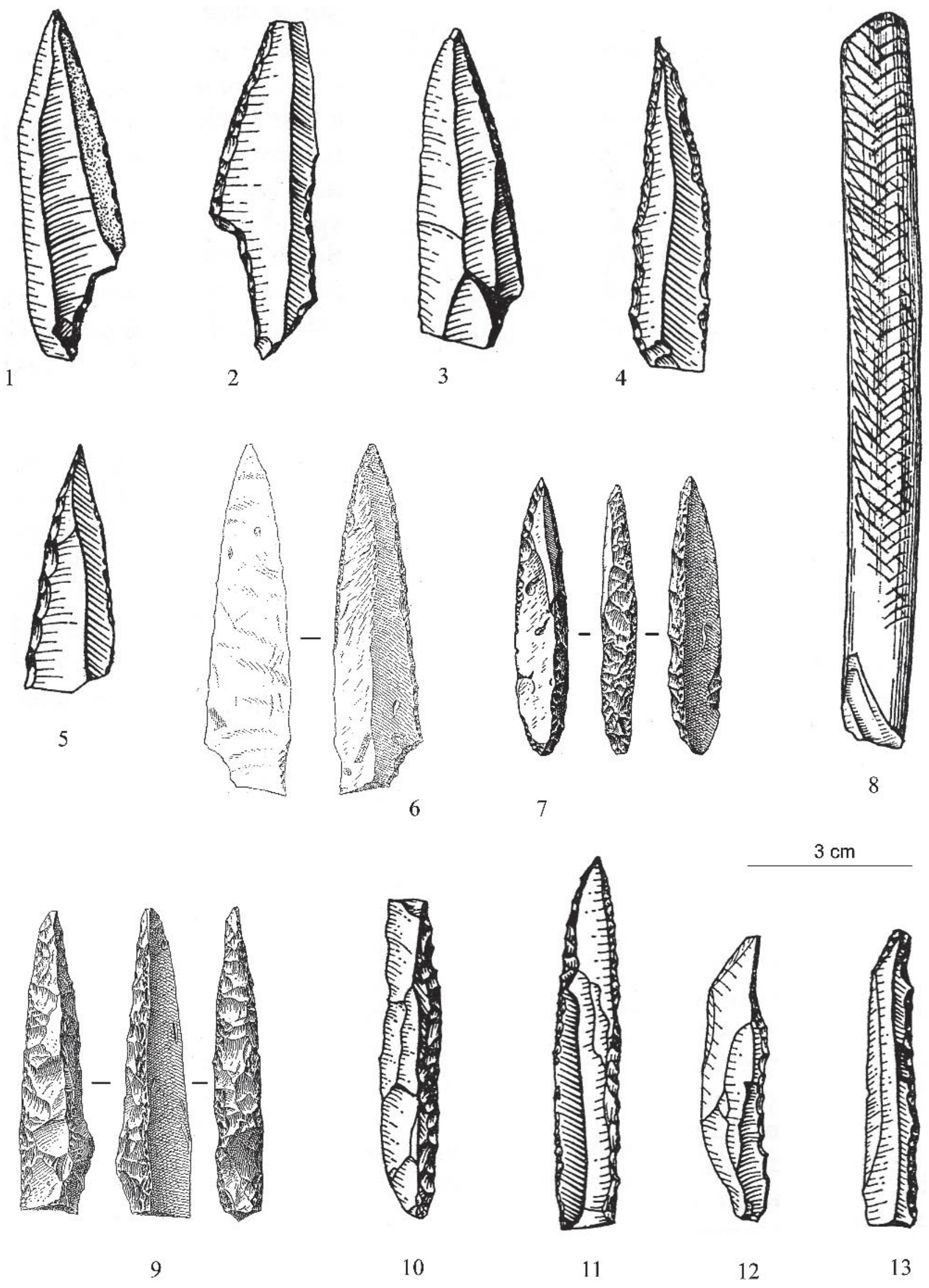
Malgré le manque de données précises sur leur localisation spatiale et stratigraphique, ces objets participent d'ores et déjà à une vision singulière du Gravettien de Brassempouy, où la répartition des objets exprime un cloisonnement fonctionnel de l'espace. Le choix de l'ivoire pour la confection des sagaies s'insère en outre dans une unité gravettienne très forte où son utilisation est réservée à la fabrication d'objets particuliers ou hautement symboliques (Vialou, 1995; Kandel, 1995; Christensen, 1999; Goutas, 2004a). Dans un tel contexte, les pointes en ivoire décorées de la grotte du Pape à Brassempouy prennent une dimension toute particulière.

\section{SYNTHÈSE}

En conclusion, l'ensemble des types d'armatures en silex du chantier I est représenté dans le secteur GG2, excepté les fines lamelles courbes et torses à retouche marginale pour lesquelles une contamination a d'ailleurs été envisagée (Klaric, 2003). Conséquence ou non d'une conservation différentielle, le problème de l'absence des armatures en ivoire dans le chantier I reste en suspens car les matières organiques n'y sont pas conservées. Toutefois, si de tels objets avaient été présents parmi le matériel abandonné dans l'entrée principale de la grotte du Pape, il y a toutes les raisons de penser que les fouilleurs du XIX ${ }^{\mathrm{e}}$ siècle, et en particulier É. Piette, y auraient prêté attention. Ceci renforce le caractère singulier de ce dépôt au sein du site de Brassempouy et contribue à singulariser ce site, d'une façon générale, dans le paysage du Gravettien français.

Pour revenir à notre comparaison avec le chantier I, laquelle porte exclusivement sur l'industrie lithique, seul diffère le rapport numérique entre les lamelles à retouche marginale et l'ensemble des armatures à dos d'une part, les armatures en général et le reste du matériel lithique d'autre part. La proportion des armatures peut d'ailleurs être largement majorée en GG2 si l'on prend en compte le fait qu'une grande part des outils (et sans doute du matériel brut) n'est pas directement associée aux armatures. Une interprétation fonctionnelle semble devoir prévaloir ici sur l'interprétation chronoculturelle : le fond de la grotte du Pape, à l'inverse de ce qui est attesté en avant de la grotte du Pape, n'a pas servi de zone d'atelier mais il concentre au contraire des objets confectionnés ailleurs, constat qui s'applique également à l'industrie en ivoire.

Fig. 30 (à droite) - Armatures découvertes par É. Piette (1896-1897) lors de ses fouilles du fond de la Grande Galerie. $\mathrm{N}^{\text {os }} 1$ à 6 : pointes à cran; $\mathrm{n}^{\text {os }} 7$ et 9 à 13 : pointes des Vachons; $n^{\circ} 8:$ pointe en ivoire décorée. Origine stratigraphique imprécise $\left(\mathrm{n}^{\mathrm{os}} 1\right.$ à 5,8 et 10 à 13 , d'après Delporte, 1967, fig. 4 et $5 ; n^{\text {os }} 6,7$ et 9 : d'après Piette et Laporterie, 1898, fig. 21, 22 et 23).

Fig. 30 (in left) - Points discovered by E. Piette (1896-1897) during his excavations at the back of the Grande Galerie. Nos. 1 to 6: shouldered points; nos. 7 and 9 to 13: Vachon points; no. 8: decorated ivory point. Vague stratigraphic origin (nos. 1 to 5, 8 and 10 to 13, after Delporte 1967, fig. 4 and 5; nos. 6, 7 and 9: after Piette \& Laporterie 1898, fig. 21, 22 and 23).
Les assemblages de Brassempouy sont, avec ceux d'Isturitz, les manifestations les plus importantes du Gravettien à Noailles dans les Pyrénées occidentales. Ceci tendrait à confirmer leur ancrage dans le Gravettien moyen, établi autour de 25 à 23000 BP par comparaison avec les séquences du nord de l'Aquitaine mais, dans le contexte pyrénéen, il n'est malheureusement pas possible de caler précisément ces occupations sur une échelle chronologique. En effet, dans les Pyrénées et la partie cantabrique de l'Espagne, on ne connaît guère d'autres industries attribuées au Gravettien que celles comportant des burins de Noailles et cet objet semble perdurer tout au long des phases moyennes et récentes de ce technocomplexe. Il a même été proposé que cet objet perdure lors du Solutréen (Aguirre, 2000; Altuna, 2002; Arrizabalaga et al., 2005). Dès lors, il est possible d'imaginer que l'occupation gravettienne de Brassempouy puisse être associée à une phase récente du Gravettien à Noailles pyrénéen plus ou moins contemporaine du Gravettien récent (ancien Périgordien VI) du Périgord. Toutefois, cette hypothèse mérite d'être confirmée par de plus amples données stratigraphiques et radiométriques.

\section{RÉFLEXION SUR LA MISE EN PLACE DES DÉPÔTS DANS LE SECTEUR GG2}

Si l'homogénéité des armatures lithiques et en ivoire ne fait pas de doute, la question des processus ayant conduit à former l'assemblage tel qu'il nous a été livré par les remplissages du secteur GG2 demeure difficile à résoudre. La multiplicité des raccords et la répartition spatiale (verticale et horizontale) des pièces témoignent des multiples perturbations post-dépositionnelles qu'a subi cet ensemble et corrobore l'hypothèse d'une mobilité du matériel et de leur emballage sédimentaire dans ce secteur. Rappelons que l'eau, dont l'action a été à plusieurs reprises signalée sur le matériel en ivoire et en silex, est l'agent transporteur à l'origine des dépôts sédimentaires dans le secteur GG2. Par ailleurs, les analyses sédimentologiques de D. Marguerie et les analyses micromorphologiques d'A. Gebhart ont montré que les sédiments se sont mis en place sous un courant d'eau assez fort (Gambier et al., 1998, p. 1718).

Comme nous l'avons souligné au préalable, les profils stratigraphiques réalisés sur ce secteur ont en outre montré qu'il existait une «zone de discontinuité entre le carré R7 et T9, tant sur le plan de la densité des objets que sur celui de la dispersion des couches » (Potin et Mensan, 1998, p. 35). Cette dernière correspond à une fosse identifiée à la fouille et qui résulterait davantage d'une vidange ou d'un ruissellement karstique que d'un aménagement d'origine anthropique (ibid., p. 36). Plusieurs des pièces étudiées proviennent de cette zone de perturbation, ce qui permet de mieux comprendre les incohérences spatiales dont témoigne le matériel étudié.

Plusieurs éléments relatifs à l'industrie sur ivoire pourraient suggérer un dépôt secondaire, peut-être par 
un conduit karstique reliant GG2 à l'aven de S9 (Potin et Mensan, 1998, p. 219) :

- le caractère fortement fragmenté du matériel (pouvant résulter de la chute du matériel via l'aven);

- l'origine post-dépositionnelle de la quasi-totalité des fractures affectant le matériel;

- l'orientation (NO/SE) des pièces en ivoire qui correspond exactement à celle du pendage des couches au sein du secteur GG2 mais surtout qui se situe dans le prolongement direct de l'aven identifié sur le versant du karst (cf. fig. 10).

Toutefois, et selon cette hypothèse, la zone du fond qui est la plus proche de l'aven aurait dû être la plus perturbée. Or, c'est le contraire que nous constatons. Son homogénéité taphonomique et archéologique induit en effet qu'elle ait pu être épargnée par ces apports secondaires de sédiments, probablement grâce à une localisation privilégiée à la fois par rapport à la localisation et à l'orientation du conduit et à celui des déversements. En conséquence, rien ne s'oppose à ce que les armatures en ivoire recueillies en GG2 correspondent, comme cela a été évoqué pour celles en silex, à un dépôt in situ. Ce dépôt aurait été partiellement tronqué et bouleversé par divers processus sédimentaires initiés depuis l'aven situé au-dessus de ce secteur et ayant, en outre, apporté avec eux un matériel hétérogène, contribuant à former l'assemblage tel qu'il nous est parvenu.

En tout état de cause, la partie profonde de GG2 constitue la clef de compréhension de ce secteur. Elle témoigne d'une histoire taphonomique complexe. L'hypothèse la plus probable étant un premier dépôt d'un ensemble d'armatures qui a, par la suite, subi plusieurs perturbations sous l'action de l'eau, c'est-àdire à la fois le transport par l'eau d'une partie des sédiments et du matériel qui lui est associé et, postérieurement, une vidange ou un autre type de ruissellement karstique dont il est difficile de préciser l'importance mais qui concerne de manière certaine la zone centrale (fosse) et plusieurs parties, voire l'ensemble de la zone avant (et qui explique la zone de discontinuité entre les carrés $\mathrm{R} 7$ et $\mathrm{T} 9$ et la pollution réciproque verticale des couches aurignaciennes et gravettiennes qui lui est associée).

\section{CONCLUSION : UN DÉPÔT INTENTIONNEL D'ARMATURES GRAVETTIENNES EN PARTIE REMANIÉ?}

Si l'on retient l'hypothèse que nous avons soulevée précédemment, la proportion d'armatures, qui représentent déjà pourtant plus de $50 \%$ du matériel retouché de GG2, est en réalité encore plus forte si l'on tient compte de leur association fortuite avec du matériel provenant d'apports postérieurs. À cet égard, il est peu probable que le rapport numérique de la zone du fond où les armatures représentent $90 \%$ du matériel retouché soit un hasard taphonomique. Il semble davantage constituer un témoin du dépôt gravettien originel du secteur GG2, qui contenait une concentration particulièrement élevée d'armatures lithiques et osseuses.
La concentration d'armatures en ivoire retrouvée dans le secteur GG2 est assez atypique pour le Gravettien français. Dans les autres gisements, la présence de pointes en ivoire reste généralement anecdotique ${ }^{10}$. Les seules séries conséquentes que nous connaissions sont celles du Gravettien moyen d'Arcy-sur-Cure (grotte du Renne) et du Gravettien récent de Laugerie Haute est, qui ont livré chacune une dizaine de pièces. L'industrie en ivoire de la grotte du Renne à Arcy-sur-Cure (c. V, IV et VI), bien qu'issue d'un contexte stratigraphique en partie problématique (c. IV et VI), est très intéressante car, fait rare, elle se compose à la fois de pointes finies et de nombreux fragments de supports (bruts ou ayant subi une étape de façonnage) compatibles avec la production des pointes en ivoire associées. D'après les stigmates techniques observés, les baguettes ont été extraites par double rainurage longitudinal (parallèle ou convergent). Ce procédé rarement identifié sur ivoire dans le Gravettien français (Goutas, 2004a et b) n'était, jusqu'à présent, signalé que pour le site de Brassempouy dans le cadre de la production des «bandeaux» décorés (Thiault, 1999). L'autre intérêt des pointes en ivoire d'Arcy-sur-Cure réside en la présence, sur certaines d'entre elles, d'incisions, parfois associées à une rainure longitudinale (cette dernière devant peut-être permettre l'adjonction de microlithes). Il n'est pas possible de préciser l'étendue exacte de ces incisions en raison du degré de fragmentation des pièces. Si certains de ces aménagements ont pu jouer un rôle utilitaire (emmanchement), d'autres en revanche semblent être des motifs décoratifs ou symboliques (fig. 31).

Concernant les pointes à cran, il apparaît qu'elles sont également rares dans le Gravettien français. À notre connaissance, seul le Gravettien ancien de la
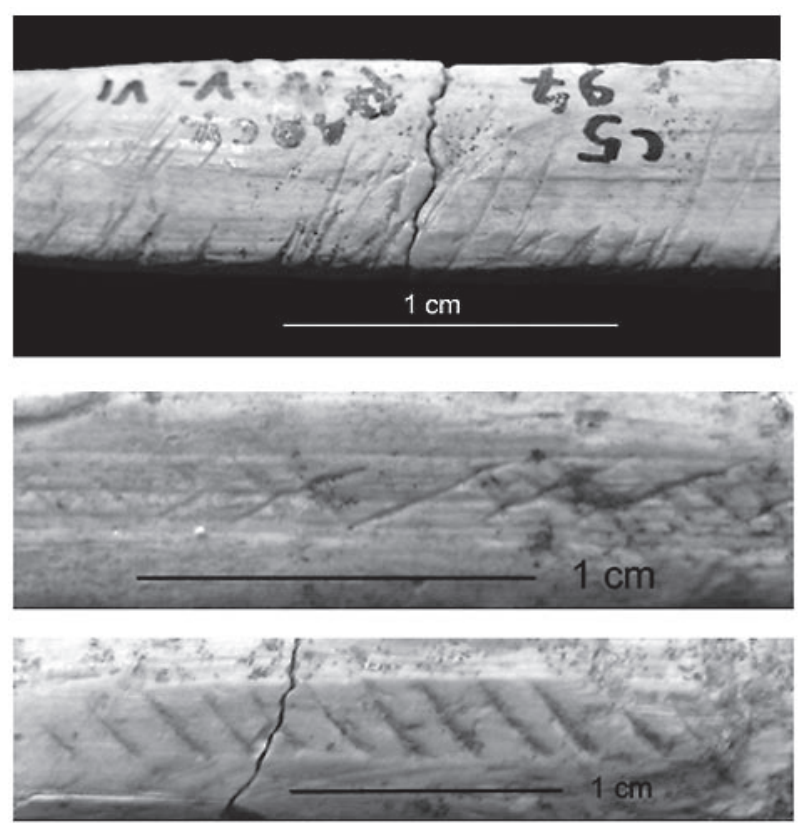

Fig. 31 - Arcy-sur-Cure (Yonne) : pointes en ivoire gravettiennes présentant un décor géométrique (clichés N. Goutas).

Fig. 31 -Arcy-sur-Cure (Yonne): Gravettian ivory points with a geometrical decoration (photographs N. Goutas). 
Gravette en livrerait une série conséquente (Lacorre, 1960). Il faut quitter la France et se tourner du côté du Gravettien moyen de Grimaldi (Italie) et de Willendorf (Autriche) pour en trouver (Boule, 1919; Felgenhauer, 1956-1959). Les concordances en industrie lithique que nous venons d'évoquer avec le site de Willendorf font écho à d'autres qui méritent d'être soulignées. La couche 9 de ce site a livré, en plus des pointes à cran, deux statuettes féminines (fig. 32, $\mathrm{n}^{\circ} 1$ ), ainsi que trois pointes en ivoire, qui appartiennent elles aussi à la catégorie des doubles-pointes et dont deux sont pourvues d'incisions géométriques (Otte, 1981). Dans un cas (fig. 32, n 2), il s'agit d'une «base appointée, à renflement latéral et stries obliques » et dans le second cas (fig. 32, n 3), il s'agit «d'une partie médiane fusiforme avec base appointée [...] striée vers l'extrémité et qui porte une décoration sur le corps du fût en $\mathrm{V}$ jointifs, finement incisés » (Otte, 1981, p. 293). Si les incisions situées sur la partie basale sont peut-être à mettre en relation avec l'emmanchement des pièces, il ne peut nullement en être question concernant celles présentes sur le fût. Leur valeur devait être symbolique et/ou décorative à l'image des motifs présents sur les pointes de Brassempouy. Par ailleurs, et bien que les motifs géométriques ne soient pas identiques entre ces deux sites, il partage néanmoins une certaine ressemblance tant par la nature anguleuse (en chevrons ou en épi) des motifs réalisés que par la composition relativement complexe que forme l'association de ces incisions. D'autres pointes découvertes dans le Gravettien morave (Predmosti, République tchèque) sont similaires en termes de matière première, de morphologie et présentent des décors assez proches (fig. 32, nn 4 à 6). Elles ont été découvertes en association cette fois
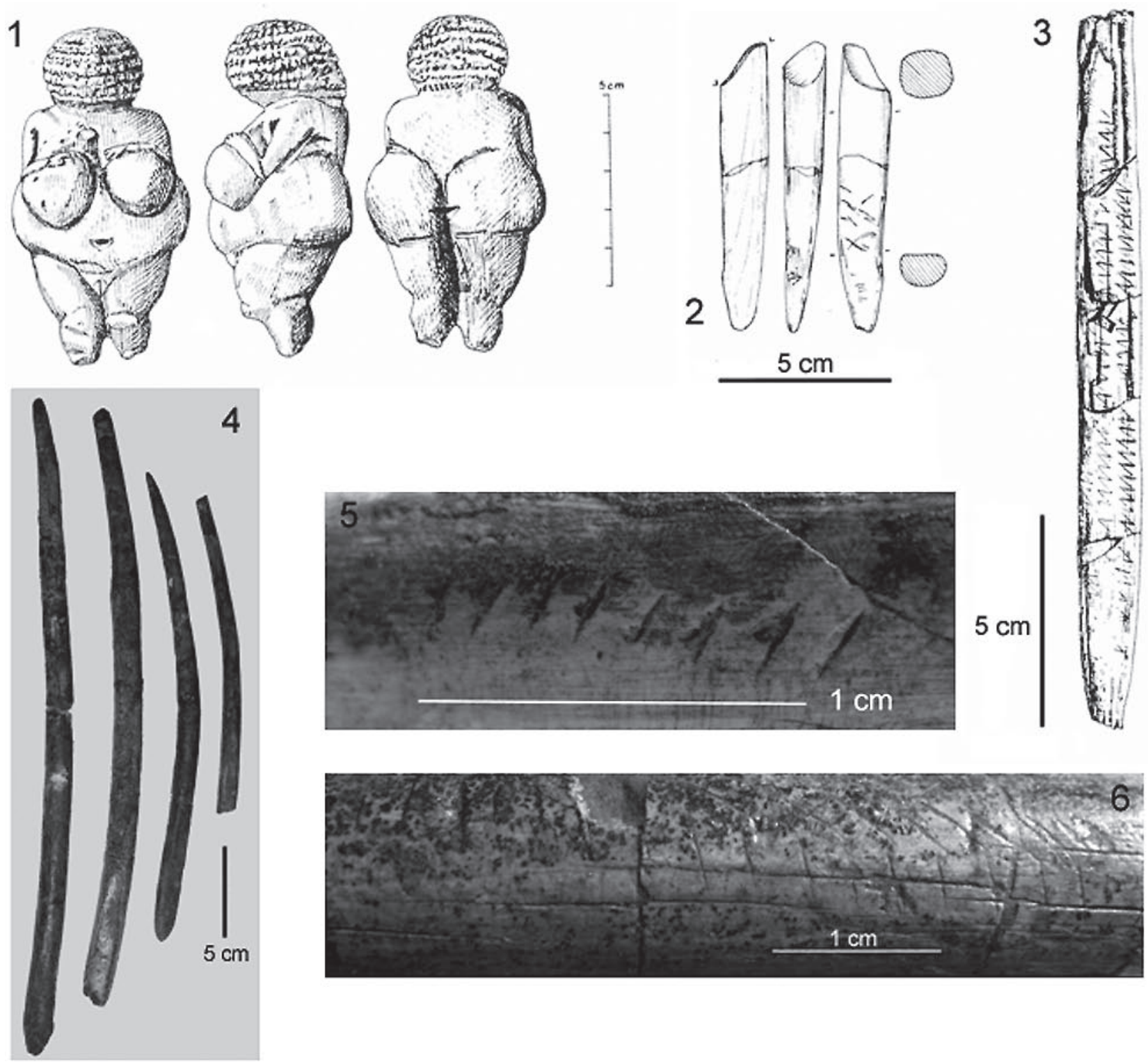

Fig. 32 - Pointes en ivoire présentant un décor géométrique proche de celui des pointes en ivoire de Brassempouy. Nos 1 à 3 : Willendorf (Autriche, d'après Otte, 1981, fig. 122, n 3 et fig. 123, n² 2); nºs 4 à 6 : Predmosti (République tchèque, clichés N. Goutas).

Fig. 32 - Ivory points with a geometrical decoration close to the Brassempouy ivory points. Nos. 1 to 3: Willendorf (Austria, after Otte, 1981, fig. 122, $n^{\circ} 3$ and fig. 123, $\left.n^{\circ} 2\right)$; nos. 4 to 6: Predmosti (Czech Republic, photographs N. Goutas). 
encore avec des pointes à cran (de type Kostienki) (comm. pers. M. Oliva). Cette association répétée pointes à cran/pointes en ivoire décorées de motifs géométriques/statuettes féminines pourrait présager de correspondances, probablement indirectes, mais néanmoins étroites entre ces différents sites.

Les matériaux utilisés pour la confection des armatures de Brassempouy accentuent le caractère exceptionnel de cette série. D'une part, l'ivoire de Mammouth est un matériau très rarement exploité dans le contexte du Paléolithique supérieur ancien de France (Goutas, 2004b). Avec le choix de travailler l'ivoire, la sélection d'un silex de très bonne qualité est également intéressante. Ce silex possède une texture particulièrement fine et homogène qui le place, sur une échelle qualitative, largement au-dessus de ce qu' on peut trouver communément en Chalosse.

Les armatures en ivoire et en silex du secteur GG2 révèlent une autre particularité, à savoir un fractionnement de la chaîne opératoire puisque ces armatures ont été produites à l'extérieur de la grotte (absence de déchets et supports), en une autre partie du site ou bien encore sur l'un des lieux d'habitat précédents. Elles ont donc été intentionnellement apportées et abandonnées sur place. En revanche, d'après R. White (2006, p. 288-289 et 294), les figurines féminines en ivoire retrouvées en d'autres parties du site (cf. fig. 33) auraient été produites sur place (du fait de l'absence de statuettes entières ou achevées, parallèlement à la présence de plusieurs figurines cassées en cours de fabrication). La zone nommée l'Avenue, à proximité de l'entrée principale, aurait servi d'atelier de fabrication de statuettes (op. cit.).

Certaines des armatures découvertes dans le secteur GG2 ont en outre été utilisées. C'est le cas notamment de trois pointes en ivoire qui portent des impacts vraisemblablement liés à leur utilisation (cf. supra). Toutefois, et à l'exception d'une pièce, les dégâts apparents n'étaient pas rédhibitoires, les pointes pouvant encore être fonctionnelles au moment de leur abandon. Concernant les pointes lithiques du secteur GG2, des traces d'impact ont pu être clairement identifiées sur $17 \%$ d'entre elles. Malgré ces fractures, la plupart des armes pouvaient être encore fonctionnelles au moment de leur dépôt. La colle et l'emmanchement auraient maintenu l'intégrité du montage puisque les fractures complexes concernent les lamelles à dos et la partie proximale d'une pointe à cran (donc une partie emmanchée). Seule une fracture complexe au niveau de la partie distale d'une armature axiale annihile la fonctionnalité d'une arme. C'est le cas de la micro-Vachons qui n'était donc plus fonctionnelle. Deux pointes à cran possèdent une fracture distale nette mais il est impossible de préciser si celle-ci a eu lieu avant ou après le dépôt des armes.

En conclusion, cette concentration quantitative et qualitative (matériau utilisé, dimension ${ }^{11}$, décors, taux de transformation du support) d'armatures exprime une valeur particulière conférée à cette partie de l'équipement technique (les armes de chasse) par les hommes qui les ont déposées. La forte valeur de ces armes contraste avec l'exiguïté de l'espace du fond de la grotte du Pape, éloigné de la zone d'activité principale identifiée à l'entrée principale de la cavité, dans l'Avenue et aux abords de la grotte du Pape (chantier I). Ces vestiges semblent témoigner d'un dépôt humain dont l'interprétation nous échappe. Notons que ces armes ont été retrouvées associées à un groupe de quatre incisives de capridés ou de cervidés, percées et tronçonnées, disposés en paquet dans la zone du fond (carré U11), une patte d'un carnivore (Renard?) en connexion anatomique (également dans le carré U11) et deux pattes de suidés en connexion anatomique (zone avant, carré R7 ; cf. fig. 10). L'association entre des objets hautement investis et des pattes d'animaux rappelle curieusement les observations d'Henri Delporte effectuées dans le Gravettien à Noailles de Tursac (Delporte, 1968). Un avant-bras de jeune bison était

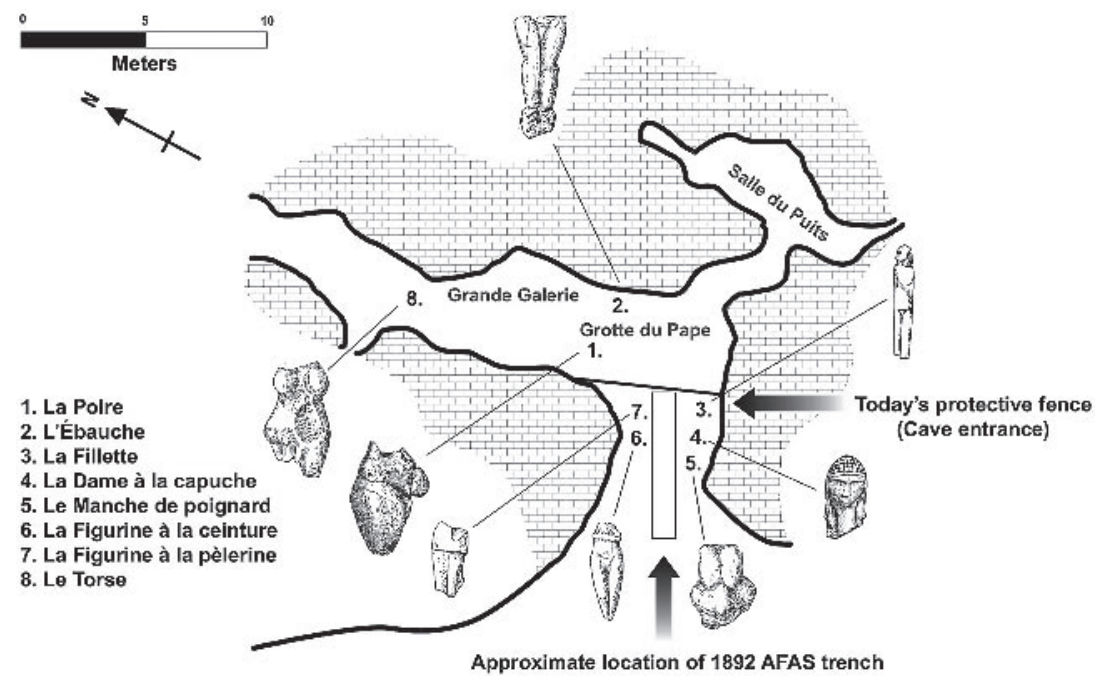

Fig. 33 - Localisation approximative des lieux de découverte des figurines de Brassempouy, d'après les indications données par Piette et Laporterie (in White, 2006, fig. 20).

Fig. 33 - Rough location of the discovery places of the Brassempouy figurines, according to the indications given by Piette \& Laporterie (in White 2006, fig. 20). 
disposé à $35 \mathrm{~cm}$ de la statuette de Tursac et représentait les seuls os longs - par ailleurs en connexion anatomique - du niveau qui contient pourtant des milliers d'esquilles osseuses. Un concours de circonstances identique se retrouve donc à Brassempouy et l'on peut se demander s'il existe une relation entre les pattes de suidés en connexion anatomique et les armes en ivoire et en silex. D'autre part, ces objets ne seraient distants que d'une quinzaine de mètres des premières statuettes féminines en ivoire (fig. 29, $\mathrm{n}^{\text {os }} 3$ et 7 et fig. 33). Les questions de l'existence d'une relation entre ces objets ainsi que celle de la gestion de l'espace de la grotte du Pape sont donc posées.

Quoiqu'il en soit, et même s'il est difficile de résoudre la signification qui accompagne la formation de ce dépôt, tout concourt à envisager que sa nature, si distincte de celle des vestiges recueillis dans l'entrée principale de la grotte du Pape lors des fouilles du XIX siècle comme, plus récemment, aux abords de cette dernière, témoigne d'une répartition spatiale entre ces secteurs à l'évidence riche de sens. Si nous avions recueilli un tel assemblage de façon isolée, dans un site dépourvu de toute autre trace d'occupations humaines, sans doute l'hypothèse d'une «halte de chasse»se serait-elle imposée, quand bien même les principaux arguments auraient manqué pour le faire, à savoir les données archéozoologiques, lesquelles sont pauvres dans le mobilier de GG2. Mais, à Brassempouy, dans l'espace confiné de cette portion de la Grande Galerie, à l'écart des riches espaces d'activités observés dans l'entrée principale qui y conduit, tout indique que nous avons ici à faire à une réalité différente : celle d'une mise à l'écart d'une catégorie d'objet dont la valeur fonctionnelle rejoint peut-être, ici, une dimension plus symbolique.

Remerciements : Nous remercions D. HenryGambier et F. Bon de nous avoir confié l'étude des séries sur lesquelles a porté le présent article, mais aussi pour leurs relectures critiques, leurs corrections, leurs conseils avisés ainsi que pour nous avoir fait partager leurs connaissances du site de Brassempouy. Un grand merci aussi à Y. Potin pour toutes les informations qu'il a eu la gentillesse de nous faire parvenir et qui nous ont été très utiles à la réalisation du présent article. Nous adressons aussi nos remerciements à Laurent Klaric pour son soutien matériel et intellectuel. Nous remercions aussi M. Julien pour nous avoir autorisé l'étude des pointes en ivoire gravettiennes d'Arcy-
sur-Cure et R. White pour ses informations concernant les statuettes féminines découvertes à Brassempouy et pour avoir mis à notre disposition un plan de répartition de ces dernières. Nos remerciements s'adressent aussi à $\mathrm{M}$. Christensen pour avoir relu la première mouture de cet article et pour ses précieux conseils concernant notamment l'industrie sur ivoire. Enfin, nous remercions l'Association du chantier archéologique de Brassempouy pour son soutien financier dans le cadre de nos séjours d'étude au musée d'Archéologie nationale de Saint-Germain-en-Laye et au laboratoire d'Anthropologie de Bordeaux 1.

\section{NOTES}

(1) Le niveau gravettien du chantier I appartient à un très vaste ensemble, s'étendant sur plusieurs centaines de $\mathrm{m}^{2}$, depuis l'entrée de la grotte du Pape jusqu'au ruisseau du Pouy.

(2) Ces fouilles furent principalement réalisées sous la responsabilité de D. Buisson. Une opération fut entreprise de nouveau en 1999-2001 sous la responsabilité de R. Mensan et Y. Potin (dir. D. Henry-Gambier et F. Bon).

(3) NR : nombre de reste; NO : nombre d'objets finis après raccord interpièces et intercouches.

(4) Au sein de la série, nous avons isolé une pièce qui n'est pas en ivoire mais très probablement en os. L'état de conservation de cette pièce rend difficile l'identification de sa matière, cependant sa morphologie et la nature de la trame spongieuse nous font rejeter un éventuel rattachement au bois de Cervidé. En effet, le rapport compact/spongieux et le module de la pièce ne nous paraissent pas compatibles avec un fragment de perche, d'épois ou d'andouiller. Qui plus est, nous n'avons observé aucune trace de façonnage ou de débitage et le rattachement de cette pièce à l'industrie osseuse ne nous paraît pas convainquant. Sa morphologie similaire à celle d'un objet appointé n'est due, selon nous, qu'à l'action d'agents corrosifs.

(5) L'outil biseauté de la série présente sur sa face inférieure (la plus plane des deux faces) une «face d'arrachement caractérisée par des stries et des rigoles » qui, selon J. Hahn, serait caractéristique d'un débitage par percussion sur ivoire vieilli (Hahn, 1995, p. 120).

(6) Si l'on ne prend en compte que les fragments mésiaux dont la largeur est intégralement conservée.

(7) Les deux extrémités sont cassées et présentent des fractures en marche d'escalier. Les pans de fracture sont émoussés par diverses altérations post-dépositionnelles et en particulier par le ruissellement.

(8) Cet objet, malheureusement isolé, confirme la présence discrète de vestiges rapportables à des occupations de l'Aurignacien récent en différentes parties du site de Brassempouy (Bon, 2004). En outre, ce «grattoir Caminade» est l'un des exemplaires les plus méridionaux d'une famille d'objet jusqu'alors rencontrée exclusivement dans le nord de l'Aquitaine.

(9) Tests de tamisage réalisés lors des campagnes de fouilles programmées (dir. C. Normand).

(10) Notons cependant que R. et S. de Saint-Périer (1952) signalaient dans le Gravettien d'Isturitz (Pyrénées-Atlantiques) la présence de plusieurs pointes en ivoire à section cylindrique ou cylindro-conique, que nous n'avons pas retrouvées dans les séries du musée d'Archéologie nationale à Saint-Germain-en-Laye.

(11) Une pièce en ivoire bien que fragmentaire dépasse en effet les $300 \mathrm{~mm}$ de long.

\section{RÉFÉRENCES BIBLIOGRAPHIQUES}

AGUIRRE M. (2000) - El paleolítico de Antoliñako Koba (GautegizArteaga, Bizkaia): secuencia estratigráfica y dinámica industrial. Avance de las campañas de excavación 1995-2000, Illunzar, t. 4, p. 39-81.

ALTUNA J. (2002) - Cueva de Aitzbitarte III (Errenteria), Arkeoikuska, 2001 , p. $128-130$.

ARRIZABALAGA A., ALTUNA J., ARESO P., FALGUERES C. IRIARTE M.J., MARIEZKURRENA K., PEMAN E., RUIZ
ALONSO M., TARRIÑO A., URIZ A., VALLVERDU J. (2005) Retorno a Lezetxiki (Arrasate, País Vasco): nuevas perspectivas de la investigación, in M. Santonja, A. Pérez-González et M.J. Machado dir., Georqueología Y Conservación del Patrimonio, Actas de la IV Reunión de Geoarqueología, Madrid, p. 63-80.

AVERBOUH A. (2000) - Technologie de la matière osseuse travaillée et implications palethnologiques : l'exemple des chaînes d'exploitation du bois de cervidé chez les Magdaléniens des Pyrénées, thèse de doctorat de Préhistoire, université de Paris I, 2 vol., 500 p. 
BON F. (2002a) - L'Aurignacien entre Mer et Océan. Réflexion sur l'unité des phases anciennes de l'Aurignacien dans le Sud de la France, Mémoire de la Société préhistorique française, t. 29, 243 p.

BON F. (2002b) - Les ressources en silex de la Chalosse centrale : gîtes et ateliers du dôme diapir de Bastennes-Gaujacq et de l'anticlina d'Audignon, PCR Comportements techniques et économiques des sociétés du Paléolithique supérieur dans le contexte pyrénéen, service régional de l'Archéologie Midi-Pyrénées, p. 47-64.

BON F. (2004) - Les industries lithiques de la partie nord du site (abri Dubalen, chantier 5 - Ouest, S9 et GG2). Bilan sur le produit des fouilles 1999-2004, in D. Henry-Gambier dir., Rapport de fouilles programmées, campagne 2004, ex. multigraph.

BON F., GAMBIER D., FERRIER C., GARDÈRE P. (1998) - Gisement de Brassempouy (Landes) : les recherches de 1995 à 1997, bilan et perspectives, Bulletin de la Société de Borda, $\mathrm{n}^{\circ} 449,2^{\mathrm{e}}$ trim., Dax, p. $203-222$

BOULE M. (1919) - Les grottes de Grimaldi. Géologie et paléontologie, imprimerie de Monaco, Monaco.

BUISSON D. (1996) - Brassempouy : présentation du site et problèmes posés par les fouilles récentes, in H. Delporte et J. Clottes dir., Pyrénées préhistoriques, Arts et sociétés, Actes du $118^{e}$ congrès national des Sociétés historiques et scientifiques, Pau, 1993, éd. du CTHS, p. 423-437.

BUISSON D. et al. (1995) - Recherches sur les habitats du Paléolithique supérieur des grottes de Brassempouy (Landes), campagne de fouilles de juillet-août 1995, ex. multigraph. p. 3-7.

CHRISTENSEN M. (1999) - Technologie de l'ivoire au Paléolithique supérieur. Caractérisation physico-chimique du matériau et analyse fonctionnelle des outils de transformation, British Archaeological Reports, International Series, S751, Oxford, 201 p.

DARTIGUEPEYROU S. (1995) - L'industrie lithique gravettienne du chantier I à Brassempouy. Approche technologique, mémoire de maîtrise présenté à l'université de Paris I - Panthéon Sorbonne, 99 p., 14 annexes.

DELPORTE H. (1967) - Brassempouy : ses industries d'après la collection Piette (musée des Antiquités nationales), Zephyrus, t. XVIII, p. 5-41.

DELPORTE H. (1968) - L'abri du Facteur à Tursac (Dordogne), Gallia Préhistoire, t. XI, p. 1-145.

DELPORTE H. (1986) - Informations archéologiques : Brassempouy, grotte du Pape, Gallia Préhistoire, t. 29, fasc. 2, p. 244-245.

DELPORTE H. (1991) - Informations archéologiques : Brassempouy, grotte des Hyènes et grotte du Pape, Gallia Informations - Préhistoire et Histoire, t. 1, p. 78-79.

DELPORTE H. (1996) - Brassempouy : histoire d'un gisement, in H. Delporte et J. Clottes dir., Pyrénées préhistoriques, Arts et sociétés, Actes du $118^{e}$ congrès national des Sociétés historiques et scientifiques, Pau, 1993, éd. du CTHS, p. 415-421.

DELPORTE H. et al. dir. (1993) - Brassempouy : les fouilles de 1991 à 1993, rapport de fouilles programmées, ex. multigraph., p. 7-16.

FELGENHAUER F. (1956-1959) - Willendorf in der Wachau, Mitteilungen der prähistorischen Kommission, t. VIII et IX, 3 vol., 219 p., 79 pl., 124 fig.

FISHER A., VEMMING H.P., RASMUSSEN P. (1984) - Macro and microwear traces on lithic projectile points: experimental results and prehistoric examples, Journal of Danish Archeology, vol. 3, p. 19-46.

FOUCHER P. (2004) - Les industries lithiques du complexe gravettiensolutréen dans les Pyrénées. Technotypologie et circulation des matières siliceuses de part et d'autre de l'axe Pyrénées-Cantabres, thèse de doctorat de l'université de Toulouse-Le Mirail, 2 tomes, 334 p., 245 fig.

GAMBIER D., BON F., GARDÈRE P. (1998) - Brassempouy (Landes) Rapport intermédiaire de fouilles programmées. Campagne $1998\left(2^{e}\right.$ année), t. I, 155 p., t. II, 74 fig.
GOUTAS N. (2004a) - Caractérisation et évolution du Gravettien en France par l'approche techno-économique des industries en matières dures animales (étude de six gisements du Sud-Ouest), thèse de doctorat, université de Paris I-Panthéon Sorbonne, 2 vol., 680 p.

GOUTAS N. (2004b) - Fiche 5 : Exploitation des matières dures animales au Gravettien, in D. Ramseyer dir., L'industrie de l'os préhistorique. Cahier XI : Matières premières et techniques, Société préhistorique française, Paris, p. 53-74.

HAHN J. (1995) - Les ivoires en Allemagne, débitage, façonnage et utilisation au Paléolithique supérieur, in J. Hahn, M. Menu, Y. Taborin P. Walter et F. Widemann dir., Le travail et l'usage de l'ivoire au Paléolithique supérieur, Actes de la table ronde de Ravello, Rome, 29-31 mai 1992, p. 115-132.

HENRY-GAMBIER D., BON F., GARDÈRE P., LETOURNEUX C., MENSAN R., POTIN Y. (2004) - Nouvelle données sur la séquence culturelle du site de Brassempouy (Landes): fouille 1997-2002, Archéologie des Pyrénées occidentales et des Landes, t. 23, p. 145156.

KANDEL D. (1995) - Objets d'ivoire du musée des Antiquités nationales, in J. Hahn, M. Menu, Y. Taborin, P. Walter et F. Widemann dir., Le travail et l'usage de l'ivoire au Paléolithique supérieur, Actes de la table ronde de Ravello, Rome, 29-31 mai 1992, p. 95-102.

KLARIC L. (2003) - L'unité technique des industries à burins du Raysse dans leur contexte diachronique. Réflexions sur la diversité culturelle au Gravettien à partir des données de la Picardie, d'Arcy-sur-Cure, de Brassempouy et du Cirque de la Patrie, thèse de doctorat, université de Paris I-Panthéon-Sorbonne, $426 \mathrm{p}$.

LACORRE F. (1960) - La Gravette, le Gravettien et le Bayacien, imp. Barnéoud, Laval, 360 p.

NORMAND C. (1986) - Inventaire des gîtes à silex de la Chalosse, in R. Arambourou, L.G. Strauss et C. Normand dir., Recherches de Préhistoire dans les Landes en 1985, Bulletin de la Société de Borda, $\mathrm{n}^{\circ} 402,2^{\mathrm{e}}$ trim., p. 133-140.

NORMAND C. (2002) - Les ressources en matières premières siliceuses dans la basse vallée de l'Adour et de ses affluents. Quelques données sur leur utilisation au Paléolithique supérieur, in N. Cazals dir., Comportements techniques et économiques des sociétés du Paléolithique supérieur dans le contexte pyrénéen, projet collectif de recherche, p. 26-47.

ODELL G.H., COWAN F. (1986) - Experiments with spears and arrows on animal targets, Journal of Field Archaeology, vol. 13, p. 197212.

O'FARRELL M. (1996) - Approche technologique et fonctionnelle des pointes de la Gravette : une analyse archéologique et expérimentale appliquée à la collection de Corbiac, mémoire du DEA d'Anthropologie option Préhistoire, université de Bordeaux I, 97 p.

OTTE M. (1981) - Le Gravettien en Europe centrale, Dissertationes Archaeologicae Gandenses, De Tempel, Bruges, 2 vol., 504 p.

PATOU-MATHIS M., BOUKHIMA H. (1996) - Les grands mammifères des grottes des Hyènes et du Pape à Brassempouy (Landes) résultats préliminaires, in $\mathrm{H}$. Delporte et J. Clottes dir., Pyrénées préhistoriques, Arts et Sociétés, Actes du $118^{e}$ congrès national des Sociétés historiques et scientifiques, Pau, 1993, éd. du CTHS, p. 457472.

PIETTE É. (1894) - L'époque éburnéenne et les races humaines de la période glyptique, imprimerie C. Poette, Saint-Quentin, brochure de $27 \mathrm{p}$.

PIETTE É. (1895) - La station de Brassempouy et les statuettes humaines de la période glyptique, L'Anthropologie, t. VI, $\mathrm{n}^{\circ} 2$, p. $129-151$.

PIETTE É., LAPORTERIE J. de (1894) - Les fouilles de Brassempouy en 1894, Bulletin de la Société d'anthropologie de Paris, t. 5, IV série, p. 633-648.

PIETTE É., LAPORTERIE J. de (1898) - Études d'ethnographie préhistorique, V, Fouilles à Brassempouy en 1897, L'Anthropologie, t. IX, $\mathrm{n}^{\circ} 5$, p. 531-555. 
POPLIN F. (1995) - Délitage et débitage dans le travail de l'ivoire vrai sur des exemples du Paléolithique supérieur, in J. Hahn, M. Menu, Y. Taborin, P. Walter et F. Widemann dir., Le travail et l'usage de l'ivoire au Paléolithique supérieur, Actes de la table ronde de Ravello, Rome, 29-31 mai 1992, p. 17-28.

POTINY., MENSAN R. (1998) - Grotte du Pape, chantier GG2 : premier bilan rétrospectif, in D. Gambier, F. Bon et P. Gardère dir., Brassempouy (Landes). Rapport intermédiaire de fouilles programmées. Campagne 1998, $2^{2}$ année, p. 20-38.

SAINT-PÉRIER R. de (1922) - Statuette de femme stéatopyge découverte à Lespugue, Haute-Garonne, L'Anthropologie, p. 361.

SAINT-PÉRIER R. et S. de (1952) - La grotte d'Isturitz III : les Solutréens, les Aurignaciens et les Moustériens, Archives de 1'Institut de paléontologie humaine, Mémoire $\mathrm{n}^{\circ} 25$, éd. Masson, Paris, 264 p.

SIMONET A. (2005) - Les armatures lithiques. Méthodes d'étude et enjeux: l'exemple des armatures gravettiennes d'Isturitz, mémoire de DEA de l'université de Toulouse II-Le Mirail, 94 p.

SONNEVILLE-BORDES D. de (1960) - Le Paléolithique supérieur en Périgord, éd. Delmas, Bordeaux, 558 p.

THIAULT M.-H. (1999) - L'exploitation et la transformation de l'ivoire de mammouth. Etude technologique à partir du matériel des niveaux Périgordiens de la grotte du Pape (Brassempouy, Landes), mémoire de DEA, université de Paris I, $54 \mathrm{p}$.
VIALOU D. (1995) - Objets en ivoire du Paléolithique supérieur conservés au Muséum national d'histoire naturelle, Paris, in J. Hahn, M. Menu, Y. Taborin, P. Walter et F. Widemann dir., Le travail et l'usage de l'ivoire au Paléolithique supérieur, Actes de la table ronde de Ravello, Rome, 29-31 mai 1992, p. 81-90.

WHITE R. (2006) - The Women of Brassempouy: a century of research and interpretation, Journal of Archaeological Method and Theory, vol. $13, \mathrm{n}^{\circ} 4$, p. 251-304.

Nejma GOUTAS

45, rue des Boulets, 75011 Paris ngoutas@gmail.com

LAMPEA, UMR 6636

Maison méditerranéenne des sciences de l'Homme 5, rue du Château-de-l'Horloge BP 647, 13094 Aix-en-Provence Cedex 2

Aurélien SIMONET Résidence les Jardins de l'université, apt 11A 31, rue Valade, 31000 Toulouse simonetaurelien@yahoo.fr

TRACES - UMR 5608 - Maison de la Recherche 5, allée A. Machado, 31058 Toulouse Cedex 9 